\title{
jpen
}

AUTARQUIA ASSOCIADA À UNIVERSIDADE DE SÃO PAULO

\section{CARACTERIZAÇÃO DOSIMÉTRICA DE AMOSTRAS DE BeO EM FEIXES DE RADIAÇÃO ALFA, BETA E X POR TÉCNICAS LUMINESCENTES}

\author{
Daniela Piai Groppo
}

Dissertação apresentada como parte dos requisitos para obtenção do Grau de Mestre em Ciências na Área de Tecnologia Nuclear - Aplicações

Orientadora:

Profa. Dra. Linda V. E. Caldas 


\title{
INSTITUTO DE PESQUISAS ENERGÉTICAS E NUCLEARES
}

Autarquia associada à Universidade de São Paulo

\section{CARACTERIZAÇÃO DOSIMÉTRICA DE AMOSTRAS DE BeO EM FEIXES DE RADIAÇÃO ALFA, BETA E X POR TÉCNICAS LUMINESCENTES}

Daniela Piai Groppo

\begin{abstract}
Dissertação apresentada como parte dos requisitos para obtenção do Grau de Mestre em Ciências na Área de Tecnologia Nuclear - Aplicações

Orientadora:

Profa. Dra. Linda V. E. Caldas
\end{abstract}

Versão Corrigida

Versão Original disponível no IPEN 
Aos meus pais, Odilair e Cláudia, Aos meus irmãos Danilo e Anna Cláudia e ao meu noivo Henrique. 


\section{AGRADECIMENTOS}

À minha orientadora, Dra. Linda V. E. Caldas, serei sempre grata pela acolhida, pela oportunidade de crescimento que me proporcionou durante a orientação do mestrado, por todo incentivo, por vibrar com cada conquista alcançada, por toda paciência e pela bela amizade que construímos.

À Dra. Maria da Penha Albuquerque Potiens, ao Dr. Vitor Vivolo e à Dra. Letícia L. C. Rodrigues, por todo o auxílio prestado durante a realização deste trabalho.

Ao Sr. Marcos Xavier, pelo apoio técnico e sugestões.

À Sra. Donata Celicea de Oliveira Zanin, por toda ajuda em assuntos administrativos e pela amizade.

À Dra. Maíra Tiemi Yoshizumi, pelo auxílio nos espectros de emissão TL.

Ao Sr. Marcos dos Santos, pela usinagem dos suportes para irradiação das amostras.

Ao Centro de Ciência e Tecnologia de Materiais (CCTM/IPEN), pelas medições de difração de raios $X$.

Ao Centro de Lasers e Aplicações (CLA), pelas medições de fluorescência de raios $X$.

Ao Centro de Tecnologia das Radiações (CTR), pelas irradiações das amostras.

Ao Instituto de Pesquisas Energéticas e Nucleares (IPEN), por possibilitar o desenvolvimento deste trabalho.

Aos órgãos CAPES, CNPq e FAPESP, pelo suporte financeiro.

Aos meus queridos amigos Christianne Cobello Cavinato, Fernanda Beatrice Conceição Nonato, Glauco Rogério Veneziani, Maíra Tiemi Yoshizumi e Nathalia Almeida, pela amizade construída nestes anos de convivência, pelo apoio incondicional, pelas sugestões, pelos inúmeros momentos de alegria e por serem grandes responsáveis pelo meu crescimento pessoal e profissional.

Aos amigos e colegas do IPEN Amanda, Ana, Cristiane, Eduardo, Elaine, Felipe, Jonas, Luciana, Lúcio, Patrícia, Maria Inês, Mateus e Tallyson, pela 
excelente relação profissional e pessoal. Serei sempre grata por todo o companheirismo, convivência e amizade.

Ao meu amigo, Prof. Homero Lavieri Martins, pelas palavras sempre tão sinceras e pelos infinitos ensinamentos, mesmo nos encontrando tão pouco.

Aos meus queridos amigos, Antonio Carlos e Sueli, pelo apoio, incentivo e por terem feito da vossa casa paulistana o meu doce lar durante todo o desenvolvimento deste trabalho.

À toda minha família, em especial aos meus pais Odilair e Cláudia, aos meus irmãos Danilo e Anna Cláudia e aos meus avôs Otávio e Orides, pelo amor, carinho e incentivo inestimável. A nossa convivência nos finais de semana me incentivaram a continuar nesta longa jornada que é a vida acadêmica.

Ao Henrique Pravatta, por todo amor, dedicação, paciência e companheirismo e por ter me incentivado durante todo este trabalho de modo que eu não desistisse dos meus ideais em momento algum.

A todos os amigos e pessoas que direta ou indiretamente contribuíram para a realização deste projeto. 


\title{
CARACTERIZAÇÃO DOSIMÉTRICA DE AMOSTRAS DE BeO EM FEIXES DE RADIAÇÃO ALFA, BETA E X POR TÉCNICAS LUMINESCENTES
}

\author{
Daniela Piai Groppo
}

\section{RESUMO}

No campo da medicina, a radiação ionizante é utilizada tanto para fins terapêuticos como para fins diagnósticos, englobando assim um amplo intervalo de doses de diferentes tipos de radiações. Para assegurar que a finalidade da prática esteja sendo alcançada, são necessários estudos detalhados de detectores e dispositivos que respondam a diferentes tipos de radiações. Neste trabalho foi realizada a caracterização dosimétrica de amostras de $\mathrm{BeO}$ utilizando as técnicas de termoluminescência (TL) e luminescência opticamente estimulada (OSL) comparando-se as respostas para as radiações alfa, beta e $\mathrm{X}$ e propondose um sistema adequado para sua utilização em monitoração de feixes destas radiações. Dentre os principais resultados obtidos estão: alta sensibilidade à radiação beta para ambas as técnicas empregadas, boa reprodutibilidade das respostas TL e OSL (coeficientes de variação inferiores a 5\%), uma dependência energética máxima da radiação $X$ de $28 \%$ para técnica $T L$, e de apenas $7 \%$ para a técnica OSL, dentro dos intervalos de energia estudados. As características dosimétricas obtidas neste trabalho mostram a possibilidade de aplicação das amostras de $\mathrm{BeO}$ em dosimetria das radiações ionizantes $\mathrm{X}$, alfa e beta, considerando os intervalos de dose empregados, pelas técnicas de TL e OSL. Pelos resultados obtidos, as amostras de $\mathrm{BeO}$ apresentaram sua utilização potencial para dosimetria de feixes de radiodiagnóstico e radioterapia. 


\title{
DOSIMETRIC CHARACTERIZATION OF BeO SAMPLES IN ALPHA, BETA AND X RADIATION BEAMS USING LUMINESCENT TECHNIQUES
}

\author{
Daniela Piai Groppo
}

\begin{abstract}
In the medical field, the ionizing radiation is used both for therapeutic and diagnostic purposes, in a wide range of radiation doses. In order to ensure that the objective is achieved in practice, detailed studies of detectors and devices in different types of radiations beams are necessary. In this work a dosimetric characterization of $\mathrm{BeO}$ samples was performed using the techniques of thermoluminescence (TL) and optically stimulated luminescence (OSL) by a comparision of their response for alpha, beta and $X$ radiations and the establishment of an appropriated system for use in monitoring of these radiations beams. The main results are: the high sensitivity to beta radiation for both techniques, good reproducibility of TL and OSL response (coefficients of variation lower than $5 \%$ ), maximum energy dependence of the $X$ radiation of $28 \%$ for the $T L$ technique, and only $7 \%$ for the OSL technique, whithin the studied energy range. The dosimetric characteristics obtained in this work show the possibility of applying $\mathrm{BeO}$ samples to dosimetry of alpha, beta and $\mathrm{X}$ radiations, considering the studied dose ranges, using the TL and OSL techniques. From the results obtained, the samples of $\mathrm{BeO}$ showed their potential use for beam dosimetry in diagnostic radiology and radiotherapy.
\end{abstract}




\section{SUMÁRIO}

\section{LISTA DE TABELAS}

LISTA DE FIGURAS ....................................................... iii

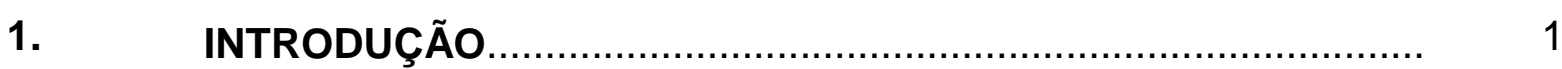

1.1. Objetivos do Trabalho.............................................................. 3

2. CONCEITOS BÁSICOS ...........................................................

2.1. Interação da Radiação com a Matéria........................................... 4

2.1.1. Interação da Radiação Eletromagnética com a Matéria.................. 5

2.1.1.1. Efeito Fotoelétrico.....................................................................

2.1.1.2. Efeito Comptom......................................................................

2.1.1.3. Espalhamento Coerente.............................................................. 8

2.1.1.4. Produção de Pares.................................................................. 8

2.1.1.5. Predominância dos Efeitos provocados pela Radiação Eletromagnética......................................................................... 9

2.1.2. Interação de Elétrons com a Matéria............................................. 10

2.1.2.1. Partículas Beta........................................................................ 11

2.1.3. Interação das Partículas Alfa com a Matéria.................................. 13

2.2. Dosimetria das Radiações........................................................ 15

2.3. Luminescência................................................................... 15

2.3.1. Termoluminescência (TL) ........................................................ 16

2.3.2. Luminescência Opticamente Estimulada (OSL)............................. 21

2.4. Óxido de Berílio.......................................................................... 24

2.5. Propriedades Dosimétricas TL e OSL............................................. 25

2.5.1. Curva de Emissão TL e Curva de Decaimento OSL........................ 26

2.5.2. Curva de Dose-Resposta.......................................................... 27

2.5.3. Sensibilidade da Resposta TL e OSL........................................... 28

2.5.4. Dependência Energética da Resposta TL e OSL.......................... 28

2.5.5. Tratamento Térmico e Tratamento Óptico..................................... 29

2.5.6. Limite Inferior de Detecção....................................................... 29

2.5.7. Espectro de Emissão.............................................................. 30 


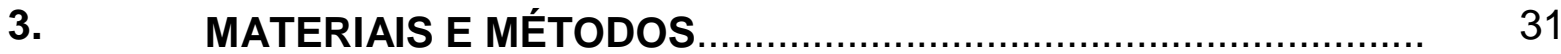

3.1. Amostras Dosimétricas............................................................. 31

3.2. Sistemas de Medição TL e OSL..................................................... 34

3.3. Sistemas e Fontes de Radiação.................................................. 36

3.3.1. Sistema de Radiação X................................................................ 36

3.3.2. Sistemas de Radiação Alfa e Beta da Leitora RISÖ

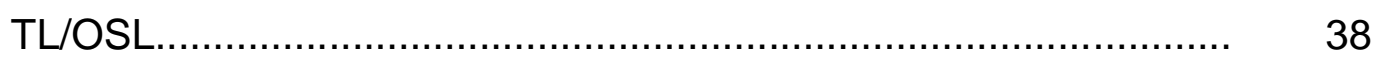

3.3.3. Sistema de Radiação Gama....................................................... 39

3.4. Reutilização das Amostras...................................................... 40

3.5. Análise Estatística.................................................................. 42

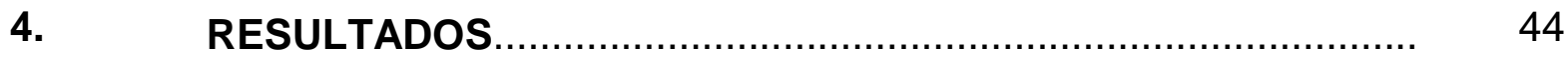

4.1. Características das Amostras de $\mathrm{BeO}$.............................................. 44

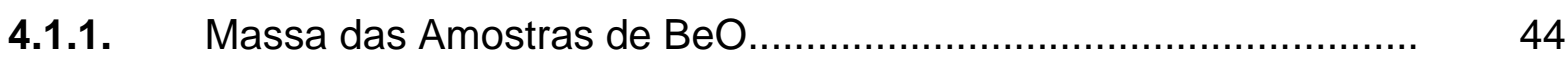

4.1.2. Determinação do Material............................................................... 45

4.2. Tratamento Óptico ..................................................................... 4

4.3. Seleção dos Dosímetros........................................................... 48

4.4. Curva de Emissão TL e Curva de Decaimento OSL....................... 50

4.5. Espectro de Emissão TL............................................................ 54

4.6. Reprodutibilidade da Resposta................................................. 54

4.7. Curvas de Dose-Resposta............................................................ 57

4.8. Limite Inferior de Detecção (LID)................................................ 67

4.9. Sinal Residual..................................................................... 68

4.10. Dependência Energética........................................................... 71

4.11. Desvanecimento da Resposta TL e OSL..................................... 74

4.12. Efeito da Temperatura nas Medições OSL.................................... 77

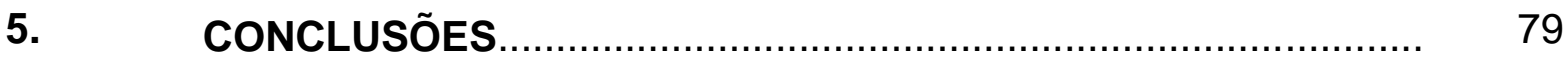

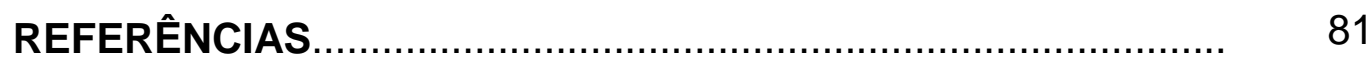




\section{LISTA DE TABELAS}

TABELA 3.1 - Características dos feixes diretos padronizados de radiação $X$ (radiodiagnóstico convencional), estabelecidos no equipamento Pantak/Seifert, de acordo com a norma IEC 61267 (IEC, 2005)

TABELA 3.2 - Características dos feixes atenuados padronizados de radiação $X$ (radiodiagnóstico convencional), estabelecidos no equipamento Pantak/Seifert, de acordo com a norma IEC 61267 (IEC, 2005)

TABELA 4.1 - Comparação entre picos de uma amostra de BeO padrão e as amostras analisadas.

TABELA 4.2 - Resultado da análise de FRX das amostras de BeO

TABELA 4.3 - Sensibilidades médias relativas das amostras de BeO para as radiações alfa, beta $\mathrm{X}$

TABELA 4.4 - Reprodutibilidade do $\mathrm{BeO}$ para radiação alfa, beta e X e seus respectivos fatores de correção para cada tipo de radiação

TABELA 4.5 - Intervalo de linearidade de resposta TL e OSL para radiações alfa, beta e $X$.

TABELA 4.6 - Limite inferior de detecção das amostras de BeO utilizando as técnicas TL e OSL, para diferentes tipos de radiação.

TABELA 4.7 - Sinal residual na resposta TL das amostras realizando-se uma medição TL subsequente.

TABELA 4.8 - Coeficientes de calibração TL e fatores de correção TL para amostras de $\mathrm{BeO}$ irradiadas em feixes diretos (RQR) de radiação com qualidade de radiodiagnóstico convencional

TABELA 4.9 - Coeficientes de calibração OSL e fatores de correção OSL para amostras de $\mathrm{BeO}$ irradiadas em feixes diretos $(\mathrm{RQR})$ de radiação com qualidade de radiodiagnóstico convencional. 
TABELA 4.10 - Coeficientes de calibração TL e fatores de correção TL para amostras de $\mathrm{BeO}$ irradiadas em feixes atenuados (RQA) de radiação com qualidade de radiodiagnóstico

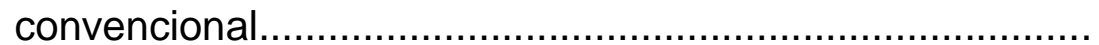

TABELA 4.11 - Coeficientes de calibração OSL e fatores de correção OSL para amostras de $\mathrm{BeO}$ irradiadas em feixes atenuados (RQA) de radiação com qualidade de radiodiagnóstico convencional. 


\section{LISTA DE FIGURAS}

FIGURA 2.1 - Esquema representativo do efeito fotoelétrico...................... 6

FIGURA 2.2 - Esquema representativo do efeito Compton......................... 7

FIGURA 2.3 - Esquema representativo da produção de pares................... 9

FIGURA 2.4 - Predominância dos principais tipos de interação de fótons com a matéria em função da energia do fóton e do número atômico do material.

FIGURA 2.5 - Espalhamento dos elétrons ao interagir com a matéria.......

FIGURA 2.6 - Atenuação de partículas beta no alumínio, cobre e prata....

FIGURA 2.7 - Alcance das partículas beta em vários materiais (densidade em $\mathrm{g} / \mathrm{cm}^{3}$ ): (1) Ferro $=7,8$; (2) Pirex $=2,6$; (3) $\mathrm{PVC}=1,38$; (4) Plexiglass $=1,18$ e (5) $\mathrm{Ar}=0,0013$.

FIGURA 2.8 - Representação qualitativa do poder de freamento de uma partícula alfa ao interagir com um material.

FIGURA 2.9 - $\quad$ Alcance $R$ de partículas alfa para diferentes materiais (densidades em g/cm ${ }^{3}$ ): (1) $\mathrm{Ar}=0,0013$; (2) Tecido = 1,0; (3) Alumínio $=2,70$ e (4) Cobre $=8,96$.

FIGURA 2.10 - Diagrama esquemático dos níveis de energia de um cristal isolante que desencadeia o fenômeno de termoluminescência devido à radiação. (a) Ionização devido à radiação ionizante; armadilhamento de elétrons (b) e buracos (e); liberação de elétron (c) e buraco (f) devido ao aquecimento; (d) e (g) recombinação indireta; (h) recombinação direta. Os elétrons são representados por círculos cheios e os buracos são representados por círculos vazios

FIGURA 2.11 - Curva de emissão TL pelo modelo de Randall-Wilkins ....... 19

FIGURA 2.12 - Curva de emissão TL típica do LiF (TLD-100)..................... 21

FIGURA 2.13 - Representação dos modos principais de estimulação OSL. 
FIGURA 2.14 - Curva de decaimento OSL com estimulação de LEDs verdes para sedimentos de quartzo.

FIGURA 3.1 - $\quad$ Amostras de $\mathrm{BeO}$ em relação à uma régua $(\mathrm{cm})$................. 31

FIGURA 3.2 - $\quad$ Balança Metler Toledo, modelo ABS204-S.......................... 32

FIGURA 3.3 - $\quad$ Difratômetro de raios X modelo Multiflex, Rigaku Co........... 33

FIGURA 3.4 - Espectrômetro de FRX EDX-720, Shimadzu Co.................. 33

FIGURA 3.5 - $\quad$ Espectrômetro (modelo USB4000, Ocean Optics)................ 33

FIGURA 3.6 - Sistema leitor RISÖ TL/OSL, modelo TL/OSL-DA-20......... $\quad 34$

FIGURA 3.7 - Carrosel do sistema leitor TL/OSL (TL/OSL-DA-20) com capacidade para 48 amostras.

FIGURA 3.8 - (a) Sistema de radiação $X$ Pantak/Seifert, modelo ISOVOLT HS 160, com roda de filtros PTW (modelo T90010/90011) acoplada, e seu (b) controlador.

FIGURA 3.9 - Sistemas de radiação (a) alfa e (b) beta da leitora RISÖ TL/OSL

FIGURA 3.10 - Fonte de ${ }^{60} \mathrm{Co}$ do CTR/IPEN............................................... 40

FIGURA 3.11 - Forno tipo mufla, modelo MFLO1000................................ 41

FIGURA 3.12 - Sistema para tratamento óptico com LEDs azuis................ 41

FIGURA 4.1 - Massa de 109 amostras de BeO......................................... 44

FIGURA 4.2 - Difratogramas de raios $X$ de (a) uma amostra de $\mathrm{BeO}$, comparada com (b) um elemento padrão: Bromellite.......... 46

FIGURA 4.3 - Resposta OSL relativa para amostras tratadas

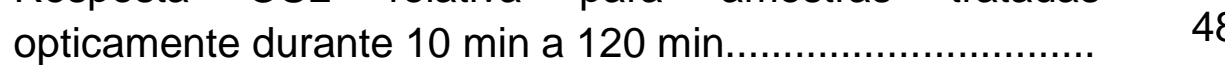

FIGURA 4.4 - Histograma da variação da sensibilidade da resposta TL das pastilhas de $\mathrm{BeO}$ 
FIGURA 4.5 - Curva de emissão TL de uma mesma amostra de BeO exposta a uma dose absorvida de 1 Gy de radiações (a)

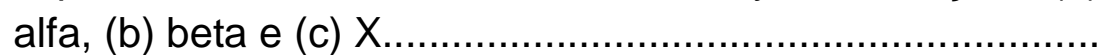

FIGURA 4.6 - Curva de decaimento OSL de uma mesma amostra de $\mathrm{BeO}$ exposta a uma dose absorvida de 1 Gy de radiações (a) alfa, (b) beta e (c) X. As linhas tracejadas indicam o ponto em que a intensidade da resposta OSL reduz em $50 \%$

FIGURA 4.7 - (a) Curvas de emissão TL e (b) curvas de decaimento OSL para amostras de $\mathrm{BeO}$ irradiadas com uma dose de 1 Gy de radiações alfa, beta e $X$

FIGURA 4.8 - Espectro de emissão da amostra de $\mathrm{BeO}$ exposta a uma dose de $1 \mathrm{kGy}$ de radiação gama $\left({ }^{60} \mathrm{Co}\right)$ : (a) gráfico isométrico e (b) gráfico de contorno.

FIGURA 4.9 -

(a) Curva de dose-resposta TL para amostras de $\mathrm{BeO}$, expostas à radiação alfa, com doses absorvidas de 0,2 Gy a 200,0 Gy. (b) Curvas de emissão TL de uma amostra de $\mathrm{BeO}$ exposta a doses de radiação alfa no seu intervalo de linearidade (0,2 Gy a 20,0 Gy)...

FIGURA 4.10 - (a) Curva de dose-resposta OSL para amostras de BeO, expostas à radiação alfa, com doses absorvidas de $0,2 \mathrm{~Gy}$ a 200,0 Gy. (b) Curvas de decaimento OSL de uma amostra de $\mathrm{BeO}$ exposta a doses de radiação alfa no seu intervalo de linearidade (0,2 Gy a 200,0 Gy)

FIGURA 4.11 - (a) Curva de dose-resposta TL para amostras de BeO, expostas à radiação beta, com doses absorvidas de 0,1 Gy a 200,0 Gy. (b) Curvas de emissão TL de uma amostra de $\mathrm{BeO}$ exposta a doses de radiação beta no seu intervalo de linearidade (0,2 Gy a 2,0 Gy)

FIGURA 4.12 - (a) Curva de dose-resposta OSL para amostras de BeO, expostas à radiação beta, com doses absorvidas de 0,1 Gy a 200,0 Gy. (b) Curvas de decaimento OSL de uma amostra de $\mathrm{BeO}$ exposta a doses de radiação beta no seu intervalo de linearidade (1,0 Gy a 20,0 Gy)..... 
FIGURA 4.13 - (a) Curva de dose-resposta TL para amostras de BeO, expostas à radiação $X$, com doses absorvidas de $0,01 \mathrm{~Gy}$ a 2,0 Gy. (b) Curvas de emissão TL de uma amostra de $\mathrm{BeO}$ exposta a doses de radiação beta no seu intervalo de linearidade $(0,01$ Gy a 1,0 Gy)

FIGURA 4.14 - (a) Curva de dose-resposta OSL para amostras de BeO, expostas à radiação $\mathrm{X}$, com doses absorvidas de $0,01 \mathrm{~Gy}$ a 2,0 Gy. (b) Curvas de decaimento OSL de uma amostra de $\mathrm{BeO}$ exposta a doses de radiação $X$ no seu intervalo de linearidade (0,01 Gy a 2,0 Gy)

FIGURA 4.15 - (a) Curva de dose-resposta TL sem colimação para amostras de $\mathrm{BeO}$, expostas à radiação alfa, com doses absorvidas de 0,1 Gy a 200,0 Gy. (b) Curvas de emissão TL sem colimação de uma amostra de $\mathrm{BeO}$ exposta a doses de radiação alfa no seu intervalo de linearidade (0,2 Gy a 200,0 Gy)

FIGURA 4.16 - (a) Curva de dose-resposta OSL sem colimação para amostras de $\mathrm{BeO}$, expostas à radiação alfa, com doses absorvidas de 0,1 Gy a 200,0 Gy. (b) Curvas de decaimento OSL sem colimação de uma amostra de $\mathrm{BeO}$ exposta a doses de radiação alfa no seu intervalo de linearidade (0,1 Gy a 200,0 Gy)

FIGURA 4.17 - Curva de emissão TL para amostras de BeO obtida após medição da curva de decaimento OSL, para vários intervalos de dose absorvida de radiações (a) alfa, (b) beta e (c) $\mathrm{X}$

FIGURA 4.18 - Desvanecimento da resposta TL de amostras de BeO expostas às radiações alfa, beta $\mathrm{e} X$. As linhas pontilhadas indicam um desvanecimento da resposta $\mathrm{TL}$ de aproximadamente $10 \%$ no período de estudo.

FIGURA 4.19 - Desvanecimento da resposta OSL de amostras de BeO expostas às radiações alfa, beta $\mathrm{e} X$. As linhas pontilhadas indicam um desvanecimento da resposta OSL de aproximadamente $6 \%$ no período de estudo 
FIGURA 4.20 - (a) Curvas OSL da amostra de beO para diferentes temperaturas de leitura. (b) Resposta OSL em função da temperatura de medição, normalizada para temperatura de $20^{\circ} \mathrm{C}$ (temperatura ambiente). 


\section{INTRODUÇÃO}

Desde que Röentgen descobriu os raios-X em 1895 e Bequerel descobriu a radioatividade em 1896, o homem tem usado sua criatividade e seu conhecimento para desenvolver aplicações utilizando as propriedades da radiação ionizante a favor da humanidade.

A dosimetria das radiações representa papel fundamental em todos os processos de irradiação, pois permite garantir que qualquer procedimento esteja de acordo com os níveis aceitáveis ao indivíduo, ao ambiente e que seja realizado de maneira que atinja os objetivos da prática. A dosimetria, por meio de sistemas dosimétricos, associa os efeitos físico-químicos produzidos na matéria à quantidade de radiação empregada na exposição. Para que se estabeleça o tipo de sistema dosimétrico mais adequado para uma determinada prática é necessário um estudo detalhado das características dosimétricas de cada material e método.

Diante da variedade de sistemas dosimétricos utilizados é importante selecionar cuidadosamente um sistema apropriado, levando em conta a finalidade efetiva das condições de irradiação, como a dose absorvida, a taxa de dose absorvida e os efeitos provocados ao meio ambiente.

A radiação ionizante absorvida por um meio material produz ionização. A maior parte da energia absorvida transforma-se em calor enquanto uma pequena fração provoca quebra de ligações químicas. Em alguns materiais parte da energia da radiação ionizante absorvida fica armazenada em estados metaestáveis de energia que, após algum estímulo, é liberada na forma de luz ultravioleta, infravermelha ou visível; a estes processos dá-se o nome de luminescência (IAEA, 2005). A luminescência divide-se em fluorescência, se a emissão de luz se dá entre $10^{-10} \mathrm{~s}$ e $10^{-8} \mathrm{~s}$ após a irradiação, e fosforescência, quando o material emite luz ao ser submetido a algum estímulo. Quando o material é submetido ao calor e há a liberação de energia, tem-se o fenômeno 
conhecido como termoluminescência (TL); quando a estimulação é por meio de luz, tem-se a luminescência opticamente estimulada (OSL).

A técnica de OSL apresenta algumas vantagens comparadas à de $T L$, como: permitir leituras rápidas e releitura dos dosímetros, não necessitar de tratamento térmico, alta sensibilidade e leitora simples e de fácil automação (McKEEVER e MOSKOVITCH, 2003; AKSELROD et al, 2007).

Existem diversos tipos de fósforos TL de alta sensibilidade, tais como $\mathrm{MgB}_{4} \mathrm{O}_{7}, \mathrm{CaSO}_{4}, \mathrm{Al}_{2} \mathrm{O}_{3}$, LiF e BeO:Mg (AKSELROD et al, 1996). Vários materiais também foram testados com a técnica OSL (YOSHIMURA e YUKIHARA, 2008), sendo $\circ \mathrm{Al}_{2} \mathrm{O}_{3}: \mathrm{C}$ o que domina o mercado dosimétrico atualmente (YUKIHARA e McKEEVER, 2011). O óxido de berílio (BeO) tem sido extensivamente estudado usando a técnica da TL, tendo em vista a aplicação do material para dosimetria das radiações ionizantes, porém o número de publicações sobre OSL utilizando o BeO é bastante limitada (BULUR et al, 1998; SOMMER et al, 2007; YUKIHARA, 2011; JAHN et al, 2013).

No campo da medicina, a radiação ionizante é utilizada tanto para fins terapêuticos como para fins diagnósticos, englobando assim um amplo intervalo de doses de diferentes tipos de radiação. Os procedimentos principais fazem uso da radiação $X$ para diagnóstico e tratamento, da radiação gama em medicina nuclear; e ainda da radiação beta ou elétrons produzidos por aceleradores lineares e betatrons para tratamento (KRON, 1999). Para assegurar que a finalidade da prática esteja sendo alcançada, são necessários estudos detalhados de detectores e dispositivos que respondam a diferentes tipos de radiação.

Para se analisar a viabilidade da aplicação de amostras de $\mathrm{BeO}$ na dosimetria de feixes de radiação foi realizada a comparação das respostas TL e OSL na dosimetria de feixes de radiação alfa, beta e $X$. 


\subsection{Objetivos do Trabalho}

O objetivo principal deste trabalho é avaliar o desempenho de amostras de $\mathrm{BeO}$, utilizando as técnicas de termoluminescência e luminescência opticamente estimulada, em feixes de radiação alfa, beta e X para estabelecer um sistema dosimétrico adequado para utilização em monitoração de feixe.

Os objetivos específicos deste trabalho são:

- Caracterizar as amostras de BeO em relação à sua composição e massa;

- Obter o tratamento óptico adequado para reutilização das amostras em medições OSL.

- Selecionar um lote que apresente sensibilidade similar para realização dos estudos de caracterização dosimétrica do material;

- Obter as curvas de emissão TL e as curvas de decaimento OSL para as amostras de $\mathrm{BeO}$ expostas às radiações alfa, beta e $\mathrm{X}$;

- Caracterizar as amostras de $\mathrm{BeO}$ em relação à sua reprodutibilidade da resposta, à curva de dose-resposta, à dependência energética e ao limite inferior de detecção;

- Caracterizar as amostras de BeO em relação ao sinal residual obtido após as leituras TL;

- Caracterizar as amostras de $\mathrm{BeO}$ em relação ao desvanecimento da resposta OSL;

- Caracterizar as amostras de $\mathrm{BeO}$ em relação ao efeito provocado pela variação da temperatura nas medições OSL; 


\section{CONCEITOS BÁSICOS}

\subsection{Interação da Radiação com a Matéria}

A interação da radiação com a matéria está relacionada com a transferência de energia ao meio. A transferência pode se dar com os elétrons presentes no átomo ou mesmo com o núcleo atômico. A radiação ao interagir com o material pode provocar a excitação atômica ou nuclear, ionização ou ativação do núcleo. (SPRAWLS, 1993).

A interação na qual os elétrons recebem energia suficiente para saltar do seu estado fundamental para um estado excitado recebe o nome de excitação; ao retornarem para seu estado fundamental há a emissão de luz ou de raios $X$ característicos, para liberar a energia excedente. Na ionização, a energia absorvida pelo elétron é suficiente para provocar a quebra de ligações químicas, resultando então em elétrons de alta energia, íons positivos ou radicais livres. Quando as interações ocorrem com o núcleo atômico, podem acontecer perdas colisionais ou radiativas.

A forma de interação depende dos tipos de radiações, sendo elas classificadas em dois grupos principais: radiações diretamente ionizantes e radiações indiretamente ionizantes. Para radiações com carga, como por exemplo os elétrons, partículas alfa e fragmentos de fissão, a interação ocorre por meio do campo elétrico transferindo sua energia para muitos átomos ao mesmo tempo, que é o caso de radiações diretamente ionizantes. As radiações indiretamente ionizantes, que não possuem cargas, como as radiações eletromagnéticas e de nêutrons, interagem individualmente transferindo sua energia para elétrons que irão provocar novas interações (SPRAWLS, 1993; KNOLL, 2010; OKUNO e YOSHIMURA, 2010). Além do tipo de radiação, as características do meio 
absorvedor (normalmente representado pelo seu número atômico) determinam também o tipo de interação da radiação com a matéria.

\subsubsection{Interação da Radiação Eletromagnética com a Matéria}

A radiação eletromagnética (indiretamente ionizante) de interesse neste trabalho é a radiação $X$. Por possuir um caráter ondulatório e ausência de carga, este tipo de radiação penetra a matéria percorrendo grandes espessuras (quando comparadas à radiação particulada) antes de sofrer a primeira interação. O poder de penetração depende da seção de choque (probabilidade) de interação para cada tipo de evento (absorvendo ou espalhando a radiação incidente) (JOHNS e CUNNINGHAM, 1974; TAHUATA et al, 2003).

Os efeitos principais que ocorrem quando a radiação eletromagnética interage com matéria (elétrons ou com os núcleos dos átomos) são: efeito fotoelétrico, efeito Compton, espalhamento coerente e produção de pares.

\subsubsection{Efeito Fotoelétrico}

O efeito fotoelétrico (FIG. 2.1) é caracterizado pela transferência total de energia, advinda da radiação X ou gama, a um único elétron orbital, que ao ganhar energia é ejetado com uma energia cinética $E_{c}$, que é definida pela $E Q .1$ (EISBERG e RESNICK):

$$
E_{c}=h v-B_{e}
$$

onde:

$h$ é a constante de Planck

$v$ é a frequência da radiação

$B_{e}$ é a energia de ligação do elétron orbital 
Toda a energia do fóton incidente é então transferida para um elétron que é ejetado. A vacância deixada pelo elétron ejetado é preenchida por um elétron de uma camada mais energética, e o excesso de energia é liberado na forma de radiação $X$ (raios $X$ característicos). Estes raios $X$ característicos apresentam esta nominação, pois a energia advinda deste tipo de radiação é uma característica da energia de ligação da camada pertencente ao elétron de transição que, por sua vez, varia de acordo com cada átomo (SPRAWLS, 1993; KNOLL, 2010).

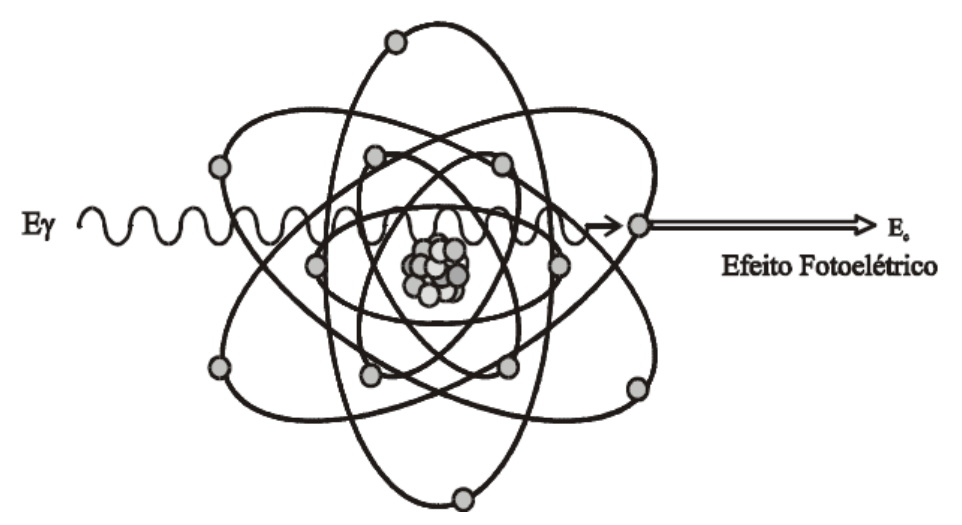

FIGURA 2.1 - Esquema representativo do efeito fotoelétrico (TAHUATA et al, 2003).

O efeito fotoelétrico predomina para elementos químicos de número atômico (Z) elevado e baixas energias, a probabilidade de ocorrência é proporcional a $(Z)^{4}$ e é inversamente proporcional ao cubo da energia do feixe (ATTIX, 1986).

Para a proteção radiológica a ocorrência do efeito fotoelétrico não é desejável, pois o paciente acaba por receber uma dose superior de radiação resultante da interação fotoelétrica do que para qualquer outro tipo de radiação (CURRY et al, 1990). Desta forma, para otimizar a prática e expor o paciente a uma dose mínima possível, faz-se o uso de energias altas, minimizando os possíveis danos celulares advindos da interação fotoelétrica. 


\subsubsection{Efeito Compton}

O efeito Compton (FIG. 2.2) é um processo no qual o fóton é espalhado por um elétron de baixa energia de ligação; ao transferir somente parte de sua energia, o fóton continua sua trajetória dentro do material, porém em outra direção; trata-se de um espalhamento incoerente ou inelástico. A energia absorvida pelo átomo é suficiente para arrancar um elétron, deixando o átomo ionizado (SAW, 2002).

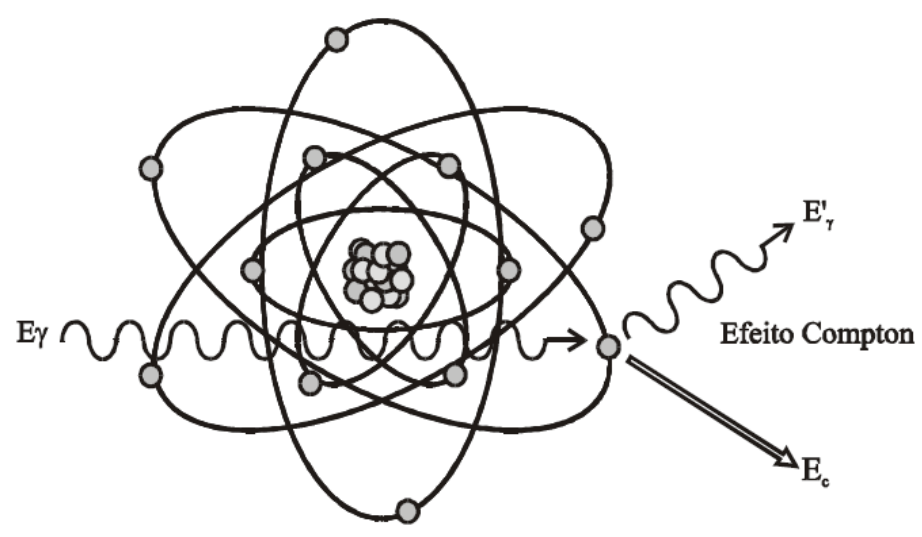

FIGURA 2.2 - Esquema representativo do efeito Compton (TAHUATA et al, 2003).

O valor da energia do fóton espalhado é a diferença entre a energia do fóton incidente e a soma da energia do elétron e da energia cinética do elétron ejetado, como representado na EQ. 2 (OKUNO e YOSHIMURA, 2010).

$$
E_{\gamma}^{\prime}=h \cdot v^{\prime}=h \cdot v_{0}^{\prime}-\left(E_{B}+E_{C}\right)
$$

onde:

$E_{\gamma}^{\prime}=h \cdot v^{\prime}$ é a energia do fóton espalhado

$h . v_{0}{ }^{\prime}$ é a energia do fóton incidente

$E_{B} \quad$ é a energia de ligação do elétron

$E_{C}$ é a energia cinética do elétron ejetado 


\subsubsection{Espalhamento Coerente}

Quando ocorre a interação de fótons de baixas energias com elétrons muito ligados, tem-se uma interação onde o fóton provoca uma excitação no átomo, porém o átomo volta ao seu estado fundamental, emitindo um fóton de mesma energia. Na verdade, o que acontece é que no momento em que o fóton interage com o elétron, este vibra com a mesma frequência de oscilação do fóton, incidente, e como resultado o fóton é reemitido com mesma energia (SPRAWLS, 1993). A interação do fóton pode se dar com o núcleo ou com o elétron orbital, processos denominados espalhamento Thomson e espalhamento Rayleigh, respectivamente.

A probabilidade de ocorrência do espalhamento coerente é diretamente proporcional a $(Z)^{2}$ do material alvo e inversamente proporcional à energia do fóton. Este processo ocorre na faixa de energia muito próxima à energia de ligação dos átomos, em aproximadamente $10 \mathrm{keV}$ (JOHNS e CUNNINGHAM, 1974; SAW, 2002).

\subsubsection{Produção de Pares}

A produção de pares elétron-pósitron (FIG. 2.3) é uma das interações predominantes para altas energias. Este efeito ocorre quando fótons de energia superior a 1,022 MeV se aproximam do núcleo com número atômico elevado interagindo fortemente com o campo elétrico nuclear; toda a energia do fóton é cedida ao núcleo, que gera duas partículas: um elétron e um pósitron. Como a energia de repouso destas duas partículas é de aproximadamente 0,511 MeV, a energia limiar para que o processo ocorra é de 1,022 MeV; para fótons com energias superiores a este valor tem-se a conversão em energia cinética para as partículas carregadas produzidas (KNOLL, 2010).

As duas partículas, por sua vez, transferem energia cinética para o meio; e o pósitron volta a se combinar com um elétron do meio dando origem a dois fótons com $511 \mathrm{keV}$ de energia (EISBERG e RESNICK, 1979). 


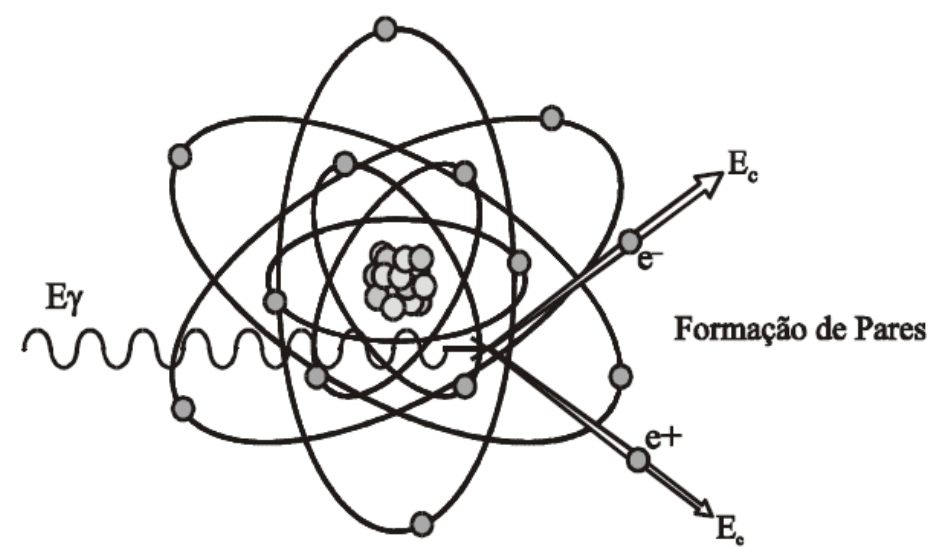

FIGURA 2.3 - Esquema representativo da produção de pares (TAHUATA et al, 2003).

\subsubsection{Predominância dos Efeitos provocados pela Radiação Eletromagnética}

As interações fotoelétricas são predominantes para energias baixas para todos os tipos de meios absorvedores, mas à medida que a energia cresce, o efeito fotoelétrico passa a dar espaço ao efeito Compton, que acaba se tornando predominante para energias de 1 a $5 \mathrm{MeV}$. Acima da energia de alguns MeV para fótons, a produção de pares é a interação predominante (ATTIX, 1986; TAHUATA et al, 2003). A FIG. 2.4 ilustra a variação da predominância destes processos em função da energia e do número atômico do meio absorvedor. 


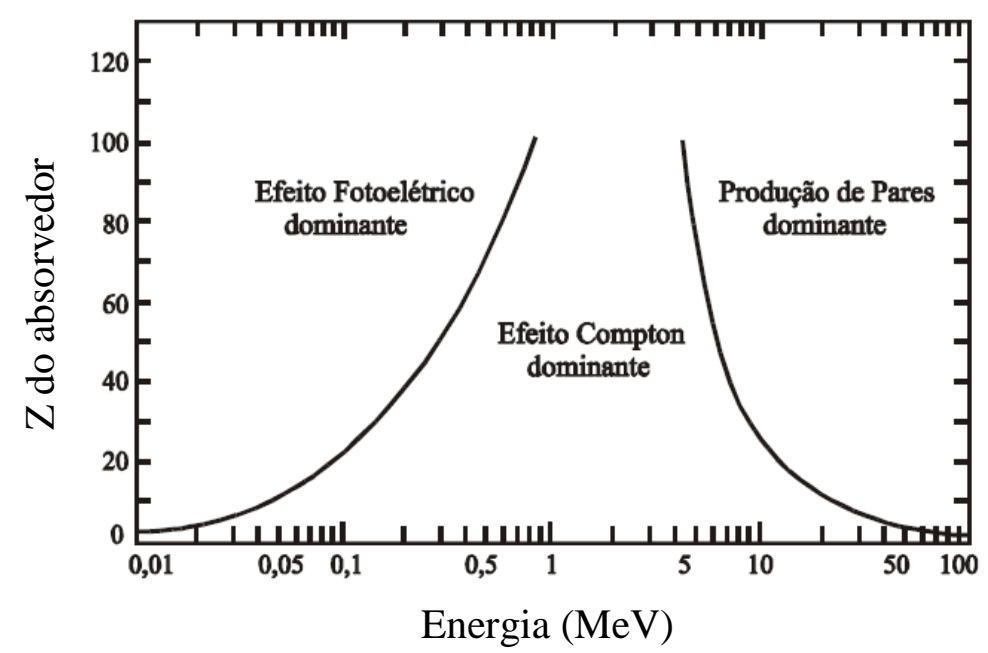

FIGURA 2.4 - Predominância dos principais tipos de interação de fótons com a matéria em função da energia do fóton e do número atômico do material (Adaptado de EISBERG e RESNICK, 1979).

\subsubsection{Interação de Elétrons com a Matéria}

Os elétrons perdem energia principalmente pelas ionizações que causam no meio material, no caso da interação com os elétrons orbitais; e também pela produção de radiação de freamento (Bremsstrahlung), para o caso da interação com o núcleo atômico (KHAN, 1994 e TAHUATA et al, 2003). Por se tratar de partículas leves, sua trajetória é muito irregular, podendo ser espalhados para todas as direções, inclusive para a direção de origem (FIG. 2.5).

As interações ou mesmo as colisões de partículas carregadas ocorrem por meio de forças coulombianas no campo elétrico da partícula (KHAN, 1994). 


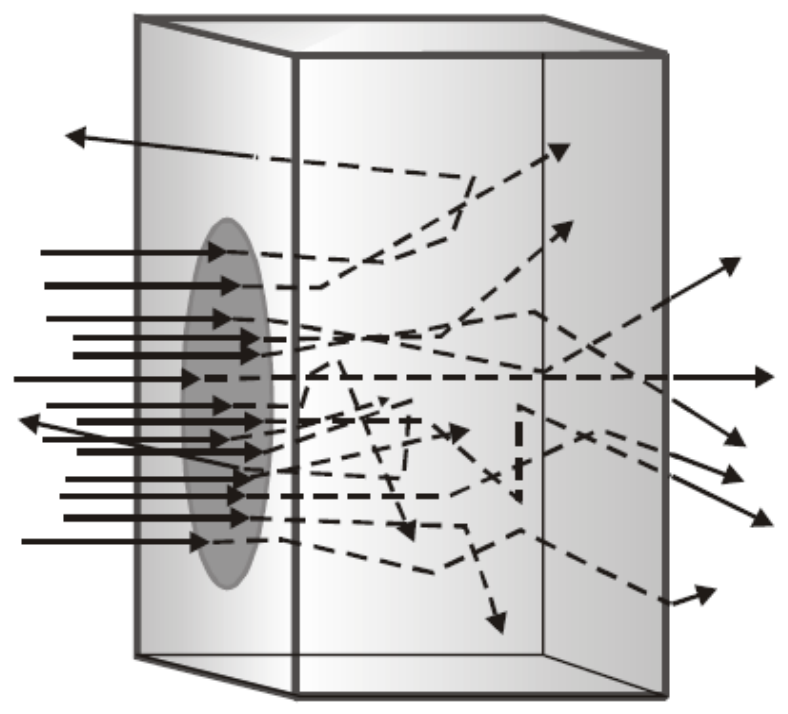

FIGURA 2.5 - Espalhamento dos elétrons ao interagir com a matéria (TAHUATA et al, 2003).

\subsubsection{Partículas Beta}

As partículas beta são atenuadas de forma exponencial na maioria de seu percurso no meio material, e o coeficiente de atenuação apresenta forte dependência com a energia máxima do espectro beta (EISBERG e RESNICK, 1979). A FIG. 2.6 representa a atenuação de partículas beta para diferentes materiais. As partículas beta não possuem um alcance preciso, porém existem várias relações semi-empíricas para determinação do alcance em função da sua energia (TAHUATA et al, 2003). Alguns valores de alcance encontrados para diferentes tipos de materiais encontram-se na FIG. 2.7. 


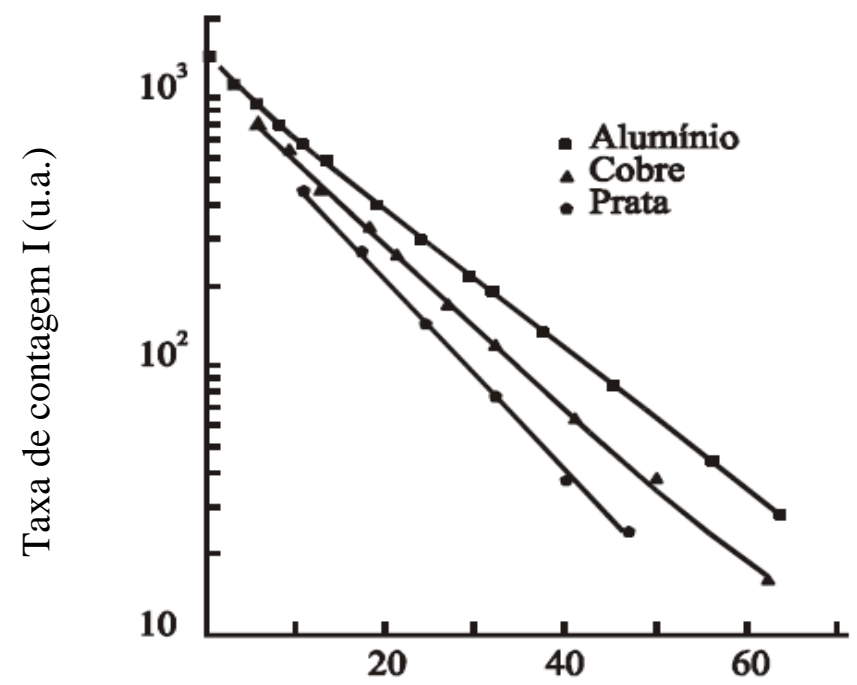

Espessura x do absorvedor $\left(\mathrm{mg} / \mathrm{cm}^{2}\right)$

FIGURA 2.6 - Atenuação de partículas beta no alumínio, cobre e prata (TAHUATA et al, 2003).

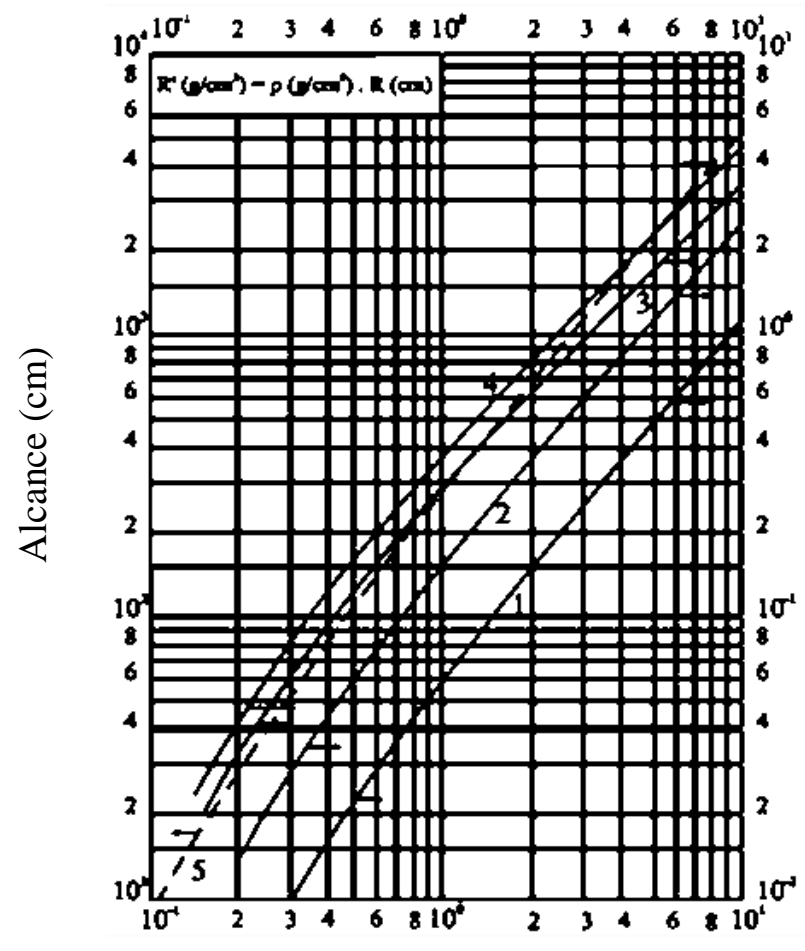

Energia máxima da radiação beta $(\mathrm{MeV})$

FIGURA 2.7 - Alcance de partículas beta em vários materiais (densidade em g/cm³): (1) Ferro = 7,8; (2) Pirex = 2,6; (3) PVC = 1,38; (4) Plexiglass = 1,18; (5) $\mathrm{Ar}=0,0013$ (TAHUATA et al, 2003). 


\subsubsection{Interação das Partículas Alfa com a Matéria}

As partículas alfa, ao interagirem com o material, perdem energia basicamente por ionização; o processo de interação destas partículas apresentam 3 etapas importantes (TAHUATA et al, 2003):

- Inicialmente, a partícula alfa tem grande velocidade interagindo por pouco tempo com os elétrons dos átomos ao seu redor, portanto, a ionização nesta etapa, é pequena e constante;

- $\quad$ Conforme a partícula alfa perde energia, ela passa a interagir mais fortemente com os elétrons envoltórios e o poder de ionização aumenta até atingir um valor máximo, momento no qual há a captura de um elétron do meio;

- Como a carga da partícula diminui, o poder de ionização cai rapidamente até chegar a zero, quando o íon captura um outro elétron e torna-se um átomo de hélio neutro.

A FIG. 2.8 representa o processo descrito e o gráfico mostra o poder de freamento da partícula alfa, dado pela taxa de perda de energia, em função da distância percorrida.

A penetração da partícula alfa é muito pequena sendo incapaz de penetrar a pele humana. $O$ alcance das partículas alfa depende das características do meio absorvedor e da energia da partícula. A FIG. 2.9 representa o alcance da partícula alfa $(\mathrm{R})$ para diferentes meios absorvedores. 


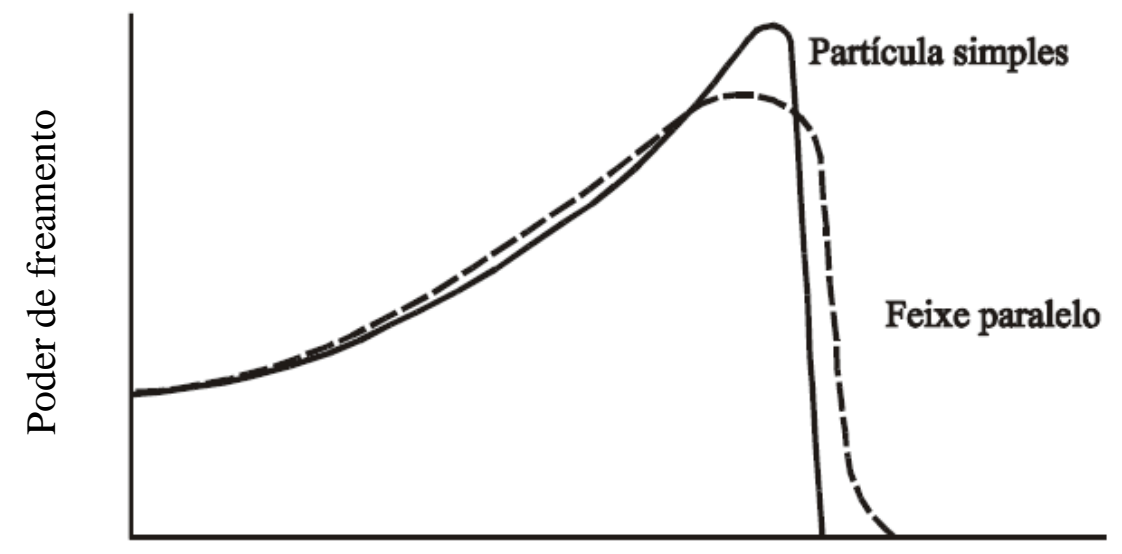

Distância de penetração

FIGURA 2.8 - Representação qualitativa do poder de freamento de uma partícula alfa ao interagir com um material (TAHUATA et al, 2003).

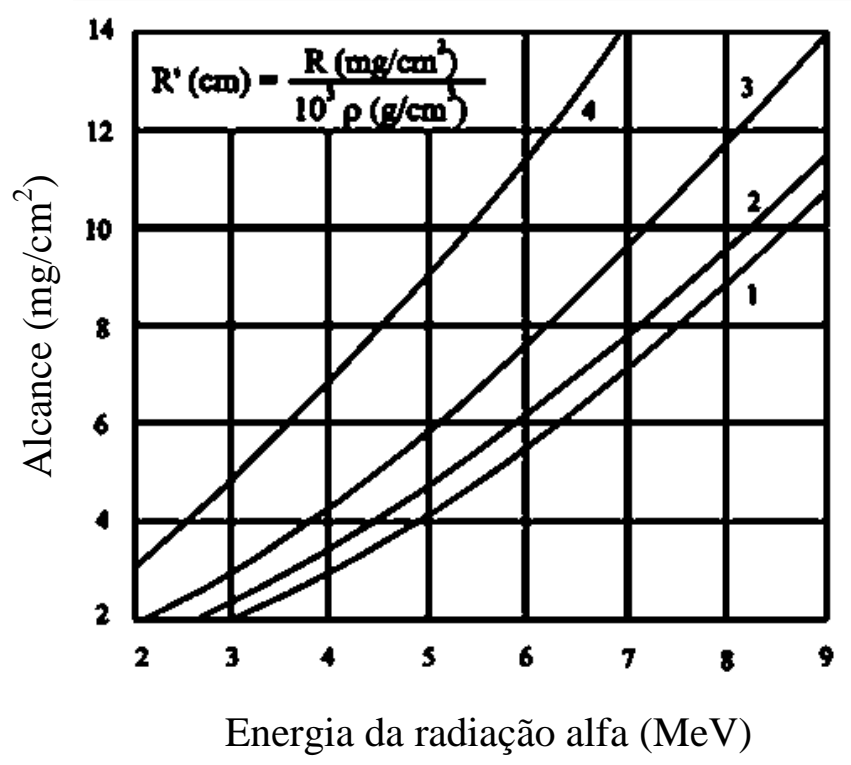

FIGURA 2.9 - Alcance $R$ de partículas alfa para diferentes materiais (densidades em g/cm³): (1) Ar =0,0013; (2) Tecido = 1,0; (3) Alumínio = 2,70; (4) Cobre = 8,96 (TAHUATA et al, 2003). 


\subsection{Dosimetria das Radiações}

A dosimetria das radiações é uma das principais ferramentas para assegurar que os procedimentos que fazem uso da radiação estejam dentro dos limites. Quando a dose é excedida, pode comprometer o ser humano e o meio ambiente. Os procedimentos com radiação ionizante são empregados nas áreas médica, industrial, agrícola e alimentícia; nestes casos a dosimetria é instrumento de grande valia para garantir que a dose entregue é a dose real desejada.

Quando a radiação interage com a matéria há a transferência de energia, mas nem toda a energia transferida é absorvida ou depositada na matéria.

As recomendações da International Commission on Radiation Units and Measurements (ICRU), em 1950, expressava a dose em termos de quantidade de energia absorvida por unidade de massa do material irradiado. Em 1953, a grandeza dose absorvida foi estabelecida (ICRU, 1954), sendo definida como a razão entre a energia depositada em um volume $d \bar{E}$ e a massa deste volume $d m$ (EQ. 3).

$$
D=\frac{d \bar{E}}{d m}
$$

Inicialmente, a unidade que expressava essa grandeza era chamada de rad (radiation absorved dose). A unidade da dose absorvida foi modificada para gray ( $1 \mathrm{~Gy}=100 \mathrm{rad}$ ) sendo que no Sistema Internacional $1 \mathrm{~Gy}$ equivale a $1 \mathrm{J.kg}^{-1}$ (ICRU, 1980).

\subsection{Luminescência}

A luminescência ocorre em certos materiais que quando submetidos à radiação eletromagnética armazenam energia, por meio de transições eletrônicas, em estados metaestáveis. Estes materiais são em geral cristais iônicos, que devido a seus defeitos e impurezas, permitem o surgimento de armadilhas, que 
correspondem aos estados de energia metaestável, na faixa de energia proibida dos elétrons.

A luminescência é basicamente dividida em dois grupos, a fluorescência e a fosforescência, dependente da duração do sinal luminescente (natureza do estado excitado). Em estados singletos, o elétron no orbital excitado está emparelhado (spin oposto) com o elétron no orbital fundamental (WINN, 1995). O retorno ao estado de equilíbrio, também conhecido como relaxação, ocorre rapidamente através da emissão de um fóton. Este processo, conhecido como fluorescência, apresenta taxa de emissão de luz entre $10^{-10}$ e $10^{-8} \mathrm{~s}$. A fosforescência é a emissão de luz a partir de um estado excitado tripleto, no qual o elétron presente no orbital excitado possui a mesma orientação de spin que o elétron do estado fundamental (LACKOWICZ, 1983). A transição para o estado fundamental é proibida por regra de seleção, necessitando assim de uma estimulação para que o processo ocorra. Quando a estimulação é pela luz, tem-se a luminescência opticamente estimulada e quando a estimulação é por meios térmicos, tem-se a termoluminescência. Estes dois fenômenos são empregados em dosimetria (pessoal, ambiental, clínica e em datação arqueológica).

\subsubsection{Termoluminescência (TL)}

A radiação ionizante absorvida por um meio material produz ionização. A maior parte da energia absorvida transforma-se em calor enquanto uma pequena fração provoca quebra de ligações químicas. Em alguns materiais parte da energia da radiação ionizante absorvida fica armazenada em estados metaestáveis de energia que, após algum estímulo, é liberada na forma de luz; a estes processos dá-se o nome de luminescência. Quando o material é submetido ao calor e há a liberação de energia, tem-se o fenômeno conhecido como termoluminescência (TL).

Este fenômeno (fótons liberados por meios térmicos) ocorre em intervalos de tempo da ordem de $10^{-8} \mathrm{~s}$ (McKEEVER et al, 1995). A luz emitida é mensurável, aumentando sua intensidade com 0 número de elétrons armadilhados, este crescendo com o aumento da dose absorvida até que se atinja 
um valor máximo. Estes cristais podem voltar às suas condições iniciais, quando submetidos a um tratamento térmico adequado que permita que todos os elétrons armadilhados sejam liberados. Desta forma, tem-se a possibilidade de aplicação deste processo em dosimetria das radiações. Cabe ainda lembrar que a radiação pode causar danos permanentes ao cristal, diminuindo assim sua emissão TL.

Para se compreender a termoluminescência e suas características principais utiliza-se o modelo de bandas de energia dos elétrons para materiais sólidos, como apresentado na FIG. 2.10.

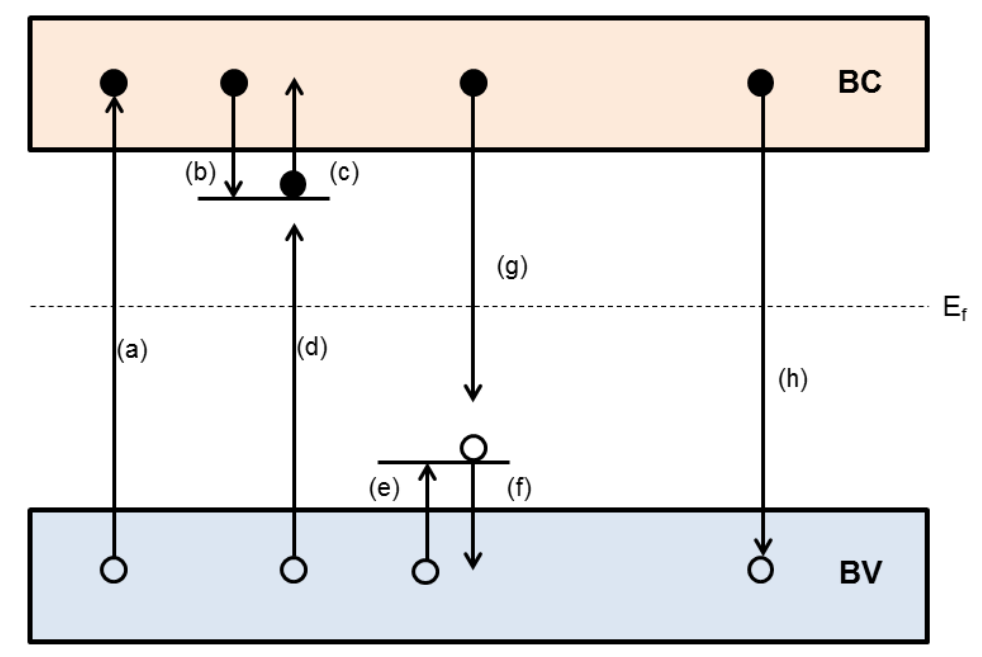

FIGURA 2.10 - Diagrama esquemático dos níveis de energia de um cristal isolante que desencadeia o fenômeno de termoluminescência devido à radiação. (a) Ionização devido à exposição à radiação ionizante; armadilhamento de elétrons (b) e buracos (e); liberação de elétron (c) e buraco (f) devido ao aquecimento; (d) e (g) recombinação indireta; (h) recombinação direta. Os elétrons são representados por círculos cheios e os buracos são representados por círculos vazios (Adaptado de McKEEVER, 1985).

Em um cristal isolante tem-se uma banda de valência (BV) repleta de elétrons e sua banda de condução $(B C)$ vazia; entre as duas bandas existe uma banda proibida (BP), uma larga faixa de estados energéticos não permitidos aos 
elétrons. Durante o processo de irradiação do cristal, são formados os pares elétron-buraco, sendo que os elétrons vão para a banda de condução e deixam livres os buracos na banda de valência, podendo ambos ser capturados em armadilhas (FIG. 2.10 (a)). A ionização produz elétrons e buracos que podem ser capturados (FIG. 2.10. (b) e (e)) e liberados dessas armadilhas quando submetidos a um estímulo térmico ou óptico (FIG. 2.10 (c) e (f)), tormado-se livres para se movimentar no cristal. Os elétrons e buracos livres podem vir a recombinar-se com cargas de sinais opostos, de forma direta (FIG. 2.10. (h)) ou indireta (FIG. 2.10. (d) e (g)). As transições (g) e (d), que provomem as recombinações elétron-buraco, são acompanhadas, em geral, pela emissão de luz TL. As armadilhas de elétrons são mais próximas da BC e as de buracos da $B V$, os dois grupos dividem-se pela energia de Fermi $\left(E_{f}\right)$.

A energia liberada sob a forma de luz é detectada fornecendo uma curva de emissão TL, que pode ser dada em função da temperatura ou do tempo de aquecimento (CAMERON et al, 1968). Uma explicação quantitativa simplificada para a termoluminescência (RANDALL e WILKINS, 1945) avalia a quantidade de elétrons que se recombinam admitindo que a probabilidade $P$ de um elétron capturado escapar da armadilha é uma distribuição maxwelliana da energia térmica dos elétrons (EQ. 4). O modelo de Randall-Wilkins (FIG. 2.11) que descreve o processo TL de primeira ordem compreende um tipo de armadilha e um só tipo de centro de recombinação:

$$
P=s \cdot \exp \left(\frac{-E_{a}}{k \cdot T}\right)
$$

onde:

$s$ é o fator de frequência, relacionado à oscilação do elétron na armadilha;

$E_{a}$ é a profundidade (ou energia) da armadilha;

$k$ é a constante de Boltzman;

$T$ é a temperatura. 


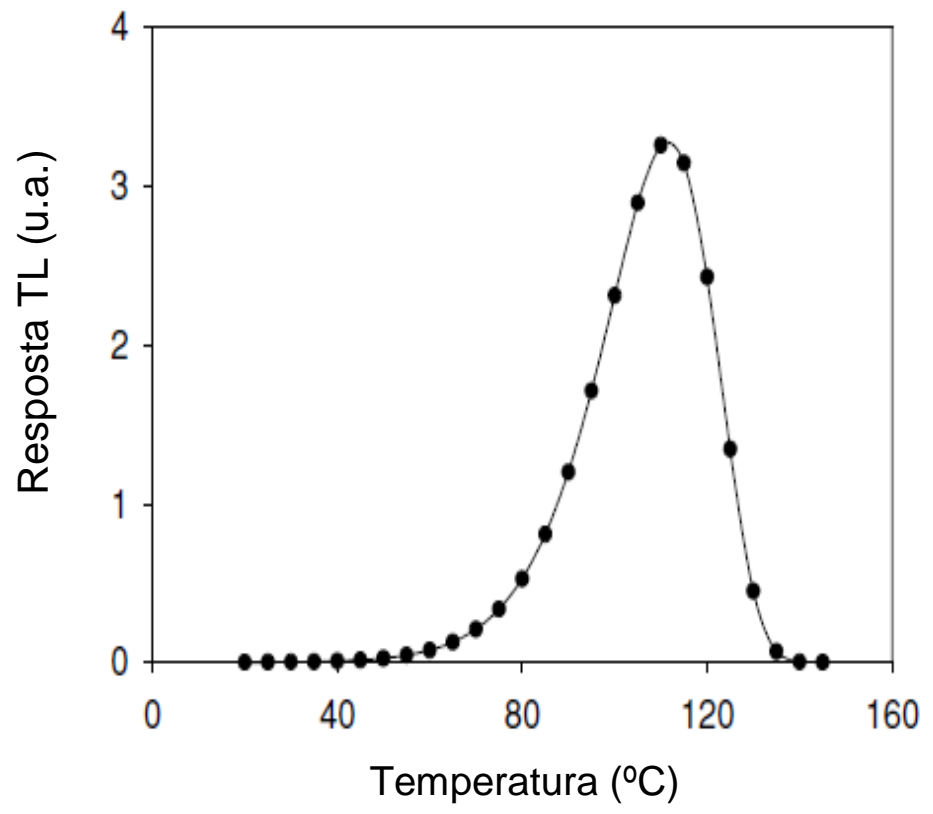

FIGURA 2.11 - Curva de emissão TL pelo modelo de Randall-Wilkins.

O aumento da temperatura provoca um aumento na taxa de recombinação, pois mais cargas armadilhadas são liberadas. Ao se atingir um valor máximo, tem-se uma diminuição no sinal TL, devido ao esvaziamento das armadilhas (CAMERON et al, 1968 e McKEEVER et al, 1995). A curva TL, para este caso, apresenta somente um pico.

Além do modelo de primeira ordem, há ainda o modelo de segunda ordem (GARLIK e GIBSON, 1948) e o de ordem geral (RASHEEDY, 1993). De maneira simplificada, os modelos se distinguem principalmente pelo processo de desarmadilhamento dos elétrons e seu novo rearmadilhamento durante o aquecimento. De forma geral, para o modelo de primeira ordem a probabilidade de os elétrons serem recapturados pelas armadilhas é praticamente nula (armadilhas monoenergéticas e a resposta TL é proporcional ao esvaziamento das armadilhas, ou seja, pelo decréscimo na concentração de elétrons aprisonados) (RANDALL E WILKINS, 1945). No modelo de segunda ordem, considera-se a probabilidade de recombinação com os centros de luminescência igual à probabilidade de recaptura; também é levada em consideração a 
conservação de carga na condição de quase equilíbrio (GARLIK e GIBSON, 1948). O modelo de ordem geral foi desenvolvido por May e Partridge (1964), pois alguns materiais não se ajustavam nem à cinética de primeira ordem nem à de segunda ordem. Então eles desenvolveram uma expressão empírica para a cinética de ordem geral. Porém ao deparar com uma dificuldade em dar significado a um dos parâmetros desta expressão, Rasheedy (1993) propôs uma nova expressão aprimorando a expressão anterior.

A curva de emissão TL representa a intensidade $T L$, dada pela luz emitida por um determinado fósforo TL em função do tempo de aquecimento ou da temperatura. A curva de emissão pode apresentar mais de um pico, pois os materiais podem apresentar diferentes grupos de armadilhas de diferentes profundidades.

A forma da curva de emissão varia então de um material para outro. Ela é dependente de taxa de aquecimento à qual as amostras são submetidas e da história térmica e de irradiação do material (McKEEVER et al, 1995).

Existem duas maneiras principais de se aplicar a resposta TL em dosimetria: altura de um pico de emissão e a área integrada sob o pico de emissão. A altura do pico é diretamente proporcional à luz emitida, que por sua vez é proporcional à população de elétrons capturados em armadilhas do mesmo tipo, no caso de a produção de fótons apresentar eficiência constante; a área integrada também pode ser usada para medição $T L$, por ser proporcional à população eletrônica da armadilha (PAGONIS et al, 2006).

A FIG. 2.12 apresenta uma curva de emissão TL típica do LiF (TLD100), um dos materiais mais utilizados na dosimetria. Nota-se a existência de 6 picos de emissão TL. 


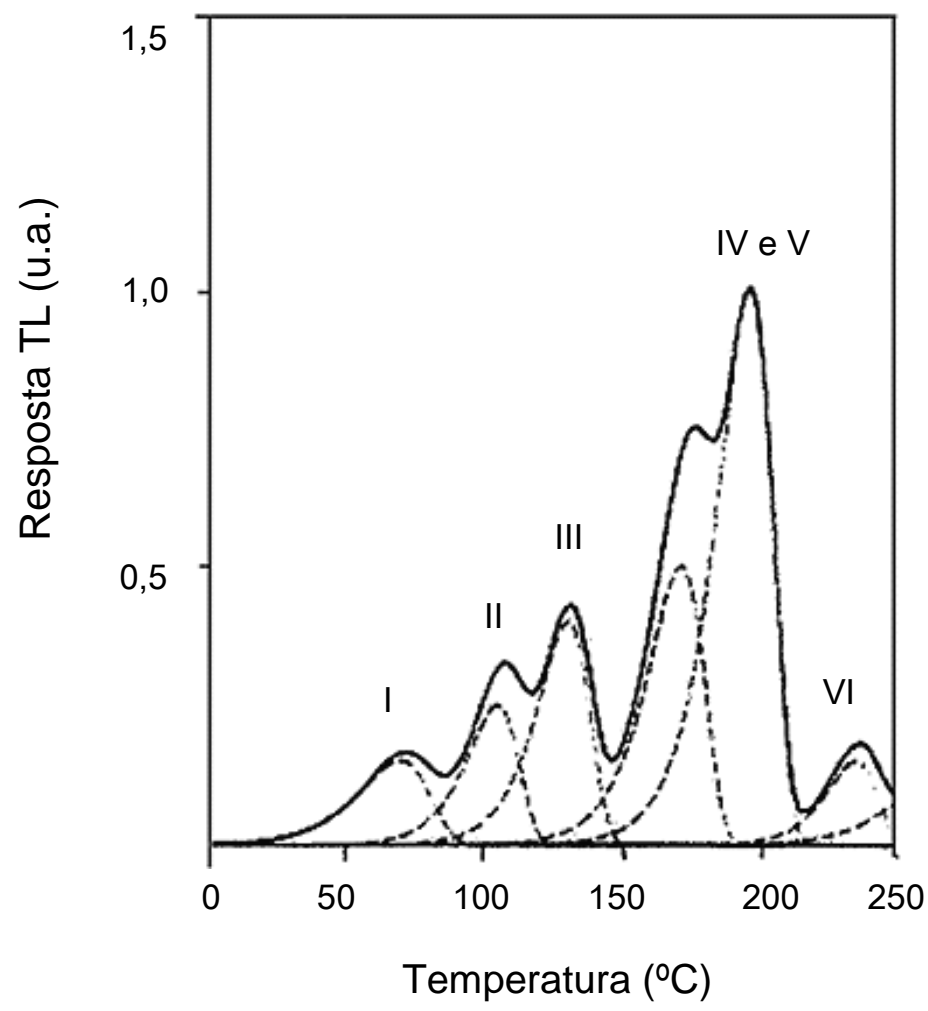

FIGURA 2.12 - Curva de emissão TL típica do LiF (TLD-100) (Adaptado de McKEEVER et al, 1995).

\subsubsection{Luminescência Opticamente Estimulada (OSL)}

A Luminescência Opticamente Estimulada (LOE), do inglês Optically Stimulated Luminescence (OSL), é o sinal luminescente emitido, devido à exposição à luz, por materiais isolantes ou semicondutores, previamente expostos à radiação ionizante. A intensidade OSL é uma função da dose absorvida na amostra e decresce proporcionalmente ao esvaziamento das armadilhas. Desta forma, a resposta luminescente pode ser usada como base de um método dosimétrico. Como na termoluminescência, o processo se inicia com a radiação provocando ionização no material, com excitação dos elétrons da camada de valência e a consequente criação de pares elétron-buraco. Os defeitos préexistentes do material armadilham os elétrons livres e os buracos em estados 
metaestáveis. Ao expor o material à luz, esses elétrons e buracos armadilhados recombinam-se e emitem um sinal luminescente (BOTTER-JENSEN et al, 2003). A integral da curva de luminescência emitida durante o período de estimulação é proporcional à dose absorvida no material.

A estimulação do material pode ser feita no modo de ondas contínuas (CW-OSL), na qual a amostra é excitada com uma intensidade constante de luz e a emissão é monitorada durante a estimulação, ou no modo linear (LM-OSL), em que a intensidade da luz usada aumenta linearmente com o tempo. A estimulação da amostra também pode ser realizada de maneira pulsada (POSL); neste caso, o sinal OSL gerado é medido no intervalo de tempo entre cada pulso (BOTTER-JENSEN et al, 2003). A FIG. 2.13 representa os 3 modos de estimulação luminosa empregados na OSL.

O fenômeno da luminescência opticamente estimulada pode ser explicado, portanto, pelo modelo da termoluminescência, adicionando-se transições ópticas que podem ocorrer quando o material é exposto à luz (YUKIHARA e McKEEVER, 2008). Muitos materiais luminescentes comumente utilizados na dosimetria TL sofrem um resfriamento brusco ("thermal quenching"), ocasionando uma perda na eficiência luminescente conforme a temperatura vai sendo elevada. A sensibilidade TL também depende da taxa de aquecimento, ou seja, quanto maior a taxa de aquecimento, menor será a sensibilidade do dosímetro; desta forma, quando se estimula a luminescência pela luz e se registra a emissão em temperatura ambiente, na qual se tem a eficiência luminescente no seu valor máximo, provém-se um aumento de aproximadamente uma ordem de magnitude na sensibilidade da emissão luminescente para os dosímetros OSL. Portanto, a dosimetria OSL evita problemas provenientes do aquecimento dos dosímetros (SCHEMBRI e HEIJMEN, 2007).

A técnica de dosimetria OSL apresenta uma aplicação diversificada em várias áreas como em dosimetria das radiações (incluindo a monitoração individual e ambiental), dosimetria retrospectiva utilizada para a datação de materiais geológicos e arqueológicos (TUDELA et al, 2012; ROCCA et al, 2012), reconstrução de doses de radiação provenientes de acidentes nucleares (BOTTER-JENSEN, 2000), dosimetria espacial (YUKIHARA et al, 2006) e dosimetria clínica (SCHEMBRI e HEIJMEN, 2007). 

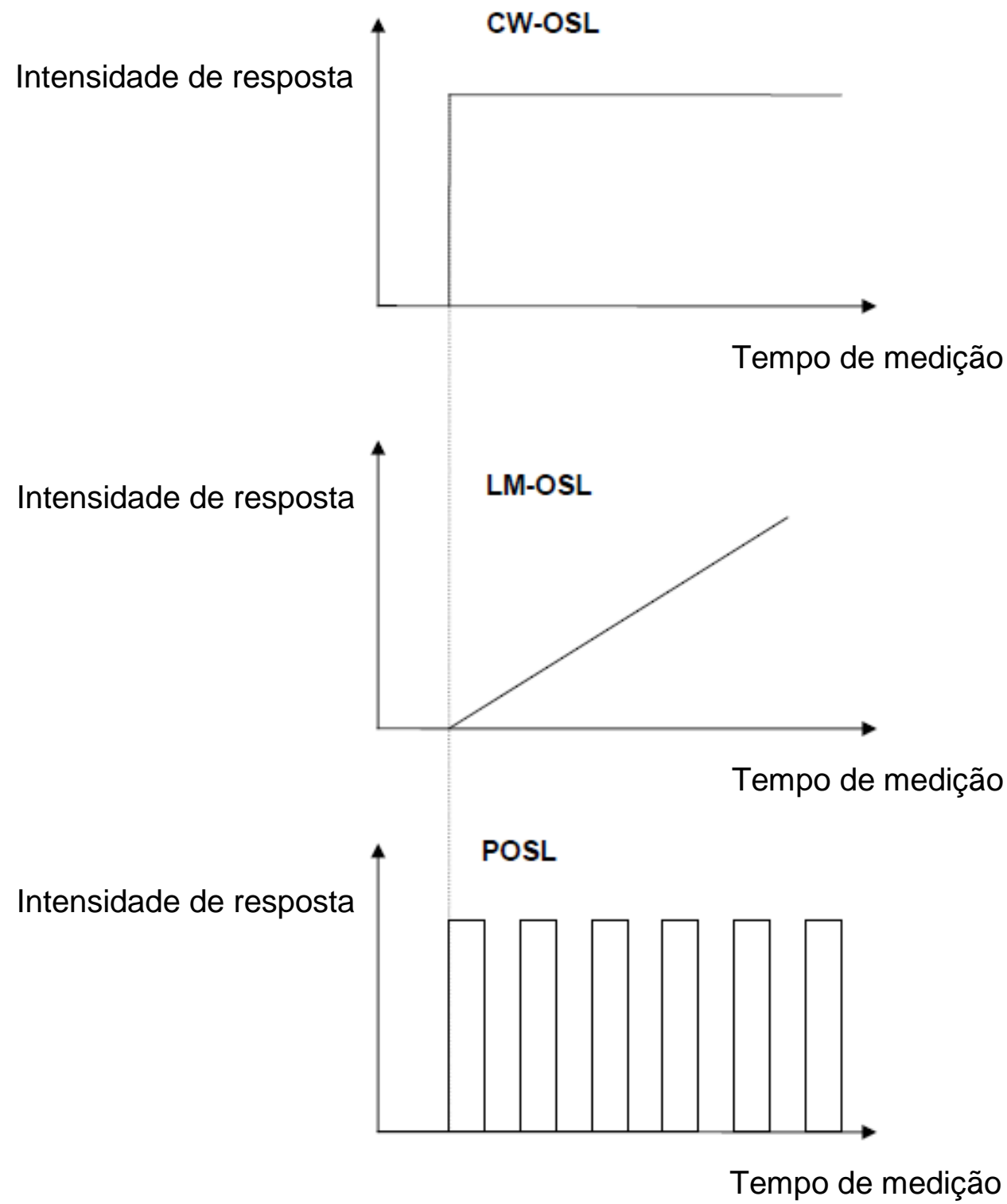

FIGURA 2.13 - Representação dos modos principais de estimulação OSL (adaptado de BOTTER-JENSEN et al, 2003).

Os métodos baseados em OSL tornaram-se uma ferramenta muito útil à área médica, tanto para dosimetria in vivo como in vitro, para terapia e procedimentos diagnósticos, principalmente mamografia (AKSELROD et al, 2007). Atualmente, a Laundauer Inc é a empresa que ocupa o cenário comercial da dosimetria OSL, com sistemas leitores OSL e seu dosímetro Luxel ${ }^{\mathrm{TM}}$ (óxido de 
alumínio), fornecendo serviços de dosimetria capazes de atender hospitais, clínicas médicas e odontológicas, centros de pesquisa e usinas nucleares (BOTTER-JENSEN et al, 2003).

O Laboratório RISÖ na Dinamarca produz leitores TL desde 1982. Na década de 90, iniciou-se a produção de acessórios para os leitores TL que possibilitaram a leitura OSL. A partir de então, o laboratório aprimorou os sistemas leitores capazes de realizar leitura TL e OSL, e é atualmente o líder mundial de fornecimento deste tipo de equipamento, principalmente no âmbito da pesquisa (RISÖ National Laboratory, 2013).

\section{4.Óxido de Berílio}

O óxido de berílio $(\mathrm{BeO})$ é um grande atrativo para dosimetria pessoal por apresentar número atômico efetivo baixo $\left(Z_{\text {efetivo }}=7,13\right)$, que é muito próximo ao do tecido biológico $\left(Z_{\text {efetivo }}=7,42\right)$. Na forma cerâmica, o $\mathrm{BeO}$ apresenta grande robustez, fácil manuseio e boa condutividade térmica (McKEEVER et al, 1995). Apesar de já ter sido estudado utilizando a técnica TL, a sua aplicação continua a ser estudada tanto para medições com TL quanto com OSL.

O óxido de berílio em pó é extremamente tóxico. A sua produção exige uma técnica extremamente rigorosa, portanto ele é produzido normalmente em laboratórios comerciais. O óxido de berílio mais vendido comercialmente é o Thermalox $^{\mathrm{TM}}$, existente em três versões: 995, 998 e 999 (Brush Wellman, USA). Em 1975, Crase e Gammage (1975) identificaram o Thermalox ${ }^{\mathrm{TM}} 995$ como o de melhor aplicação para dosimetria TL. Algumas outras formas do material também foram produzidas e comercializadas (YAMASHITA et al, 1974; KORTOV et al, 1993). Algumas impurezas como $\mathrm{Mg}, \mathrm{Si}, \mathrm{Ca}, \mathrm{B}$ e $\mathrm{Al}$ foram adicionadas ao $\mathrm{BeO}$ (BOTTER-JENSEN et al, 2003). Embora o mecanismo TL não tenha sido completamente compreendido, Kortov et al (1993) sugeriram que os centros de recombinações se dão nos sítios do $\mathrm{Al}^{2+}$, recombinação tal que induz uma emissão luminescente próximo a $330 \mathrm{~nm}$ (próximo ao valor obtido no presente trabalho). 
A curva de emissão do óxido de berílio depende da origem do material. Em geral as amostras de $\mathrm{BeO}$ apresentam três picos $\mathrm{TL}$ a $75^{\circ} \mathrm{C}, 220^{\circ} \mathrm{C}$ e $340^{\circ} \mathrm{C}$ para curvas de emissão até $400^{\circ} \mathrm{C}$ de aquecimento; o pico de $220^{\circ} \mathrm{C}$ é considerado como o pico dosimétrico principal. O primeiro estudo sistemático de OSL com óxido de berílio foi publicado em 1998 (BULUR e GÖKSU, 1998). Watanabe et al (2010) realizaram um estudo utilizando as técnicas de TL, OSL e EPR para caracterizar as propriedades dosimétricas do BeO para feixes de radiação gama.

A curva de dose-resposta do pico principal $\left(220^{\circ} \mathrm{C}\right)$ do Thermalox $^{\mathrm{TM}}$ é linear na região de 0,1 mGy até $1 \mathrm{~Gy}$, onde se torna supralinear. A curva atinge a saturação para doses absorvidas da ordem de 100 Gy (SCARPA et al, 1971).

Rhyner e Miller (1970) examinaram o potencial do uso do BeO para dosimetria com a técnica OSL. Outras investigações foram realizadas sobre as propriedades dosimétricas do BeO em OSL (BULUR e GÖKSU, 1998; BULUR et al, 2001).

Uma das maiores dificuldades com o material como dosímetro TL é a sensibilidade luminosa do sinal TL, fato que acarretou seu grande potencial para dosimetria OSL (GAMMAGE e CHEKA, 1977).

\subsection{Propriedades Dosimétricas TL e OSL}

Para que um material seja empregado em dosimetria TL e em OSL, algumas características são desejáveis, sendo elas (OBERHOFER e SCHARMANN, 1981):

- $\quad$ Alta concentração de armadilhas de elétrons e/ou buracos;

- Alta eficiência na emissão luminosa associada aos processos de recombinação;

- $\quad$ Estabilidade de armazenamento das armadilhas, de maneira que não ocorra um decaimento indesejável durante 0 período de 
armazenamento antes das leituras (temperatura ambiente ou pequenas variações de temperatura);

- Para as medições TL é desejável que o espectro da resposta TL responda de maneira satisfatória ao sistema detector, ou seja, não promova interferências devido à emissão infravermelha proveniente do aquecimento do material;

- $\quad$ Para as medições TL, o pico dosimétrico principal deve se apresentar entre $180^{\circ} \mathrm{C}$ e $250 \stackrel{\circ}{\circ}$ (para picos em temperaturas mais elevadas temse a interferência da emissão infravermelha de amostras aquecidas);

- Resistência a fatores ambientais: umidade, solventes orgânicos, gases e luz (no caso das medições TL);

- $\quad$ Baixa dependência energética;

- Resposta linear para todo o intervalo de dose;

- $\quad$ Fácil aquisição do material;

- Baixo custo.

\subsubsection{Curva de Emissão TL e Curva de Decaimento OSL}

A curva de emissão TL é dada pela variação da resposta TL em função da temperatura de aquecimento da amostra durante a leitura ou pelo tempo de aquisição dos dados. A taxa de aquecimento durante a medição TL é mantida constante; estudos anteriores comprovaram que com o aumento das taxas de aquecimento tem-se um deslocamento do pico das amostras para valores mais elevados de temperatura (PAGONIS et al, 2006). Características como o tamanho dos dosímetros e as suas impurezas apresentam influência direta na intensidade e largura dos picos presentes na curva de emissão TL, bem como em toda a sensibilidade (McKEEVER et al, 1995).

A curva OSL é dada pela intensidade da resposta OSL em função do tempo de estimulação dos dosímetros, sendo relacionada com a concentração de cargas armadilhadas. Em geral, para o caso de estimulação CW-OSL, a curva OSL é representada por uma função de decaimento que está relacionada com o 
esvaziamento das armadilhas, por isso é conhecida como curva de decaimento OSL (BOTTER-JENSEN et al, 2003). A FIG. 2.14 representa uma curva típica de decaimento OSL para sedimentos de quartzo.

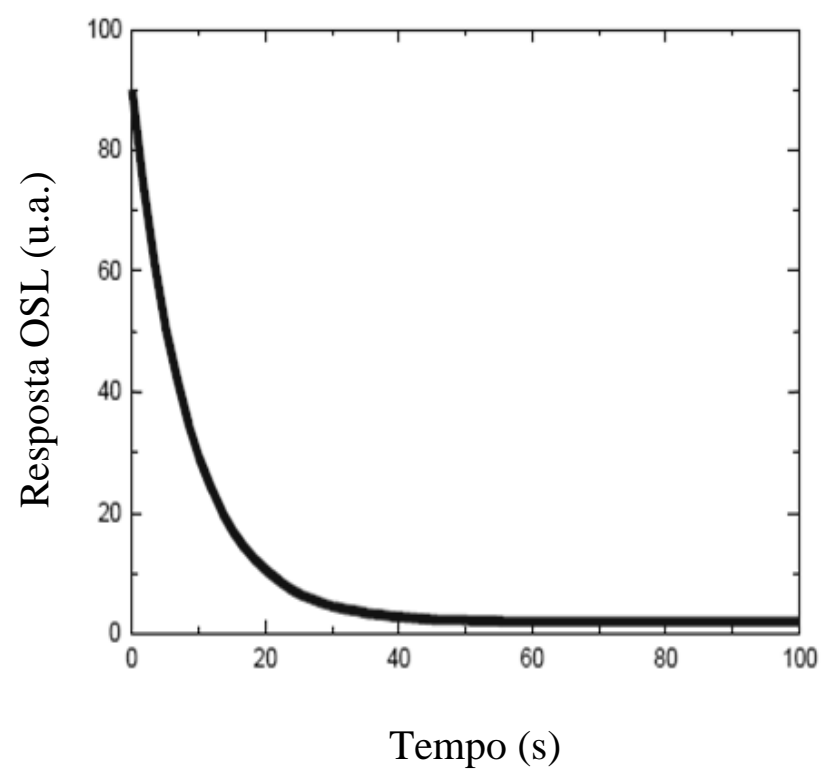

FIGURA 2.14 - Curva de decaimento OSL com estimulação de LEDs verdes para sedimentos de quartzo (Adaptado de BOTTER-JENSEN, 2000).

\subsubsection{Curva de Dose-Resposta}

A curva de dose-resposta é definida como a resposta TL ou OSL em função da dose absorvida do material irradiado. Um material ideal deveria apresentar uma relação linear da resposta TL ou OSL com a dose em um grande intervalo de dose; no entanto, a maioria dos materiais utilizados em dosimetria apresenta um comportamento não linear. Estes casos acontecem normalmente, à medida que se tem um aumento da dose, podendo ser supralinear e sublinear (McKEEVER et al, 1995). O limite inferior de detecção (LID) é o valor da dose absorvida, abaixo da qual os dosímetros não são capazes de estimar as doses com as quais foram irradiados (OBERHOFER E SCHARMANN, 1981). 


\subsubsection{Sensibilidade da resposta TL e OSL}

A sensibilidade de um material é formalmente definida como a resposta TL ou OSL por unidade de dose absorvida. Para definir a sensibilidade, deve-se considerar alguns parâmetros como o sistema de leitura usado nas medições, os filtros ópticos empregados e a taxa de aquecimento para as medições TL. A sensibilidade $(\sigma)$ de um dosímetro pode ser definida pela razão da resposta TL $\left(\mathrm{M}_{\mathrm{TL}}\right)$ pela dose absorvida (D), como mostra a EQ. 5:

$$
\sigma=\frac{M_{T L}}{D}\left[\frac{\text { contagens }}{0,5 s} \cdot G y^{-1}\right]
$$

\subsubsection{Dependência Energética da Resposta TL e OSL}

A resposta TL e OSL em função da dose absorvida pode variar com a energia da radiação incidente no material. Esta variação advém da dependência do coeficiente de absorção do material para diferentes energias e no caso dos fótons com energia definida, deve-se ao coeficiente de absorção de massa (McKEEVER et al, 2003).

Os materiais com número atômico efetivo $\left(Z_{\mathrm{ef}}\right)$ alto são fortemente dependentes da energia do fóton incidente, por isso não são recomendados para dosimetria. Para a determinação de doses absorvidas em tecidos humanos, é desejável que o material seja equivalente ao tecido mole. Os dosímetros que apresentam $Z_{\text {ef }}$ diferente ao do tecido biológico devem ter as doses corrigidas para a dependência energética da sua resposta (BOS, 2006). 


\subsubsection{Tratamento Térmico e Tratamento Óptico}

O tratamento térmico é realizado para que os dosímetros voltem às suas condições inicias existentes antes da irradiação; a finalidade é que os elétrons armadilhados que restaram após a leitura TL ou OSL retornem ao estado fundamental, removendo todo o sinal, para sua posterior reutilização (McKEEVER et al, 1995). Para se determinar o tratamento adequado a cada material é importante observar se não há alteração na sensibilidade do material e na reprodutibilidade da resposta do dosímetro. O tratamento térmico adotado deve ser realizado de forma criteriosa, repetindo sempre as mesmas condições, como a taxa de aquecimento e resfriamento da amostra (OBERHOFER E SCHARMMAN, 1981).

O sinal OSL pode ser eliminado por meio de um tratamento óptico. Neste caso as amostras devem ser iluminadas com uma fonte luminosa de comprimento de onda e intensidade adequados. Normalmente, faz-se uso de fontes de emitam o mesmo comprimento de onda das fontes luminosas utilizadas nas medições OSL (YUKIHARA e McKEEVER, 2011).

\subsubsection{Limite Inferior de Detecção}

Para que o dosímetro seja de fácil aplicação em dosimetria, a sua sensibilidade deve ser constante em um intervalo de dose absorvida. O Limite Inferior de Detecção (LID), apresentado na EQ. 6, depende de características do próprio sistema de medição TL e/ou OSL, de condições externas e das características intrínsecas do material. O limite inferior de detecção é definido experimentalmente como:

$$
L I D=M_{0}+3 . \sigma_{M_{0}} . \theta
$$




$$
\theta=\frac{D_{C}}{M}=\frac{D_{c}}{\frac{1}{N} \sum_{i=1}^{N}\left(M_{i}-M_{0 i}\right)}
$$

onde:

$M_{0}$ é a leitura do dosímetro não irradiado;

$\sigma_{M_{0}}$ é o desvio padrão da leituras dos dosímetros não irradiados;

$\theta$ é o fator de calibração

$D_{C}$ é a dose absorvida na amostra;

$M$ é a leitura do dosímetro;

$N$ é o número de amostras;

$M_{i}$ é a leitura da i-ésima amostra

$M_{0 i}$ é a leitura da i-ésima amostra com dose nula (não irradiada).

O denominador da EQ.7 representa a média das leituras, subtraindo-se as respectivas leituras de amostras não irradiadas.

\subsubsection{Espectro de Emissão}

O espectro de emissão é dado pela resposta TL ou OSL em função do comprimento de onda. O espectro é uma característica de cada material e deve estar dentro da faixa de detecção do sistema de medição utilizado, além de não sofrer interferência de emissões incandescentes, resultante do aquecimento. $O$ comprimento de onda deve se apresentar preferencialmente entre $300 \mathrm{~nm}$ e $500 \mathrm{~nm}$. 


\section{MATERIAIS E MÉTODOS}

Nesta seção serão apresentados os materiais e os equipamentos utilizados no desenvolvimento deste trabalho, além dos métodos para realização da caracterização dosimétrica do material nos feixes de radiação.

\subsection{Amostras Dosimétricas}

As amostras utilizadas neste estudo foram as pastilhas cerâmicas de óxido de berílio com diâmetro de $4,0 \mathrm{~mm}$ e espessura de 0,8 $\mathrm{mm}$. Todas as amostras de $\mathrm{BeO}$ foram selecionadas criteriosamente de acordo com sua massa, reprodutibilidade e sensibilidade. A FIG. 3.1 mostra a dimensão das pastilhas de $\mathrm{BeO}$.

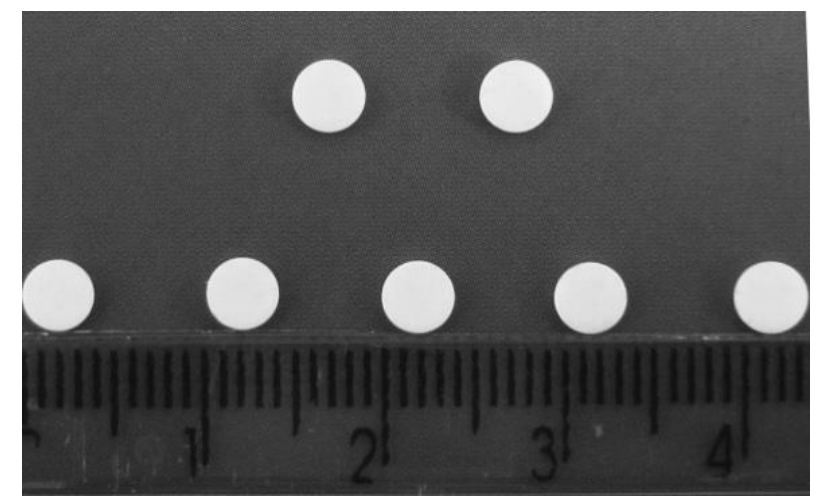

FIGURA 3.1 - Amostras de BeO em relação à escala de uma régua (cm).

Para a determinação da massa das amostras foi utilizada a balança Mettler Toledo, modelo AB204-S (FIG. 3.2), que apresenta possibilidade de leitura no intervalo de $10 \mathrm{mg}$ a $220 \mathrm{~g}$ de massa. 


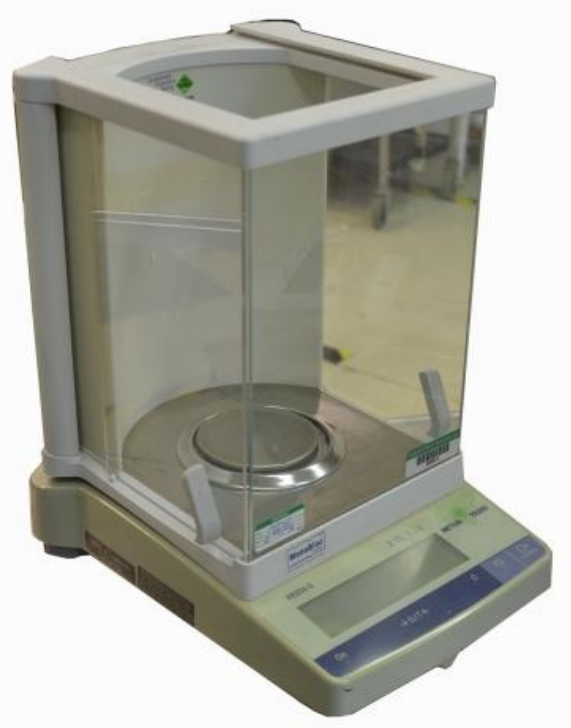

FIGURA 3.2 - Balança Metler Toledo, modelo ABS204-S.

Foram realizadas medições de difração de raios $X$ para confirmação da composição das amostras. As medições foram realizadas no difratômetro de raios $X$ modelo Multiflex, Rigaku Co, pertencente ao Centro de Ciência e Tecnologia de Materiais (CCTM/IPEN). O difratograma gerado foi comparado com 0 difratograma de um elemento padrão de $\mathrm{BeO}$.

Para a determinação dos elementos químicos presentes na amostra foi realizada uma análise semiquantitativa, pela técnica analítica de fluorescência de raios $X(F R X)$ por dispersão de energia. $O$ método de análise para determinação da concentração dos elementos químicos foi o direto; as amostras foram posicionadas em um porta-amostra específico para esse tipo de ensaio (micro $X$ cell - SPEX) utilizando-se filme fino de polipropileno (thinfilm for $X R F, 5 \mu$-SPEX). O equipamento utilizado foi um EDX-720 (FIG. 3.4), produzido pela Shimadzu Corporation, pertencente ao Centro de Lasers e Aplicações (CLA/IPEN).

Foram realizadas também medições do espectro de emissão TL das amostras de BeO; o espectrômetro (modelo USB4000, Ocean Optics) (FIG. 3.5) foi acoplado ao sistema de leitura TL/OSL, por meio de uma fibra óptica (600 $\mu \mathrm{m}$ de espessura) para obtenção dos espectros. 


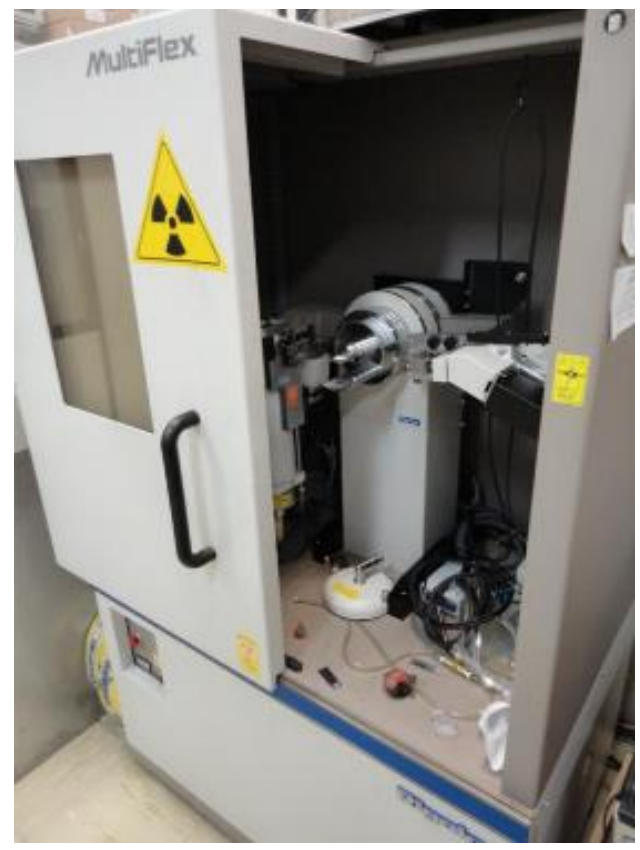

FIGURA 3.3 - Difratômetro de raios X modelo Multiflex, Rigaku Co.

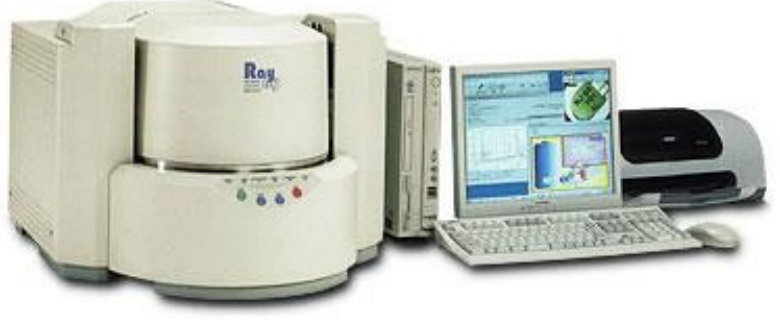

FIGURA 3.4 - Espectrômetro de FRX EDX-720, Shimadzu Co.

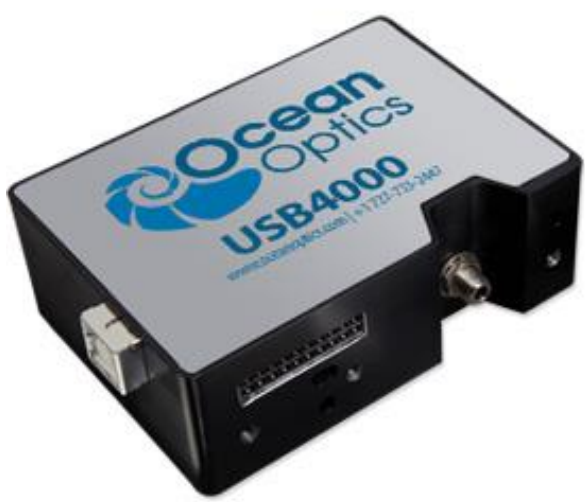

FIGURA 3.5 - Espectrômetro (modelo USB4000, Ocean Optics). 


\subsection{Sistemas de Medição TL e OSL}

As medições de TL e OSL foram realizadas no sistema leitor RISÖ TL/OSL-DA-20 (RISÖ National Laboratory, Denmark) apresentado na FIG. 3.6. O equipamento conta com um carrossel (FIG. 3.7) com capacidade para 48 amostras, que podem ser avaliadas sequencialmente ou da maneira que 0 usuário necessitar. O equipamento apresenta também duas fontes radioativas, possibilitando expor as amostras à radiação alfa $\left({ }^{241} \mathrm{Am}\right)$ e à radiação beta $\left({ }^{90} \mathrm{Sr}+{ }^{90} \mathrm{Y}\right)$. A fotomultiplicadora do sistema é do tipo bialcalino EMI 9235QB, com eficiência máxima de detecção entre 200 nm e 400 nm (RISÖ, 2013).

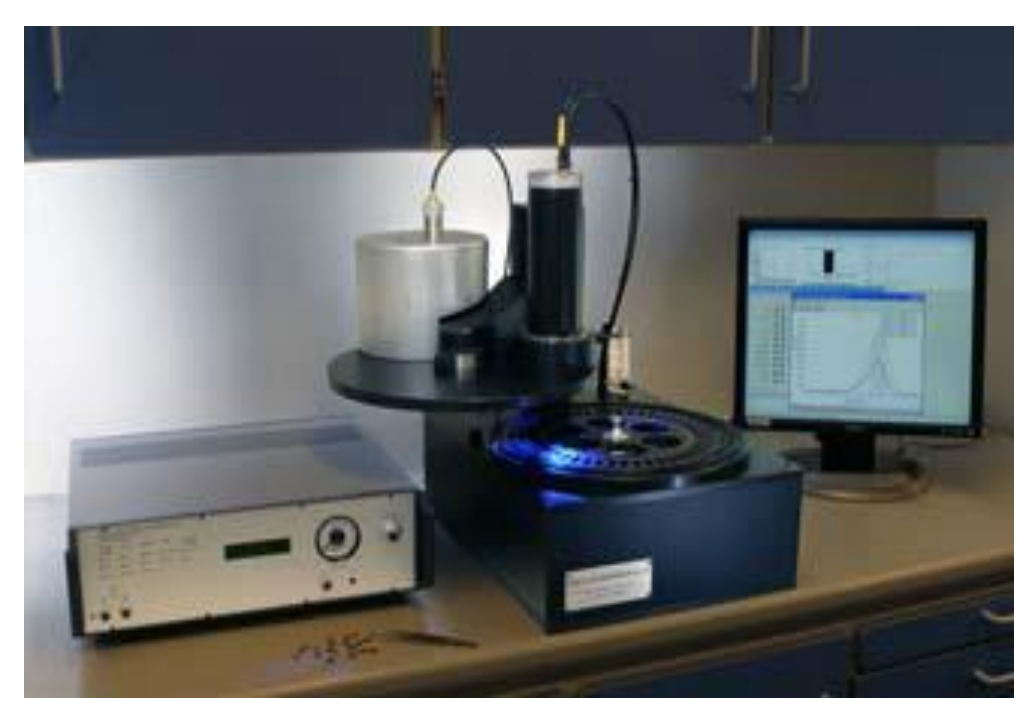

FIGURA 3.6 - Sistema leitor RISÖ TL/OSL, modelo TL/OSL-DA-20.

O sistema leitor permite realizar medições TL com taxas de aquecimento de $0,1^{\circ} \mathrm{C} / \mathrm{s}$ a $10^{\circ} \mathrm{C} / \mathrm{s}$, podendo alcançar uma temperatura máxima de $700 \stackrel{\circ}{ }$. As leituras TL foram realizadas imediatamente após as irradiações. Os parâmetros utilizados para obtenção da curva TL foram: taxa de aquecimento linear de $10^{\circ} \mathrm{C} / \mathrm{s}$, temperatura final de $450^{\circ} \mathrm{C}$ e fluxo constante de nitrogênio gasoso de 1L/min. A curva de emissão foi integrada no intervalo de temperatura entre $150^{\circ} \mathrm{C}$ e $300^{\circ} \mathrm{C}$, onde o pico dosimétrico principal se fez presente. 
Para medições com a técnica OSL é possível excitar as amostras com 28 LEDs na faixa de luz azul (470nm) e 21 LEDs na faixa do infravermelho (800nm-900nm). As leituras OSL foram obtidas no modo OSL contínuo (CWOSL), com estimulação de LEDs azuis (80 $\mathrm{mW} / \mathrm{cm}^{2}$ na posição da amostra). 0 sistema leitor possui um conjunto de filtros de detecção que devem ser utilizados para evitar que a luz espalhada a partir da estimulação atinja a fotomultiplicadora. Para estimulações com LEDs azuis foi necessário o uso do filtro Hoya U-340 (Hoya Corporation) com transmissão entre 270 nm e 380 nm, diâmetro de 45 mm e $7,5 \mathrm{~mm}$ de espessura.

O software Sequence Editor foi utilizado para introduzir as sequências de medições a serem realizadas, e o software Analyst foi usado para observar as curvas de emissão e de decaimento e extraí-las para posterior análise. Ambos os softwares foram fornecidos pelo fabricante do equipamento.

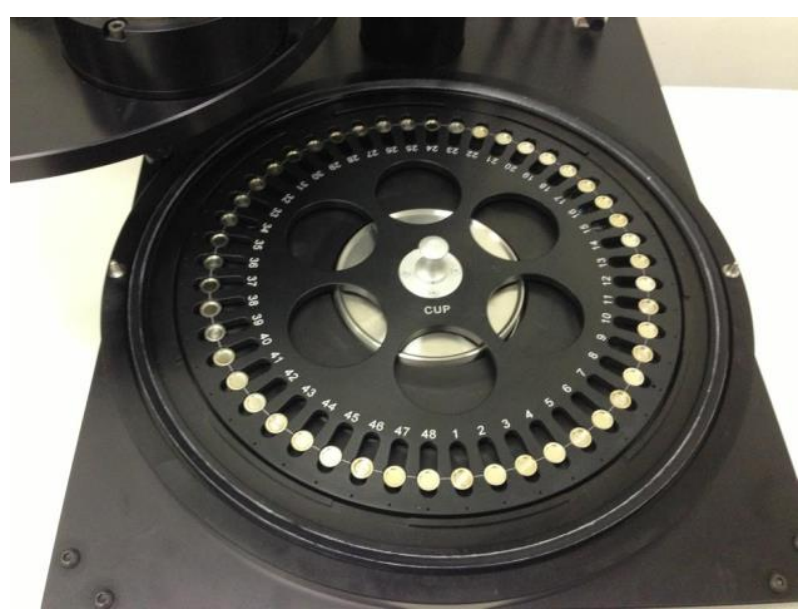

FIGURA 3.7 - Carrosel do sistema leitor RISÖ TL/OSL (TL/OSL-DA-20) com capacidade para 48 amostras. 


\subsection{Sistemas e Fontes de Radiação}

Para a caracterização das amostras foram utilizados os sistemas de radiação presentes na Gerência de Metrologia das Radiações (GMR/IPEN). Como para a determinação do espectro de emissão TL foi necessária uma dose muito elevada para obtenção de um sinal significativo, essas irradiações foram realizadas no Centro de Tecnologia das Radiações (CTR/IPEN).

\subsubsection{Sistema de Radiação X}

O sistema de radiação $X$ (FIG. 3.8) é composto por um equipamento Pantak/Seifert, modelo ISOVOLT HS 160, com feixes de energias médias de $48 \mathrm{keV}$ a $118 \mathrm{keV}$, com filtração inerente de 0,138 mmAl e janela de berílio de $0,8 \mathrm{~mm}$. Neste sistema estão disponíveis feixes padronizados e com qualidades de diagnóstico convencional, mamografia, tomografia computadorizada, radioproteção e radioterapia. A corrente aplicada para as diferentes qualidades estabelecidas pode ser variada entre $10 \mathrm{~mA}$ e $20 \mathrm{~mA}$. No sistema de radiação $X$ há uma roda de filtros PTW, modelo T90010/90011, com 24 posições disponíveis, com a filtração necessária para cada qualidade de radiação.

Para este estudo foram utilizados os feixes padrões de radiodiagnóstico convencional. Foram utilizados os feixes de referência recomendados pela norma IEC 61267 (IEC, 2005). Para todas as medições, as amostras foram posicionadas no centro do feixe de radiação $X$ a uma distância de $100 \mathrm{~cm}$ do foco do tubo de raios X. As características das qualidades de radiodiagnóstico convencional utilizadas estão apresentadas nas TAB. 3.1 e 3.2; para as irradiações com feixes diretos (RQR) a corrente do tubo aplicada foi de $10 \mathrm{~mA}$, e para as irradiações com feixes atenuados (RQA) a corrente do tubo aplicada foi de $20 \mathrm{~mA}$. 
TABELA 3.1 - Características dos feixes diretos padronizados de radiação $X$ (radiodiagnóstico convencional), estabelecidos no equipamento Pantak/Seifert, de acordo com a norma IEC 61267 (IEC, 2005).

\begin{tabular}{ccccr}
\hline $\begin{array}{c}\text { Qualidade } \\
\text { da } \\
\text { Radiação }\end{array}$ & $\begin{array}{c}\text { Tensão } \\
\text { do Tubo } \\
(\mathbf{k V})\end{array}$ & $\begin{array}{c}\text { Camada } \\
\text { Semirredutora* } \\
(\mathbf{m m A l})\end{array}$ & $\begin{array}{c}\text { Filtração } \\
\text { Adicional } \\
(\mathbf{m m A l})\end{array}$ & $\begin{array}{c}\text { Taxa de } \\
\text { Kerma no Ar } \\
\left(\mathbf{m G y} \cdot \mathbf{m i n}^{-1}\right)\end{array}$ \\
\hline RQR 3 & 50 & 1,78 & 2,4 & $22,20 \pm 0,02$ \\
RQR 5 & 70 & 2,58 & 2,8 & $38,76 \pm 0,02$ \\
RQR 8 & 100 & 3,97 & 3,2 & $68,47 \pm 0,02$ \\
RQR 10 & 150 & 6,57 & 4,2 & $119,46 \pm 0,06$ \\
\hline
\end{tabular}

TABELA 3.2 - Características dos feixes atenuados padronizados de radiação $X$ (radiodiagnóstico convencional), estabelecidos no equipamento Pantak/Seifert, de acordo com a norma IEC 61267 (IEC, 2005).

\begin{tabular}{ccccr}
\hline $\begin{array}{c}\text { Qualidade } \\
\text { da } \\
\text { Radiação }\end{array}$ & $\begin{array}{c}\text { Tensão } \\
\text { do Tubo } \\
(\mathbf{k V})\end{array}$ & $\begin{array}{c}\text { Camada } \\
\text { Semirredutora* } \\
(\mathbf{m m A l})\end{array}$ & $\begin{array}{c}\text { Filtração } \\
\text { Adicional } \\
\text { (mmAl) }\end{array}$ & $\begin{array}{c}\text { Taxa de } \\
\text { Kerma no Ar } \\
\text { (mGy.min }\end{array}$ \\
\hline RQA 3 & 50 & 3,8 & 12,4 & $3,01 \pm 0,01$ \\
RQA 5 & 70 & 6,8 & 23,8 & $2,88 \pm 0,01$ \\
RQA 8 & 100 & 10,1 & 37,2 & $4,89 \pm 0,01$ \\
RQA 10 & 150 & 13,3 & 49,2 & $11,05 \pm 0,02$ \\
\hline
\end{tabular}

\footnotetext{
"Camada semirredutora é a espessura de um material atenuador capaz de reduzir a intensidade do feixe incidente pela metade (ATTIX,1986).
} 


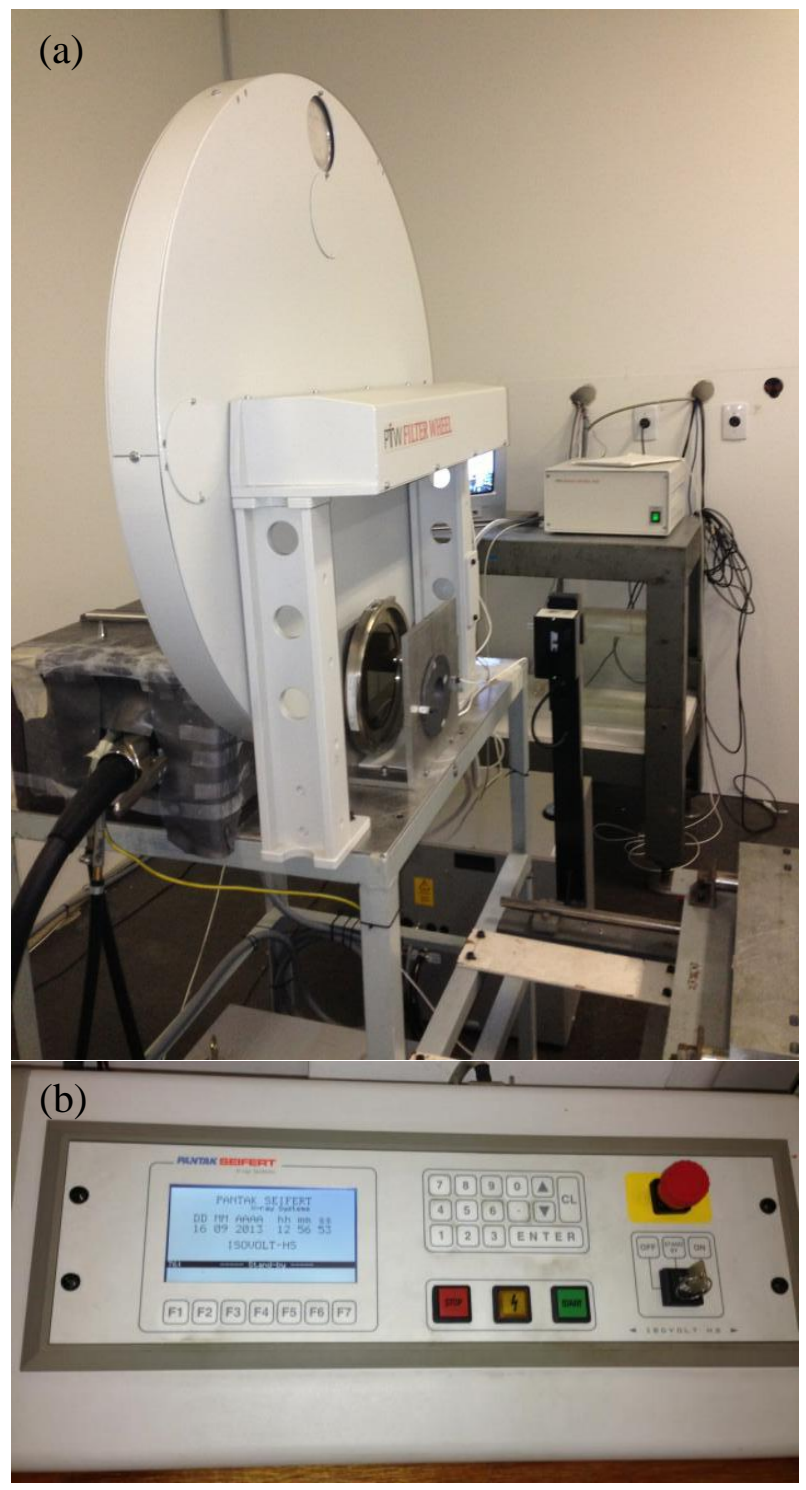

FIGURA 3.8 - (a) Sistema de radiação X Pantak/Seifert, modelo ISOVOLT HS 160, com roda de filtros PTW (modelo T90010/90011) acoplada e seu

(b) controlador.

\subsubsection{Sistemas de Radiações Alfa e Beta da Leitora RISÖ TL/OSL}

Para as irradiações com partículas alfa, foi utilizada a fonte de Amerício $\left({ }^{241} \mathrm{Am}\right)$ (FIG. 3.9 (a)) e para as irradiações com partículas beta a fonte de ${ }^{90} \mathrm{Sr}_{+}{ }^{90} \mathrm{Y}$ (FIG. 3.9 (b)), ambas do Sistema RISÖ TL/OSL. De acordo com o manual de instruções do equipamento, a taxa de dose para radiação alfa é de 
$45 \mathrm{mGy} / \mathrm{s}$ e a taxa de dose para radiação beta é de 0,1Gy/s. As atividades das fontes alfa e beta são respectivamente de 1,48 GBq e 10,7 MBq, de acordo com o certificado de calibração (06/10/2010).

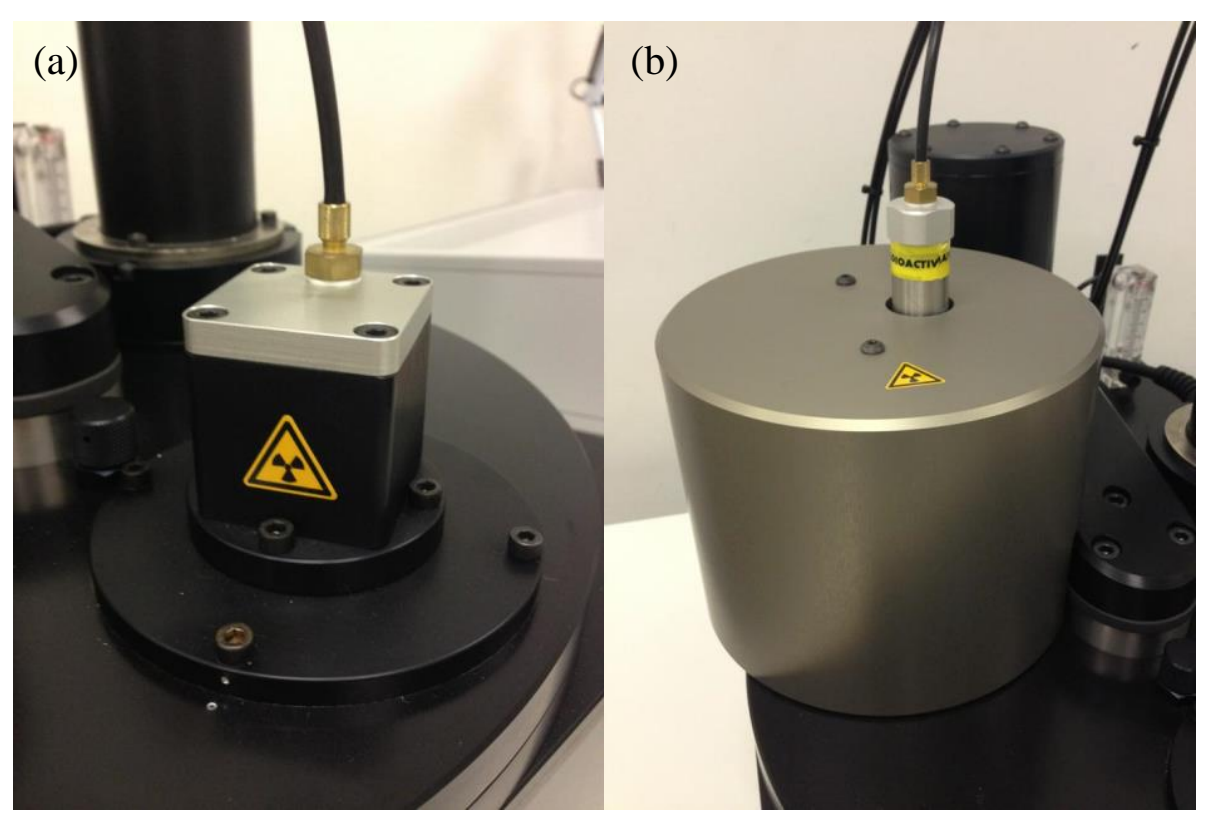

FIGURA 3.9 - Sistemas de radiação (a) alfa e (b) beta da Leitora RISÖ TL/OSL.

\subsubsection{Sistema de Radiação Gama}

As irradiações gama foram realizadas no irradiador Gamma-Cell 220 (FIG. 3.10), do Centro de Tecnologia das Radiações (CTR/IPEN) com fonte de cobalto-60, da marca Atomic Energy of Canada, modelo 220, com atividade de $60,7664 \mathrm{TBq}$ (novembro de 2012). Foram utilizadas placas de Lucite com espessura de $3 \mathrm{~mm}$ para garantir as condições de equilíbrio eletrônico. 


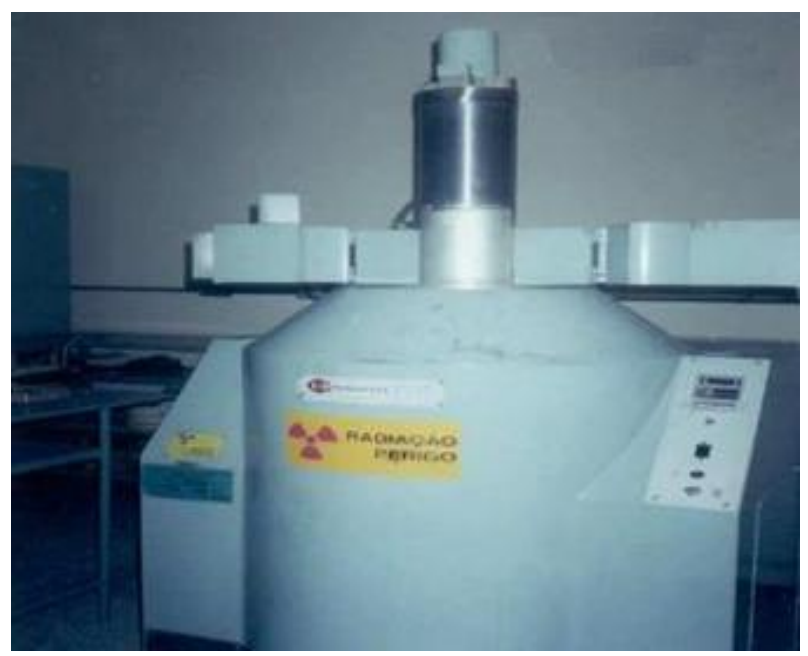

FIGURA 3.10 - Fonte de ${ }^{60}$ Co do CTR/IPEN.

\subsection{Reutilização das Amostras}

Depois que as amostras passaram pelo processo de irradiação e leitura, elas foram submetidas a um tratamento específico para esvaziar suas armadilhas, para reutilização. No caso da $T L$, as amostras foram tratadas a $750^{\circ} \mathrm{C}$ durante 15 min no forno tipo mufla com aquecimento por micro-ondas, modelo MFLO1000 (FIG. 3.11), Provecto Analítica. No caso da OSL, as amostras foram tratadas em uma caixa para tratamento óptico (FIG. 3.12) desenvolvida na Gerência de Metrologia das Radiacões (GMR/IPEN) com LEDs azuis (420-500 nm; 2,5 W; 6500 lux a 7000 lux) durante 30 min, conforme será demonstrado no item 4.2. 


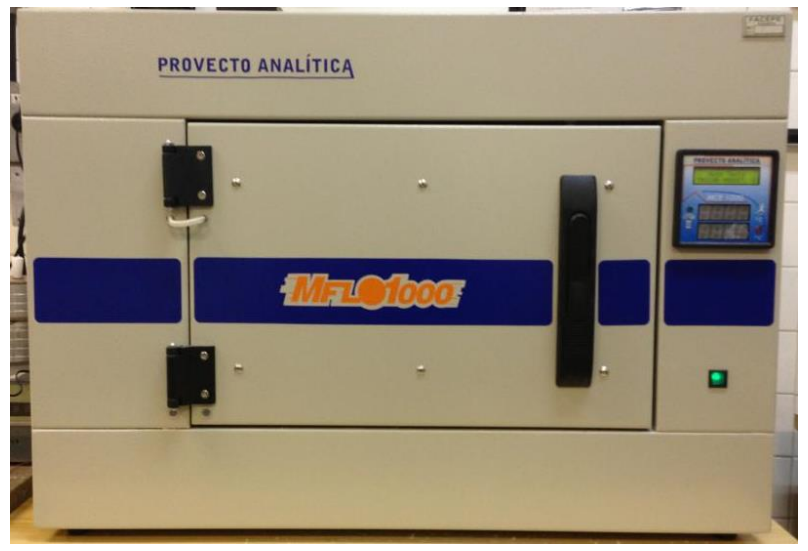

FIGURA 3.11 - Forno tipo mufla, modelo MFLO1000.

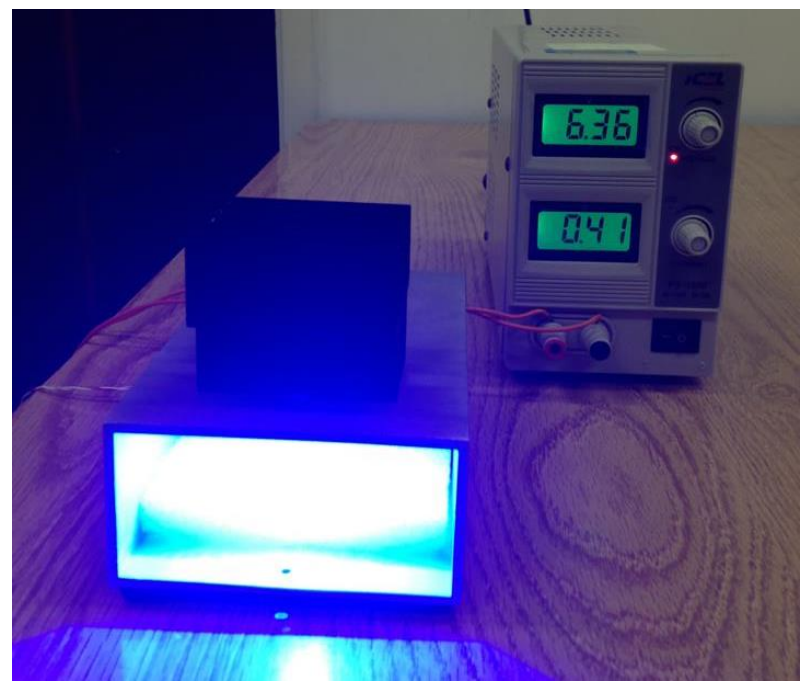

FIGURA 3.12 - Sistema para tratamento óptico com LEDs azuis. 


\subsection{Análise de Incertezas}

A avaliação e a expressão das incertezas das medições foram feitas de acordo com as recomendações do Guia para a Expressão da Incerteza de Medição (ISO, 2003), que define as incertezas em Tipo A e Tipo B, para um nível de confiança de $95 \%(k=2)$.

As incertezas do tipo $\mathrm{A}$ são aquelas relacionadas à análise estatística de uma série de obeservações (ISO, 2003). Neste trabalho foram utilizadas a média aritmética de 10 medições sob as mesmas condições e os desvios padrões (EQ. 8) e desvios padrões da média.

$$
u_{i}=\sqrt{\frac{1}{n-1} \sum_{i=1}^{n}\left(y_{i}-\bar{y}\right)^{2}}
$$

onde,

$u_{i}$ é o desvio padrão;

$n$ é o número de medições;

$y_{i}$ é o valor medido;

$\bar{y}$ é a média desses valores.

Então, o desvio padrão da média é obtido dividindo-se $0 u_{i}$ pela $\sqrt{n}$ (raíz quadrada do número de medições).

Por outro lado, as incertezas do Tipo B são aquelas não associadas à análise estatística (ISO, 2003). Dentre as incertezas do Tipo B estão as incertezas atribuídas a equipamentos de medições, dados fornecidos em certificados de calibração e outros certificados. A incerteza total das medições é dada pela EQ. 9.

$$
\sigma_{\text {Total }}^{2}=\sigma_{\text {estatistio }}^{2}+\sigma_{\text {sistemátio }}^{2}
$$


onde:

$\sigma_{\text {Total }}^{2} \quad$ : incerteza total;

$\sigma_{\text {estatistio }}^{2}$ : incerteza do Tipo A;

$\sigma_{\text {sistemátio }}^{2}$ : incerteza do Tipo B.

Para as incertezas do tipo B foram consideradas:

Incerteza nas medições das massas das amostras de $\mathrm{BeO}$ : balança com uma incerteza de $\pm 0,1 \%$;

- Incerteza nas medições TL: incerteza da leitora RISÖ TL/OSL para medições TL de \pm 0,05\% (RISÖ, 2013);

Incerteza nas medições OSL: incerteza da leitora RISÖ TL/OSL para medições OSL de \pm 0,014\% (RISÖ, 2013);

- Incerteza nas irradiações alfa e beta: incerteza devido ao posicionamento de uma amostra em relação à amostra subsequente no carrossel de $\pm 0,014 \%$ (RISÖ, 2013);

Incerteza máxima das qualidades RQR e RQA: incerteza máxima para as qualidades de feixes diretos de $\pm 0,09 \%$ e para as qualidades de feixes atenuados de $\pm 0,3 \%$;

- Incerteza na temperatura do tratamento térmico e na intensidade luminosa do tratamento óptico das amostras: incerteza de 0,04\% para ambos os tratamentos. 


\section{RESULTADOS}

\subsection{Características das Amostras de BeO}

Antes do estudo das propriedades dosimétricas das amostras foi realizado um estudo para caracterização do material.

\subsubsection{Massa das Amostras de BeO}

Duzentas amostras de $\mathrm{BeO}$ foram selecionadas randomicamente. Todas passaram por uma seleção inicial, utilizando como critério sua massa. Deste lote, foram selecionadas 109 pastilhas (FIG 4.1), de forma que se minimizassem as possíveis diferenças das respostas luminescentes decorrentes das variações da massa destas amostras. A média das massas das amostras de $\mathrm{BeO}$ foi de 27,9 mg, com uma incerteza de $\pm 1,6 \%$.

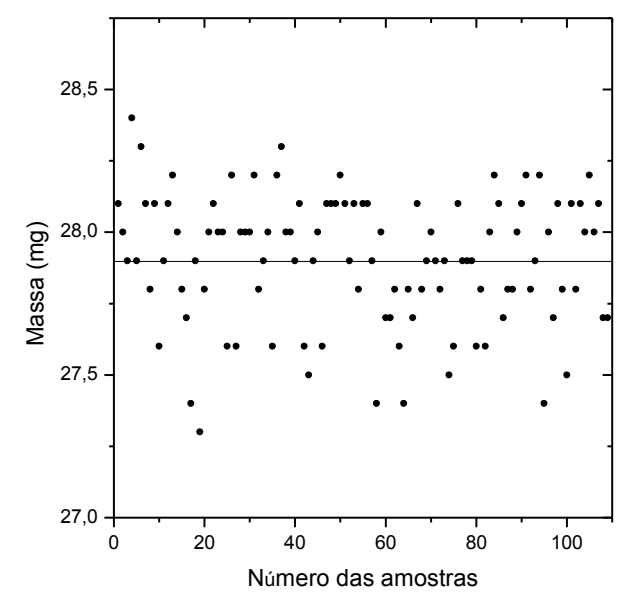

FIGURA 4.1 - Massa de 109 amostras de BeO. 


\subsubsection{Determinação do Material}

A análise de difração de raios $X$ teve como objetivo avaliar o elemento predominante na amostra. Como pode ser observado na FIG. 4.2, o difratograma da amostra estudada apresenta picos nas mesmas regiões de um elemento padrão de BeO (JCPDS, 1991), que é chamado de Bromellite. Esta semelhança dos difratogramas comprova que as amostras estudadas apresentam a mesma morfologia.

Os valores dos ângulos de difração (20) foram obtidos, e pela Lei de Bragg (EQ. 10) foi possível determinar a distância entre os planos atômicos do material $\left(d_{i n t}\right)$, também chamado de $d$-spacing. Os valores de $d_{i n t}$ do elemento padrão e das amostras em estudo estão apresentados na TAB. 4.1. Nota-se que esses valores são bem próximos, havendo variação somente na intensidade dos picos. Este fato pode ser ocasionado pela adição de outros componentes ao elemento padrão da amostra.

$$
\lambda=2 \cdot d_{\mathrm{int}} \cdot \operatorname{sen} \theta
$$

Para a determinação dos demais elementos presentes na composição das amostras de $\mathrm{BeO}$, foi realizada uma análise semiquantitativa. $\mathrm{A}$ análise das amostras de $\mathrm{BeO}$ por fluorescência de raios $X(F R X)$ apresentou o silício, 0 potássio e o alumínio como impurezas mais presentes na composição das pastilhas, que por sua vez têm o óxido de berílio com $99,0 \%$ de sua proporção. 0 restante dos elementos (1\%) estão mostrados na TAB 4.2. 


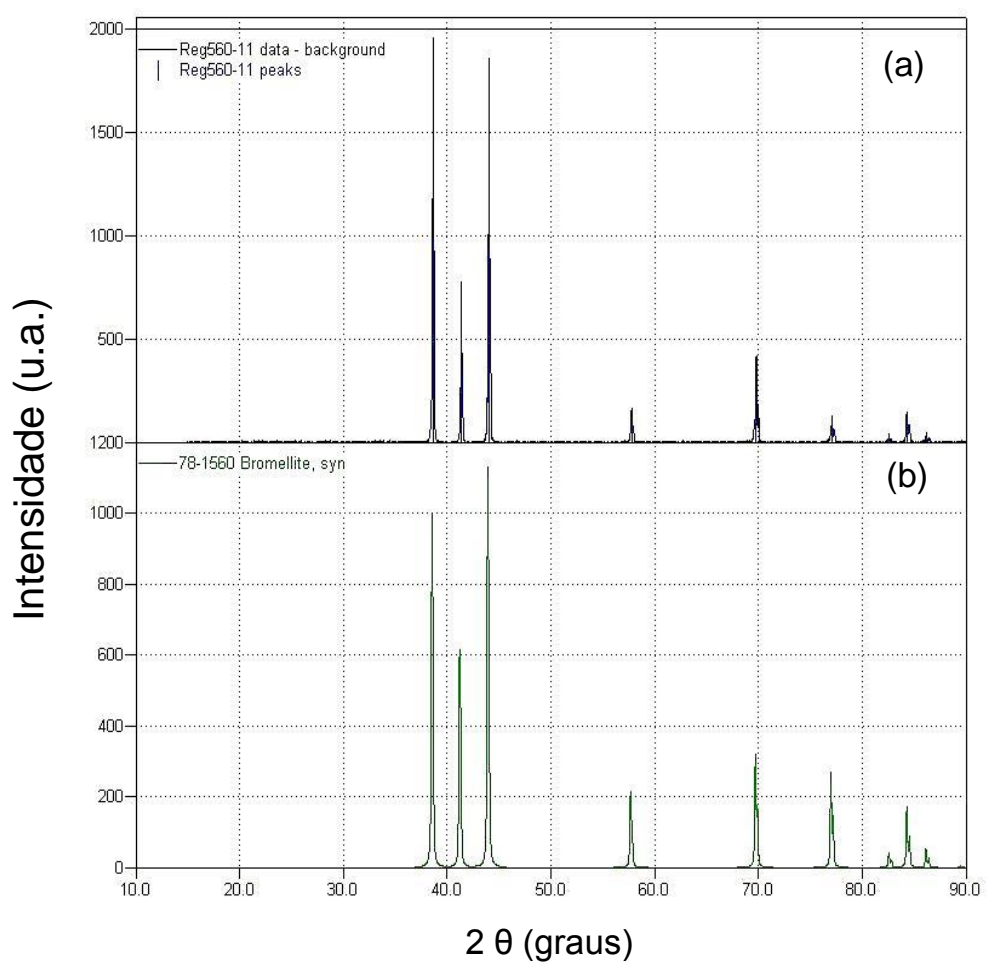

FIGURA 4.2 - Difratogramas de raios X de (a) uma amostra de BeO, comparada com (b) um elemento padrão: Bromellite.

TABELA 4.1 - Comparação entre picos de uma amostra de BeO padrão e as amostras analisadas.

\begin{tabular}{cc|cc}
\hline \multicolumn{2}{c}{ BeO Padrão } & \multicolumn{2}{c}{ Amostras Estudadas } \\
\hline $\begin{array}{c}\text { Intensidade } \\
(\%)\end{array}$ & $\mathbf{d}_{\text {int }}$ & $\begin{array}{c}\text { Intensidade } \\
(\%)\end{array}$ & $\mathbf{d}_{\text {int }}$ \\
\hline 84,6 & 2,33 & 100,0 & 2,33 \\
53,6 & 2,19 & 40,0 & 2,18 \\
100,0 & 2,06 & 95,2 & 2,06 \\
20,4 & 1,60 & 8,7 & 1,59 \\
30,9 & 1,35 & 9,7 & 1,34 \\
26,5 & 1,24 & 7,0 & 1,24 \\
4,0 & 1,17 & 2,4 & 1,17 \\
16,9 & 1,15 & 7,8 & 1,15 \\
5,0 & 1,13 & 2,4 & 1,13 \\
\hline
\end{tabular}


TABELA 4.2 - Resultado da análise de FRX das amostras de BeO

\begin{tabular}{cc}
\hline Elemento & $\begin{array}{c}\text { Concentração } \\
\text { (ppm) }\end{array}$ \\
\hline $\mathrm{Si}$ & $801 \pm 46$ \\
$\mathrm{~K}$ & $749 \pm 42$ \\
$\mathrm{Al}$ & $350 \pm 20$ \\
$\mathrm{Fe}$ & $92 \pm 6$ \\
$\mathrm{Co}$ & $68 \pm 4$ \\
$\mathrm{Mn}$ & $81 \pm 4$ \\
$\mathrm{~S}$ & $74 \pm 4$ \\
$\mathrm{~W}$ & $<10$ \\
$\mathrm{TI}$ & $48 \pm 6$ \\
$\mathrm{Os}$ & $46 \pm 6$ \\
$\mathrm{Zn}$ & $28 \pm 4$ \\
$\mathrm{Ra}$ & $12 \pm 2$ \\
\hline
\end{tabular}

\subsection{Tratamento Óptico}

Para se determinar o tratamento óptico para reutilização das pastilhas após as medições com a técnica OSL, as amostras foram irradiadas com uma dose absorvida de 200 Gy de radiação beta. As amostras foram tratadas opticamente durante diferentes intervalos de tempo: $5 \mathrm{~min}$; $10 \mathrm{~min} ; 15 \mathrm{~min}$; $20 \mathrm{~min} ; 30 \mathrm{~min} ; 1 \mathrm{~h} ; 1,5 \mathrm{~h}$ e $2 \mathrm{~h}$. A resposta OSL foi normalizada para a leitura obtida sem tratamento óptico e os resultados estão apresentados na FIG. 4.3.

Nota-se que, a partir de 30 minutos de tratamento óptico, a resposta OSL mantém-se constante, portanto este foi o tratamento adotado no decorrer deste trabalho. 


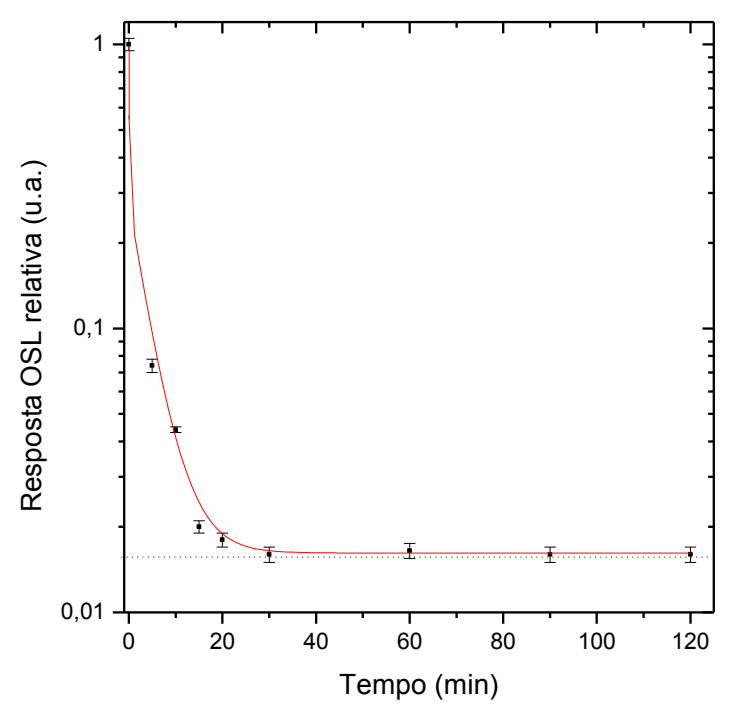

FIGURA 4.3 - Resposta OSL relativa para amostras tratadas opticamente durante $5 \min$ a $120 \mathrm{~min}$.

\subsection{Seleção dos Dosímetros}

Os dosímetros foram selecionados pela técnica termoluminescente, e posteriormente eles foram utilizados para a realização do estudo com luminescência opticamente estimulada. Foi determinada a sensibilidade da resposta $\mathrm{TL}$ do $\mathrm{BeO}$ após a exposição das amostras à radiação beta da fonte de ${ }^{90} \mathrm{Sr}_{+}{ }^{90} \mathrm{Y}$ (FIG. 4.4). Como o sinal TL obtido foi muito elevado, fez-se necessário o uso de um colimador para que a fotomultiplicadora não atingisse a saturação. Assim, todos os testes foram realizados com um colimador com abertura de $2 \mathrm{~mm}$ de diâmetro.

A sensibilidade $(\sigma)$ de um dosímetro pode ser definida pela razão da resposta $T L\left(\mathrm{M}_{\mathrm{TL}}\right)$ pela dose absorvida (D), como mostra a $E Q$. 5, a dose absorvida utilizada para este teste foi de 1 Gy. 


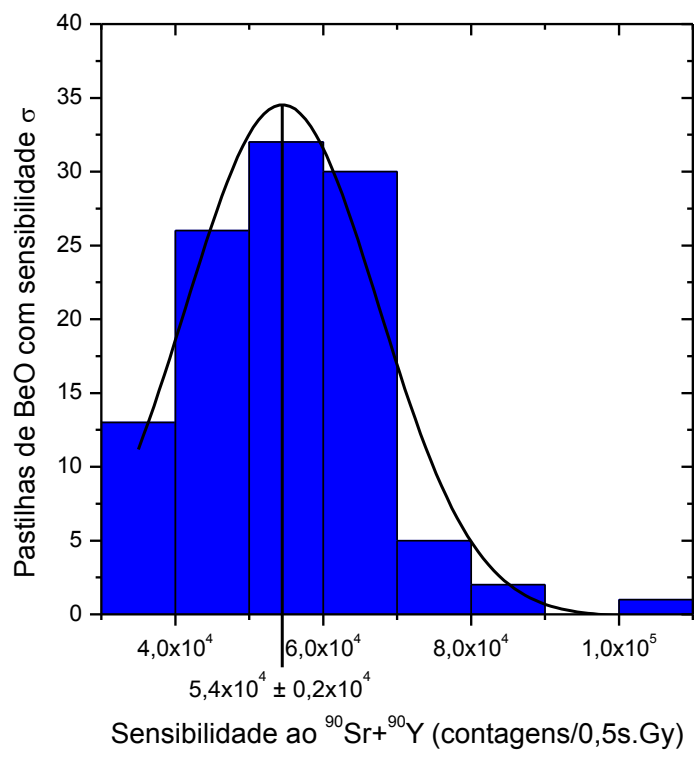

FIGURA 4.4 - Histograma da variação da sensibilidade da resposta TL das pastilhas de $\mathrm{BeO}$.

Como as amostras não apresentaram o mesmo comportamento para cada tipo de radiação, também foram determinadas suas sensibilidades, que foram normalizadas para os valores obtidos para o feixe de radiação beta. As sensibilidades médias aos feixes de radiação alfa, beta e X estão apresentadas na $\mathrm{TAB}$. 4.3. As amostras de $\mathrm{BeO}$ apresentaram maior sensibilidade para radiação beta; para a radiação $X$ a sensibilidade foi $15 \%$ menor e para a radiação alfa $98 \%$ menor.

TABELA 4.3 - Sensibilidades médias relativas das amostras de BeO para as radiações alfa, beta e $X$.

\begin{tabular}{c|c}
\hline $\begin{array}{c}\text { Tipo de } \\
\text { radiação }\end{array}$ & $\begin{array}{c}\text { Sensibilidade média } \\
\text { (u.a.) }\end{array}$ \\
\hline alfa & $0,021 \pm 0,001$ \\
\hline beta & $1,000 \pm 0,010$ \\
\hline$X$ & $0,853 \pm 0,068$ \\
\hline
\end{tabular}




\subsection{Curva de Emissão TL e Curva de Decaimento OSL}

A curva de emissão TL representa a variação da resposta $T L$ em função da temperatura de aquecimento ou do tempo de aquecimento, e a curva de decaimento OSL é representada pela intensidade da resposta OSL (no caso do sistema leitor RISÖ TL/OSL, em contagens por segundo), em função do tempo de estimulação óptica da amostra.

As curvas de emissão TL e de decaimento OSL para uma amostra de $\mathrm{BeO}$ irradiada com uma dose absorvida de 1 Gy de radiação alfa, beta e $X$ (RQR5) estão representadas na FIG. 4.5 e na FIG. 4.6, respectivamente.

Todas as amostras de $\mathrm{BeO}$ apresentaram o mesmo comportamento $\mathrm{TL}$, ou seja, pico dosimétrico principal em aproximadamente $220^{\circ} \mathrm{C}$ e um segundo pico a $380^{\circ} \mathrm{C}$, mudando somente a intensidade devido ao tipo de radiação. $\mathrm{O}$ primeiro pico, característico do óxido de berílio, a $75^{\circ} \mathrm{C}$, não foi possível visualizar nestas medições. Este fato pode ter ocorrido devido a uma baixa intensidade deste pico, que ficou desprezível em relação aos outros picos TL. No caso das curvas de decaimento OSL (FIG. 4.6) pode-se notar também que a resposta OSL depende do tipo de radiação, não alterando seu comportamento mas somente a intensidade da resposta OSL, ou seja, para todas as curvas nota-se uma redução de $50 \%$ da intensidade em aproximadamente $12 \mathrm{~s}$. 

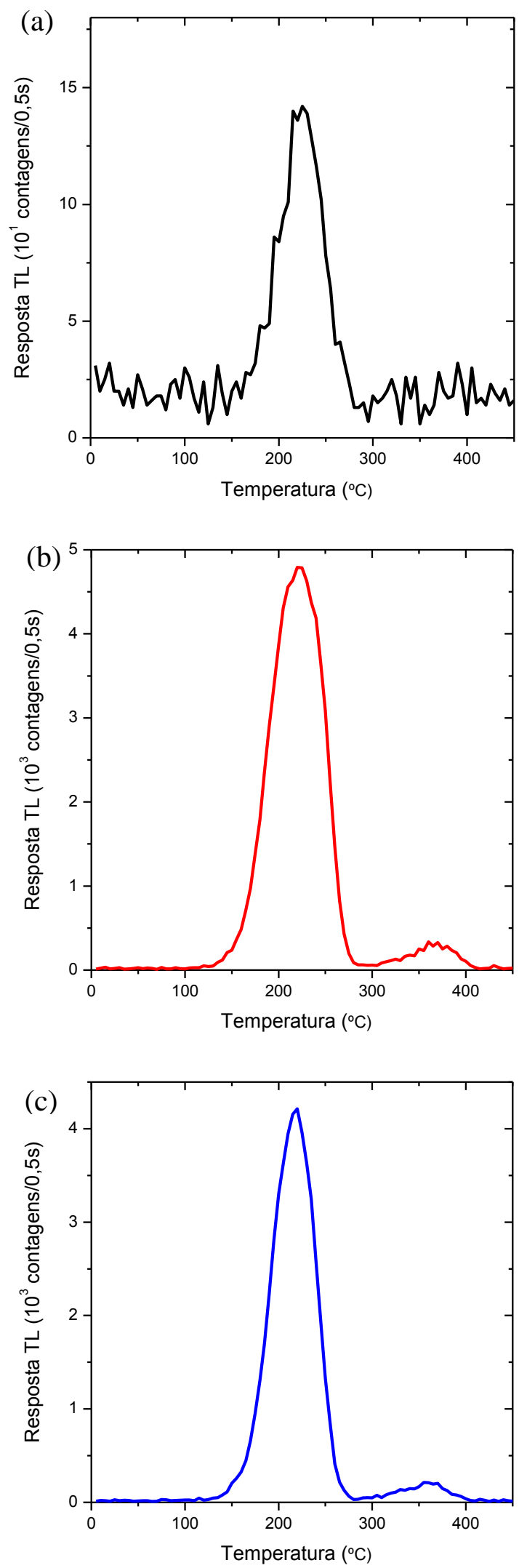

FIGURA 4.5 - Curva de emissão TL de uma mesma amostra de BeO exposta a uma dose absorvida de 1 Gy de radiações (a) alfa,(b) beta e (c) $X$. 

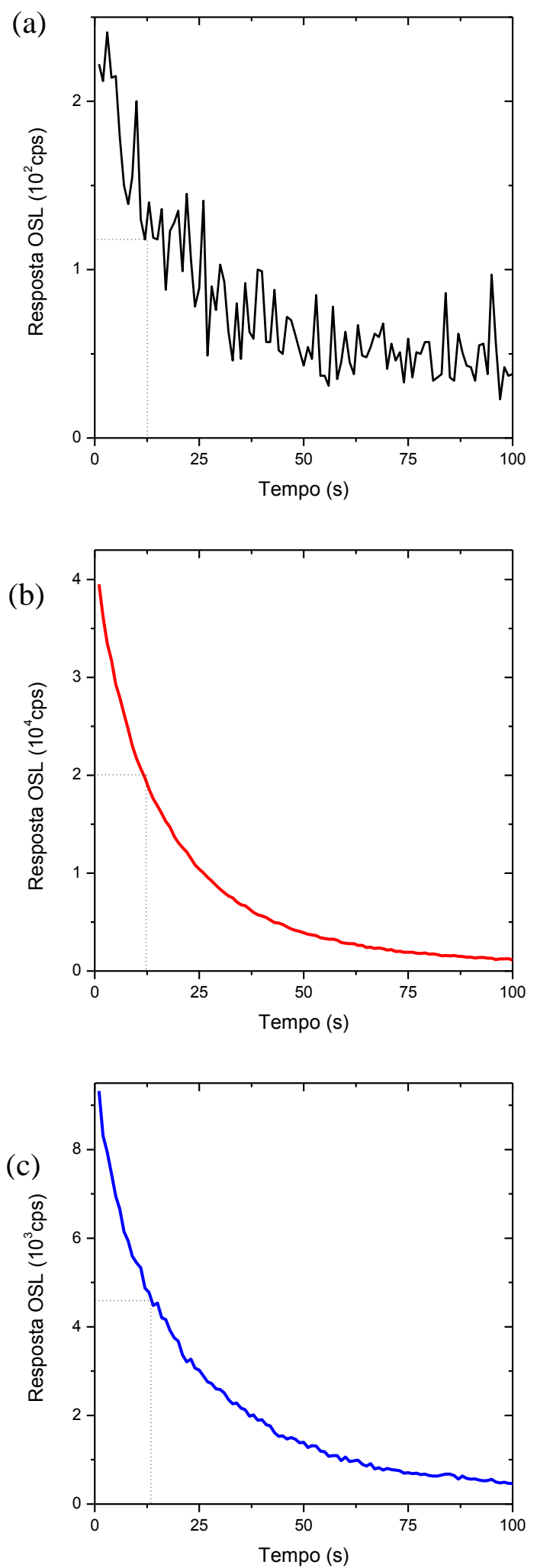

FIGURA 4.6 - Curva de decaimento OSL de uma mesma amostra de BeO exposta a uma dose absorvida de 1 Gy de radiações (a) alfa, (b) beta e (c) X. As linhas tracejadas indicam o ponto em que a intensidade da resposta OSL é reduzida em $50 \%$. 
As curvas de emissão TL e as curvas de decaimento OSL obtidas para uma mesma dose absorvida são apresentadas na FIG. 4.7, para uma visualização comparativa das intensidades das respostas TL e OSL para os diferentes tipos de radiação; pode-se notar que as amostras são mais sensíveis para radiação beta e menos sensíveis para radiação alfa, para ambas as técnicas.
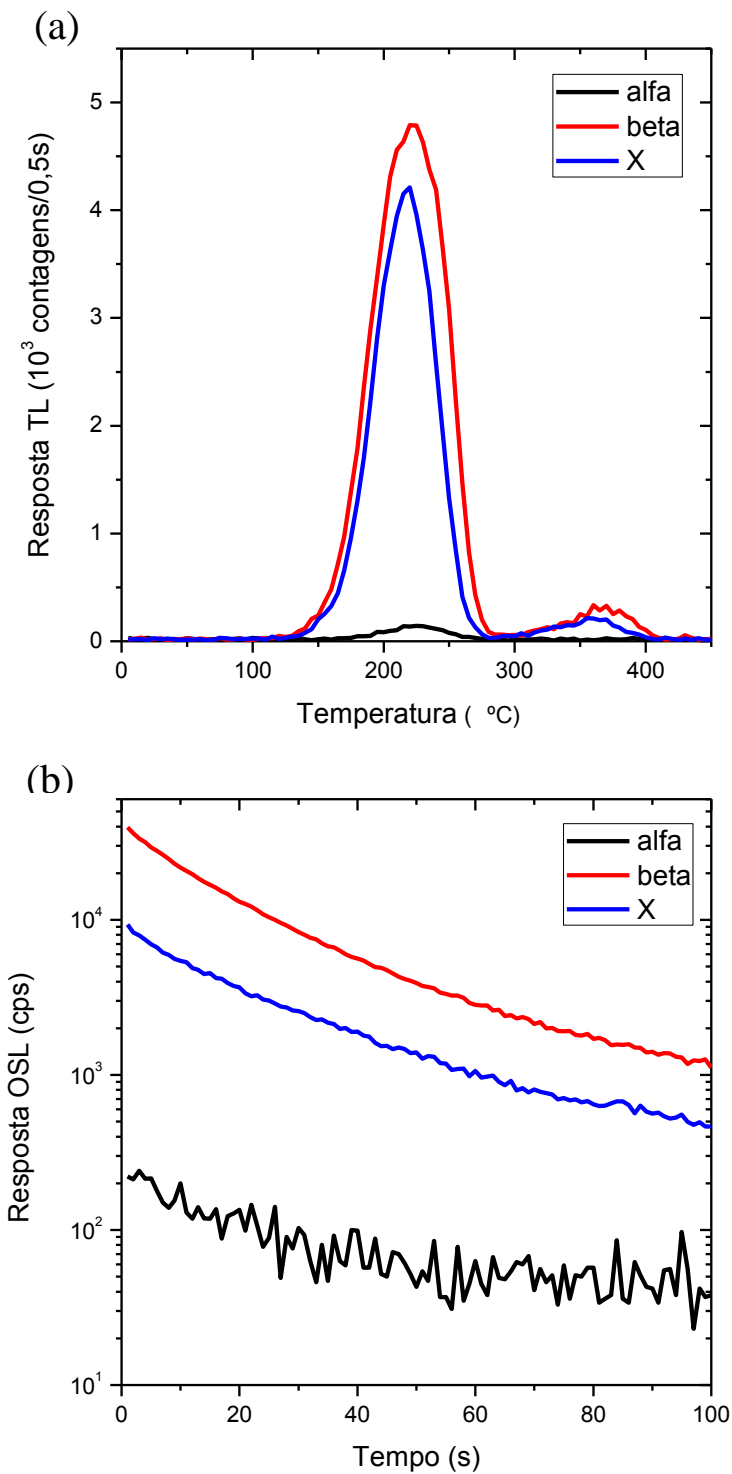

FIGURA 4.7 - (a) Curvas de emissão TL e (b) curvas de decaimento OSL para amostras de $\mathrm{BeO}$ irradiadas com uma dose de $1 \mathrm{~Gy}$ de radiações alfa, beta e $\mathrm{X}$. 


\subsection{Espectro de Emissão TL}

Para a obtenção do espectro de emissão TL, as amostras foram tratadas termicamente durante $15 \mathrm{~min}$ a $750^{\circ} \mathrm{C}$, e posteriormente foram expostas a uma dose de 1 kGy de radiação gama (Gammacell). Os mesmos parâmetros da TL foram utilizados para a obtenção do espectro. O espectro de emissão (FIG. 4.8) consiste em um pico com banda de emissão em aproximadamente $335 \mathrm{~nm}$, com um alongamento entre $400 \mathrm{~nm}$ e $450 \mathrm{~nm}$. Este pico é correspondente ao pico dosimétrico do material, que para esta amostra ocorre em aproximadamente $230^{\circ} \mathrm{C}$. Os outros dois picos do óxido de berílio talvez não tenham sido observados devido à pequena intensidade do sinal. Os dados obtidos para esta amostra de BeO são os mesmos apresentados para a curva de emissão do Thermalox ${ }^{\text {TM }} 995$ (McKEEVER et al, 1995).

\subsection{Reprodutibilidade da Resposta}

Para se determinar a reprodutibilidade da resposta luminescente para as técnicas TL e OSL, foram separadas 8 amostras e realizados 10 ciclos de irradiação, medição luminescente e tratamento térmico/óptico para reutilização das amostras (para as técnicas TL e OSL). De cada valor obtido foi subtraído o valor da resposta da mesma amostra não irradiada, no caso da OSL, somente tratadas opticamente com LEDs azuis, e no caso TL, somente tratadas termicamente.

As amostras foram irradiadas com uma dose de $1 \mathrm{~Gy}$, avaliadas e tratadas para uma nova medição. As irradiações foram feitas nos feixes de radiação alfa, beta e $X(R Q R 5)$. A reprodutibilidade, neste caso, é dada pelo coeficiente de variação percentual (CV\%), que é o quociente entre o desvio padrão das respostas luminescentes e a média das medições de cada amostra, em porcentagem. Na TAB. 4.4 são apresentados os valores de reprodutibilidade obtidos para cada técnica. Além dos resultados de reprodutibilidade, para cada amostra foi determinado um fator de correção (FC), que é o quociente da média das dez leituras realizadas em relação à resposta de cada amostra. Desta forma 
foram obtidos os valores para radiação alfa $\left(F C_{\alpha}\right)$, radiação beta $\left(\mathrm{FC}_{\beta}\right)$ e radiação $\mathrm{X}(\mathrm{FCX})$.

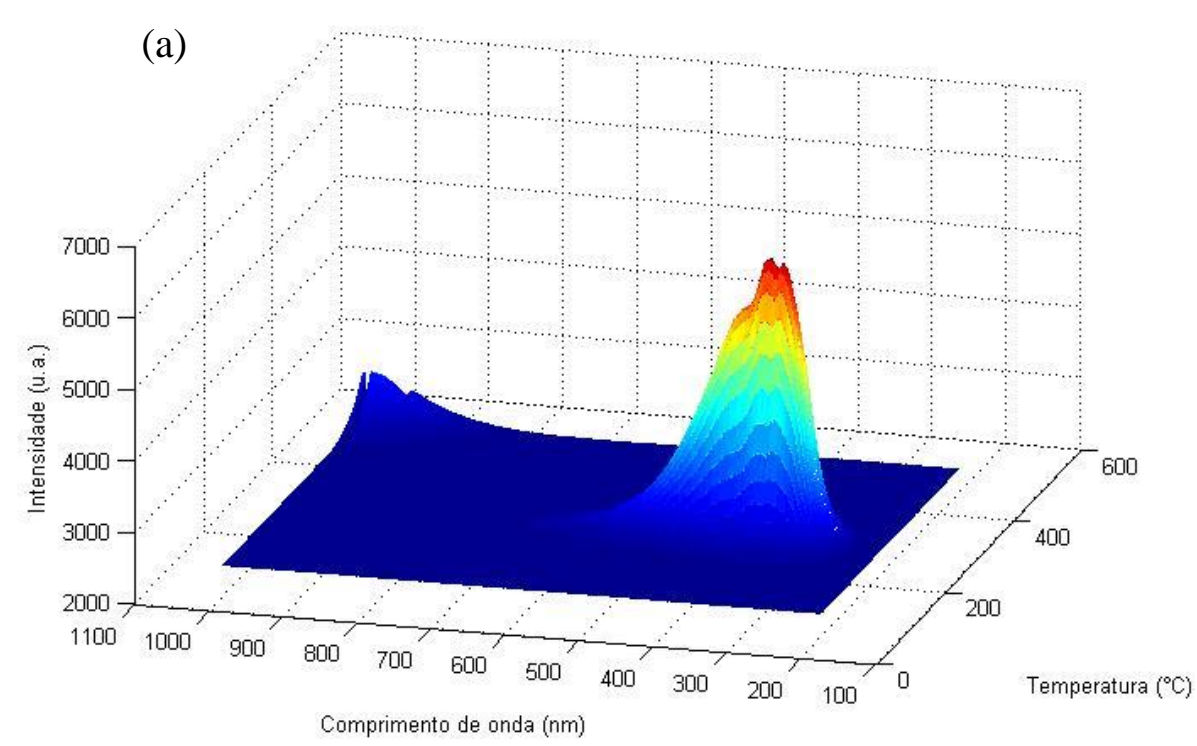

(b)

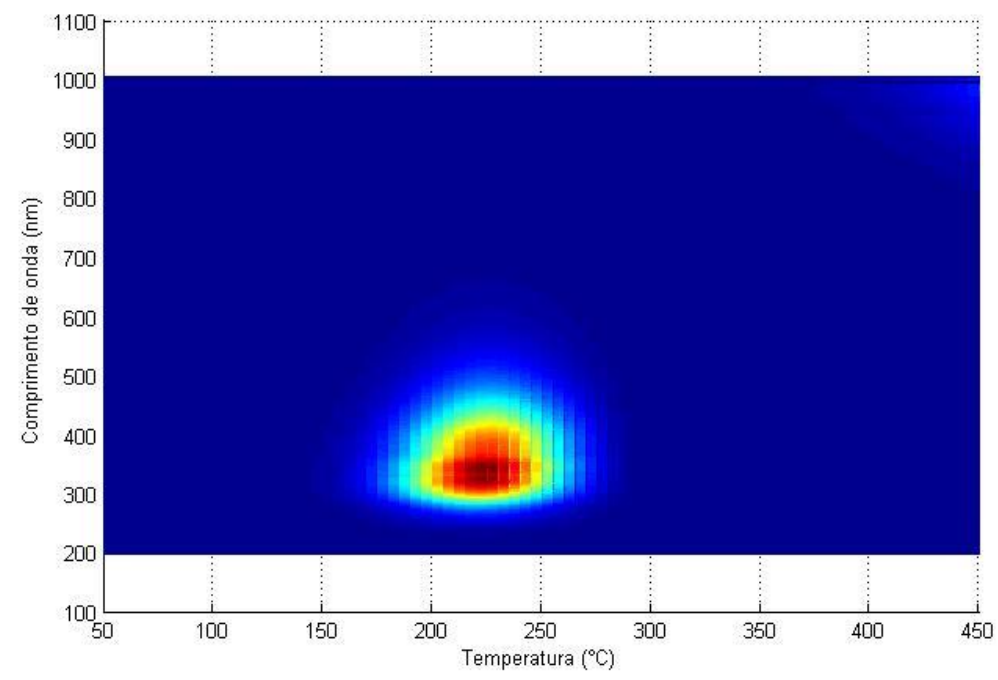

FIGURA 4.8 - Espectro de emissão da amostra de BeO exposta a uma dose de 1 kGy de radiação gama $\left({ }^{60} \mathrm{Co}\right)$ : (a) gráfico isométrico e (b) gráfico de contorno. 
TABELA 4.4 - Reprodutibilidade do BeO para radiação alfa, beta e X e seus respectivos fatores de correção para cada tipo de radiação.

\begin{tabular}{|c|c|c|c|c|c|c|c|}
\hline \multirow{4}{*}{$\begin{array}{c}\text { Técnica } \\
\text { luminescente }\end{array}$} & \multirow{4}{*}{ Amostra } & \multicolumn{6}{|c|}{ Radiação } \\
\hline & & \multicolumn{2}{|c|}{ Alfa } & \multicolumn{2}{|c|}{ Beta } & \multicolumn{2}{|c|}{$\mathbf{x}$} \\
\hline & & CV & FC & CV & FC & CV & $F C_{0}$ \\
\hline & & (\%) & $C_{\alpha}$ & $(\%)$ & $\sigma_{\beta}$ & $(\%)$ & $10 x$ \\
\hline \multirow{8}{*}{ TL } & 1 & 0,4 & 0,974 & 1,3 & 0,985 & 2,3 & 0,981 \\
\hline & 2 & 2,5 & 0,966 & 1,4 & 0,968 & 1,6 & 0,945 \\
\hline & 3 & 1,8 & 1,014 & 1,1 & 1,006 & 2,2 & 1,049 \\
\hline & 4 & 0,3 & 1,028 & 1,4 & 1,009 & 2,8 & 0,960 \\
\hline & 5 & 1,3 & 1,031 & 2,0 & 1,005 & 1,2 & 1,031 \\
\hline & 6 & 3,2 & 1,040 & 0,9 & 1,015 & 1,2 & 0,955 \\
\hline & 7 & 3,6 & 0,928 & 2,2 & 1,002 & 1,7 & 0,980 \\
\hline & 8 & 1,3 & 1,030 & 1,4 & 1,011 & 2,3 & 1,123 \\
\hline \multirow{8}{*}{ OSL } & 1 & 0,8 & 0,884 & 1,3 & 0,821 & 2,7 & 0,868 \\
\hline & 2 & 2,4 & 0,809 & 4,2 & 0,634 & 0,9 & 0,730 \\
\hline & 3 & 1,8 & 1,006 & 2,7 & 1,100 & 1,2 & 1,084 \\
\hline & 4 & 2,3 & 1,035 & 2,7 & 1,063 & 1,4 & 1,042 \\
\hline & 5 & 2,4 & 1,405 & 3,5 & 1,913 & 0,3 & 1,542 \\
\hline & 6 & 2,8 & 1,002 & 3,5 & 0,990 & 1,2 & 0,937 \\
\hline & 7 & 2,6 & 0,918 & 3,6 & 0,906 & 2,6 & 0,948 \\
\hline & 8 & 1,4 & 1,147 & 2,6 & 1,393 & 1,4 & 1,211 \\
\hline
\end{tabular}

É possível notar que as amostras responderam de maneira diferente para cada tipo de radiação; a amostra 7 apresentou os maiores coeficientes de variação na maior parte dos testes realizados, apesar de todos os valores serem inferiores a $4,2 \%$. 


\subsection{Curvas de Dose-Resposta}

A curva de dose-resposta do detector de radiação é representada por sua resposta em função da dose absorvida. O uso de detectores luminescentes é recomendado principalmente na região linear da resposta; então um bom detector é aquele que apresenta um grande faixa de linearidade de resposta. As curvas de dose-resposta foram obtidas da seguinte forma: (TL) Área integrada da curva TL no intervalo de $150^{\circ} \mathrm{C}$ a $300^{\circ} \mathrm{C}$ versus Dose absorvida (Gy) e (OSL) Área integrada da curva OSL (100s) versus Dose absorvida (Gy).

Foi realizado um ajuste linear para verificar a faixa de linearidade para cada tipo de radiação. Todos os ajustes realizados apresentaram coeficiente de correlação linear superiores a 0,995. O intervalo de estudo da curva de doseresposta foi determinado pelas limitações de cada fonte de radiação. Por exemplo, para a fonte de radiação beta não foi possível obter doses abaixo de 0,1 Gy, já que o tempo de exposição para a fonte depositar esta dose é apenas de $1 \mathrm{~s}$; da mesma maneira, o tempo para deposição de 0,1 Gy para a fonte de radiação alfa foi de aproximadamente $2 \mathrm{~s}$. Sabe-se que intervalos tão pequenos de exposição não garantem boa confiabilidade, devido aos erros possíveis em processos tão rápidos. Por outro lado, para se expor as amostras a doses superiores a 2 Gy de radiação $X$, seriam necessários intervalos de irradiações superiores a uma hora. Assim sendo, para radiações alfa e beta, foram utilizados intervalos de dose absorvida entre 0,1 Gy e 200 Gy e para radiação $X$, intervalos entre 0,01 Gy e $1 \mathrm{~Gy}$. Os resultados obtidos para as técnicas luminescentes TL e OSL estão apresentadas nas FIG. 4.9, 4.10, 4.11, 4.12, 4.13 e 4.14. Um resumo destes resultados é apresentado na TAB. 4.5. 

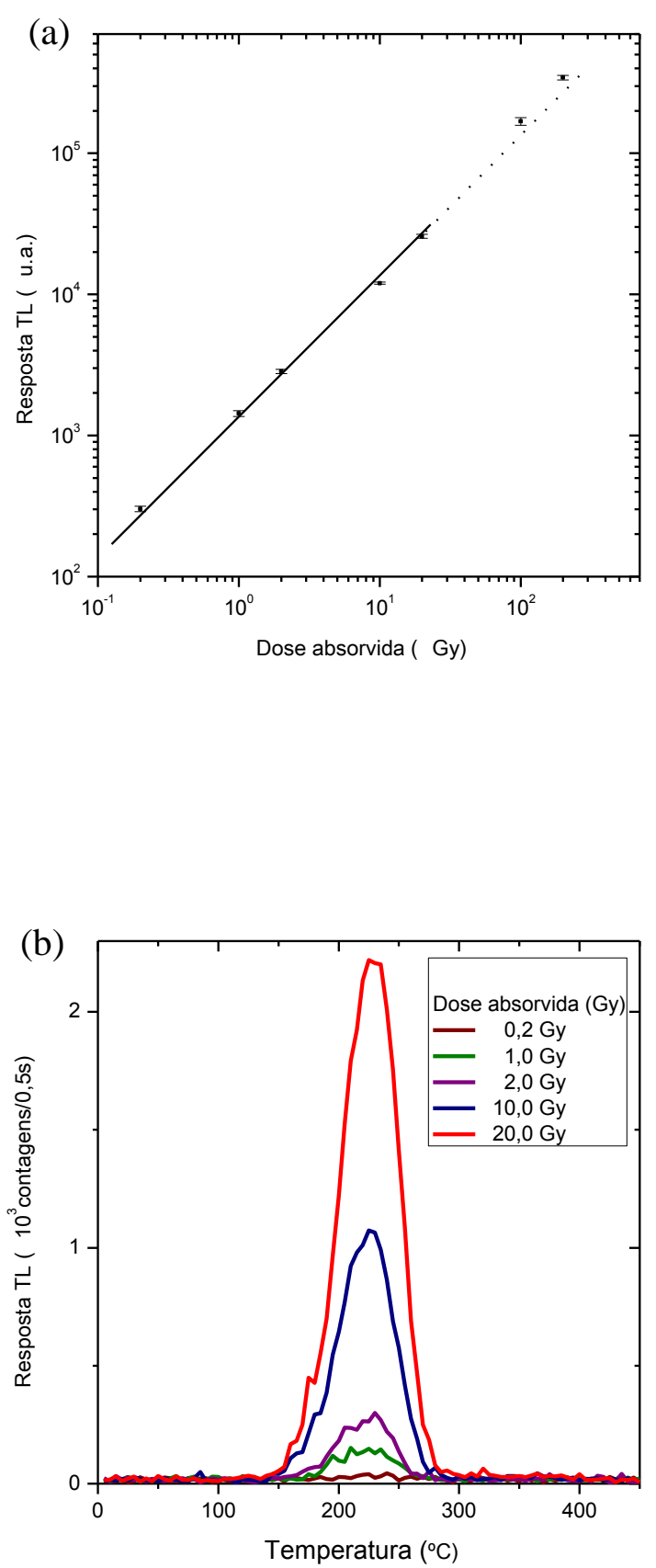

FIGURA 4.9 - (a) Curva de dose-resposta TL para amostras de BeO, expostas à radiação alfa, com doses absorvidas de 0,2 Gy a 200,0 Gy.(b) Curvas de emissão TL de uma amostra de BeO exposta a doses de radiação alfa no seu intervalo de linearidade (0,2 Gy a 20,0 Gy). 

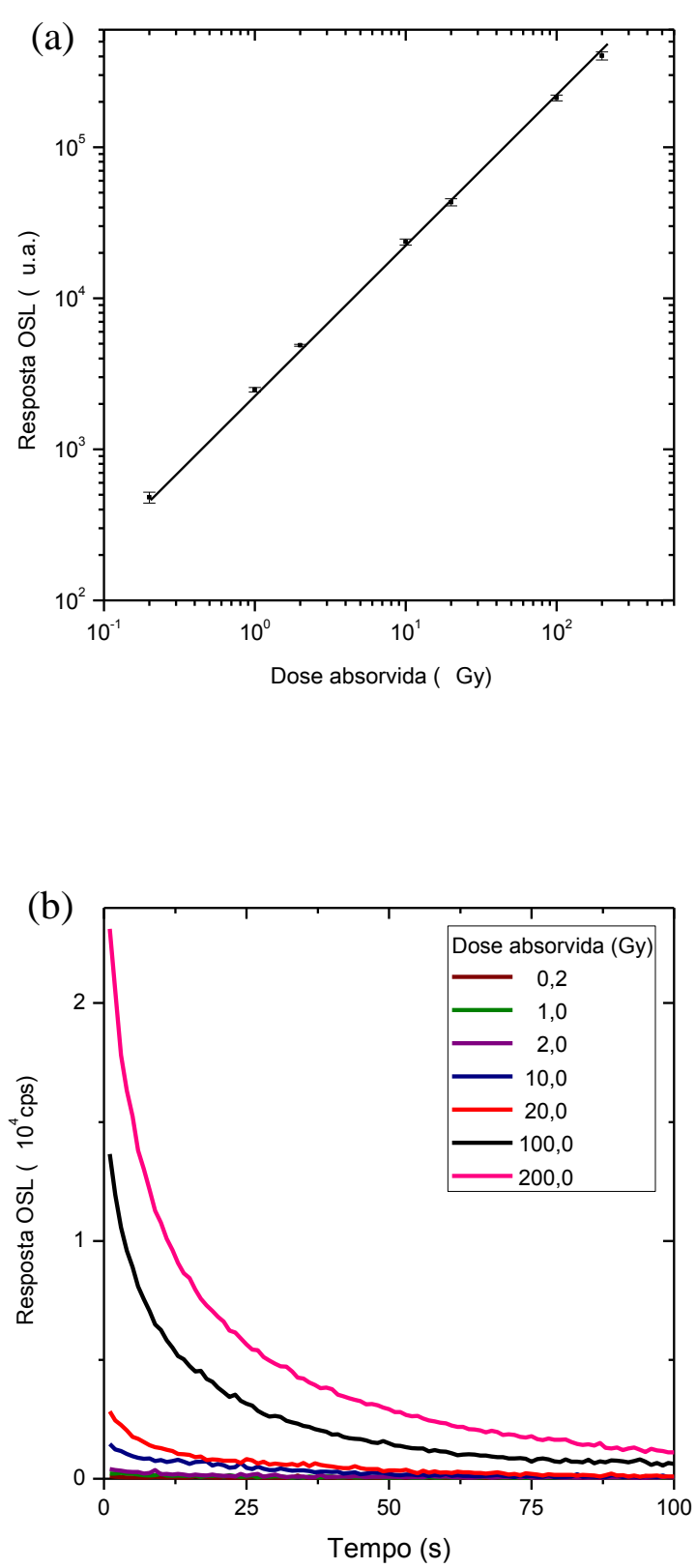

FIGURA 4.10 - (a) Curva de dose-resposta OSL para amostras de BeO, expostas à radiação alfa, com doses absorvidas de 0,2 Gy a 200,0 Gy.(b) Curvas de decaimento $\mathrm{OSL}$ de uma amostra de $\mathrm{BeO}$ exposta a doses de radiação alfa no seu intervalo de linearidade (0,2 Gy a 200,0 Gy). 

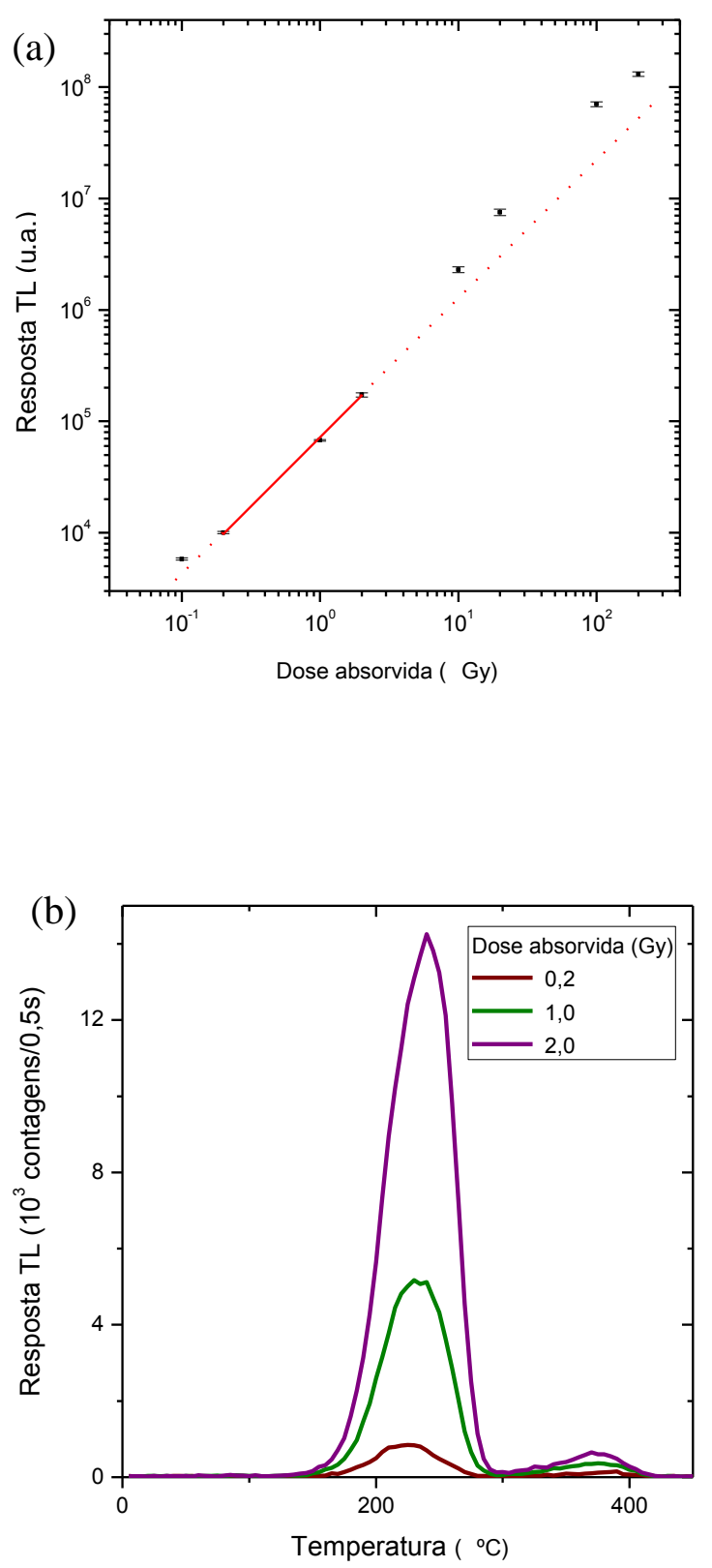

FIGURA 4.11 - (a) Curva de dose-resposta TL para amostras de $\mathrm{BeO}$, expostas à radiação beta, com doses absorvidas de 0,1 Gy a 200,0Gy.(b) Curvas de emissão TL de uma amostra de $\mathrm{BeO}$ exposta a doses de radiação beta no seu intervalo de linearidade (0,2 Gy a 2,0 Gy). 

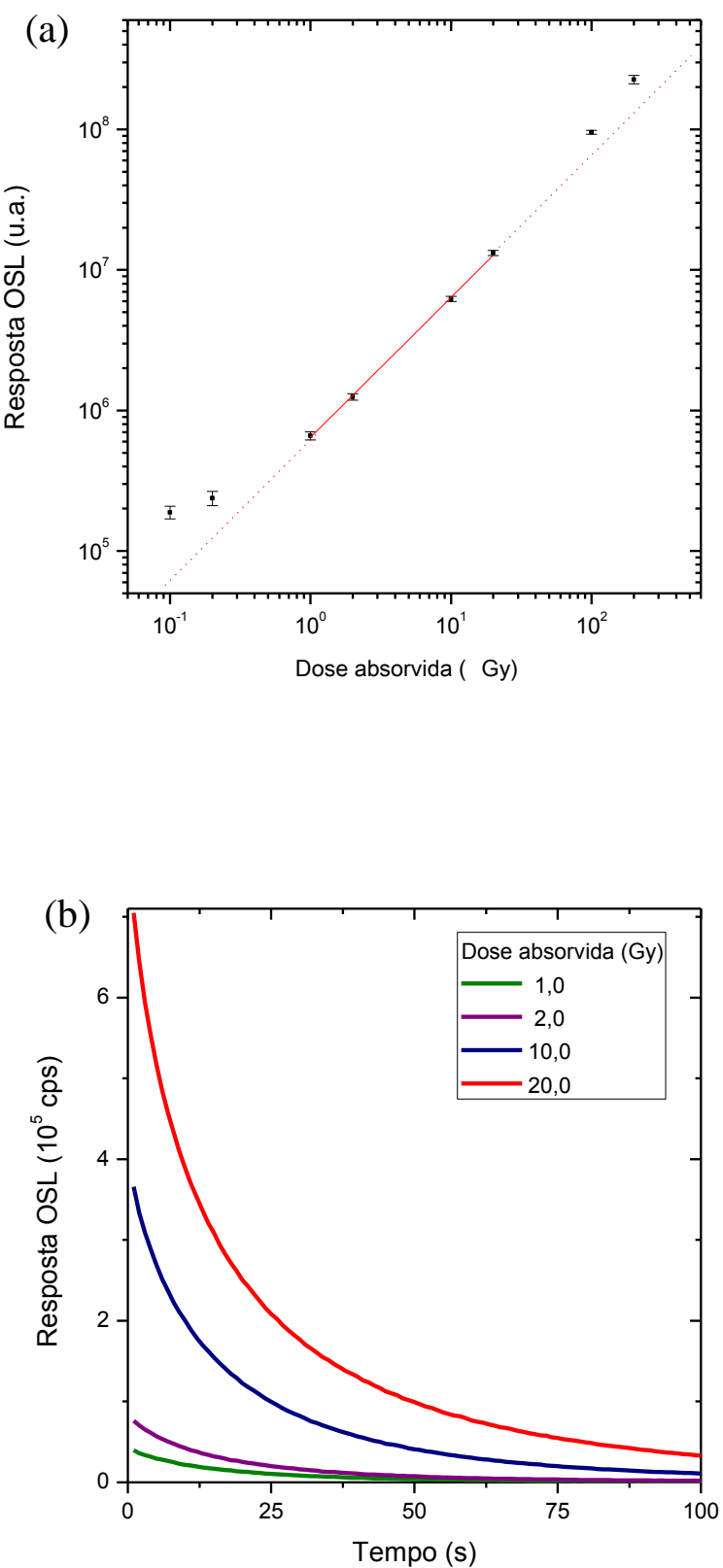

FIGURA 4.12 - (a) Curva de dose-resposta OSL para amostras de $\mathrm{BeO}$, expostas à radiação beta, com doses absorvidas de 0,1 Gy a 200,0 Gy.(b) Curvas de decaimento OSL de uma amostra de BeO exposta a doses de radiação beta no seu intervalo de linearidade (1,0 Gy a 20,0 Gy). 

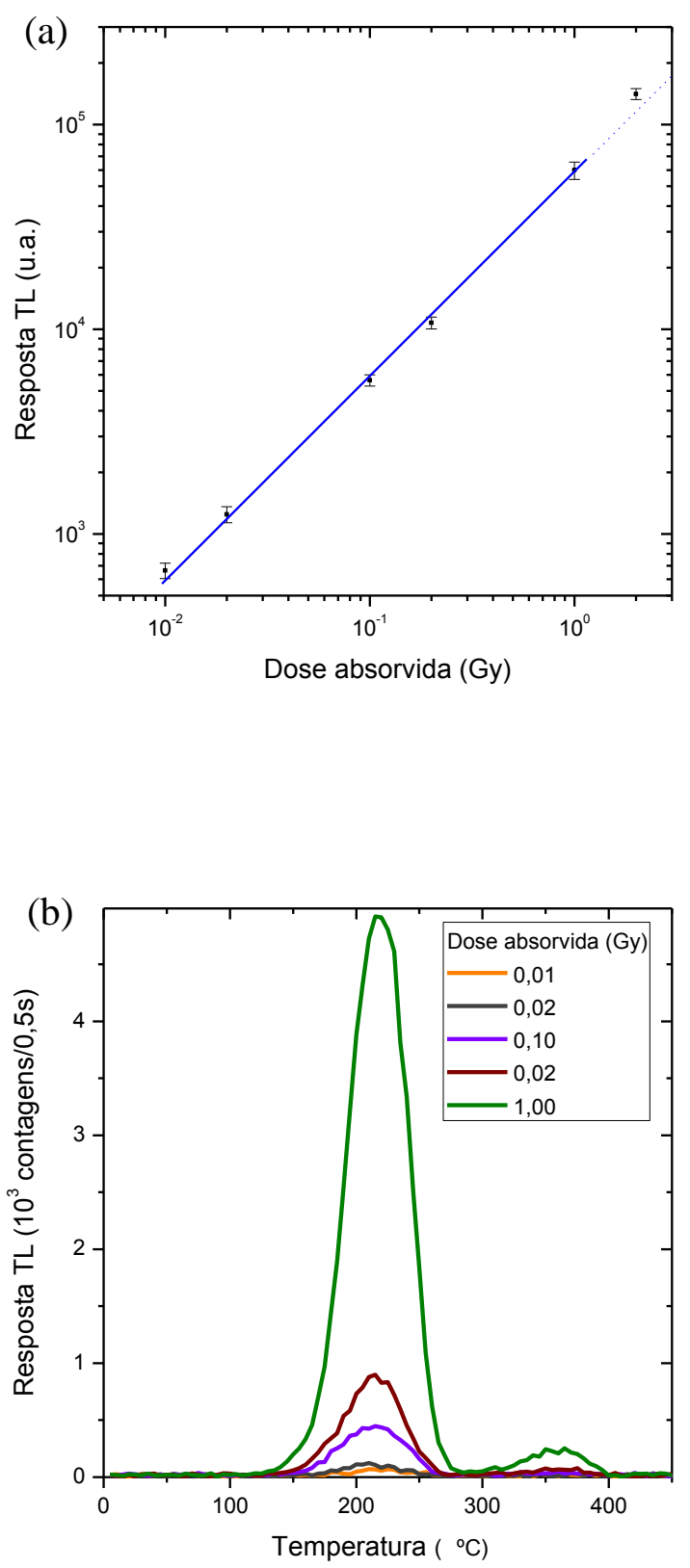

FIGURA 4.13 - (a) Curva de dose-resposta TL para amostras de BeO, expostas à radiação X, com doses absorvidas de 0,01 Gy a 2,0 Gy.(b) Curvas de emissão TL de uma amostra de $\mathrm{BeO}$ exposta a doses de radiação $\mathrm{X}$ no seu intervalo de linearidade (0,01 Gy a 1,0 Gy). 

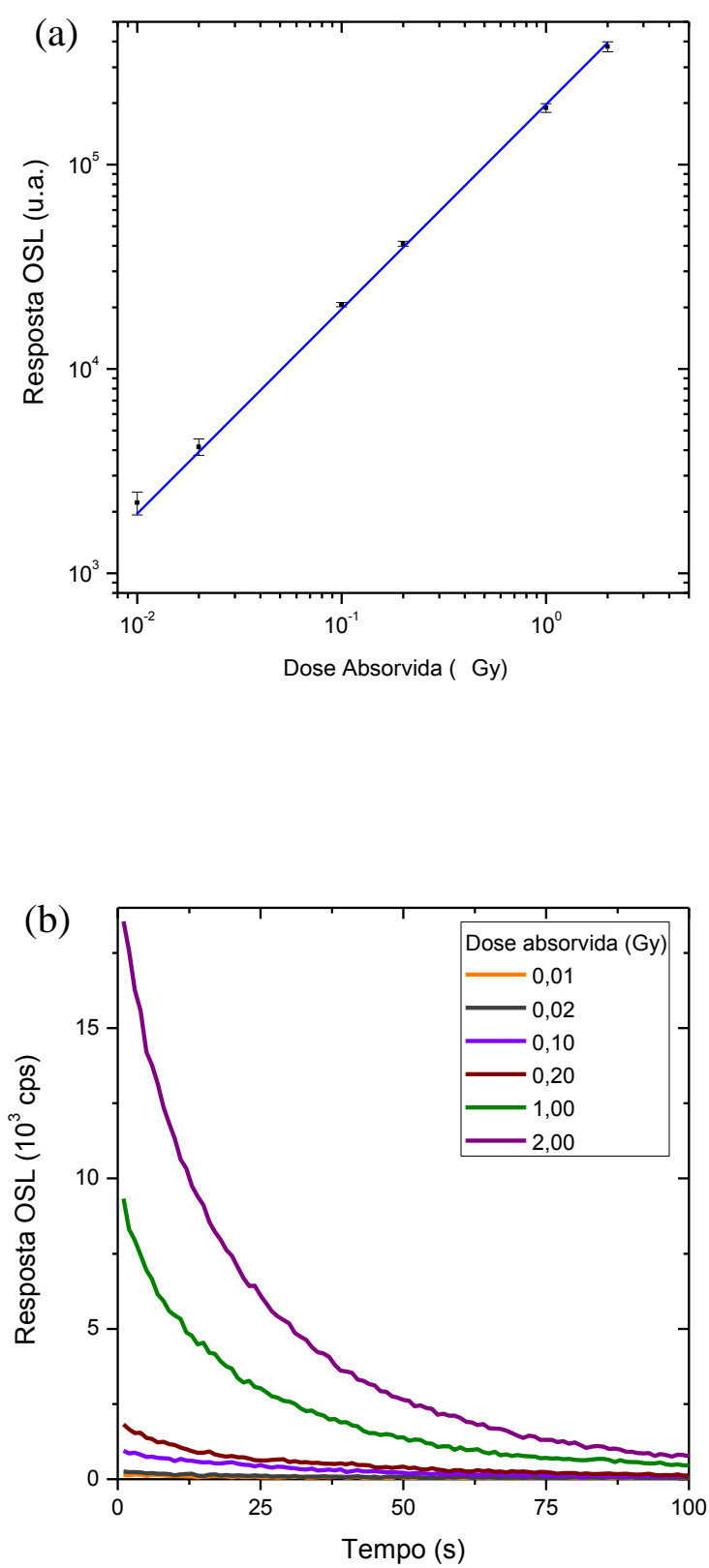

FIGURA 4.14 - (a) Curva de dose-resposta OSL para amostras de $\mathrm{BeO}$, expostas à radiação $X$, com doses absorvidas de 0,01 Gy a 2,0 Gy.(b) Curvas de decaimento OSL de uma amostra de $\mathrm{BeO}$ exposta a doses de radiação alfa no seu intervalo de linearidade (0,01 Gy a 2,0 Gy). 
As respostas obtidas para amostras expostas a uma dose de 0,1 Gy de radiação alfa não apresentaram qualquer diferença comparada aos resultados obtidos para amostras não irradiadas, por este motivo, não estão apresentados nos gráficos. As amostras responderam de maneira diferente para cada tipo de radiação e técnica de medição, mostrando que as respostas TL e OSL dependem do tipo de radiação utilizado. Para todos os casos as amostras apresentaram maior intervalo de linearidade para a técnica de OSL. As doses absorvidas de 0,1 Gy e 0,2 Gy de radiação beta não se mostraram dentro do intervalo de linearidade da resposta OSL; e a dose absorvida de 0,1 Gy também não se apresentou dentro do intervalo de linearidade da resposta TL: estes resultados podem ser desconsiderados, pois os intervalos de tempo de irradiação para obtenção destas doses foram de apenas 1 s e 2 s.

TABELA 4.5 - Intervalo de linearidade de resposta TL e OSL para radiações alfa, beta e X

\begin{tabular}{|c|c|c|c|}
\hline \multirow{2}{*}{$\begin{array}{c}\text { Técnica } \\
\text { luminescente }\end{array}$} & \multicolumn{3}{|c|}{ Intervalo de linearidade (Gy) } \\
\cline { 2 - 4 } & alfa & beta & X \\
\cline { 2 - 4 } & 0,20 a 20,00 & 0,20 a 2,00 & 0,01 a 1,00 \\
\hline TL & 0,20 a 200,00 & 1,00 a 20,00 & 0,01 a 2,00 \\
\hline
\end{tabular}

Como as respostas OSL e TL obtidas para as amostras expostas à radiação alfa foram muito baixas, os mesmos estudos foram repetidos, porém sem a utilização do aparato de colimação no sistema leitor RISÖ TL/OSL-DA-20. Para a reprodutibilidade da resposta luminescente, o coeficiente de variação máximo obtido foi 2,0\% para a técnica TL e 2,1\% para a técnica OSL. O fator de correção para cada pastilha também foi determinado e assim foi possível obter uma resposta homogênea. Foram realizados estudos da variação da resposta em função da dose para as duas técnicas empregadas (TL e OSL). As curvas de dose-resposta são apresentadas nas FIG. 4.15 e 4.16. As respostas TL e OSL apresentaram linearidade em todo o intervalo de dose estudado, exceto a 
resposta TL obtida para a dose de 0,1 Gy. Comparando-se estas curvas de doseresposta com as curvas obtidas sem o uso do aparato de colimação, em relação à resposta TL, o intervalo de linearidade passou de [0,2 Gy - 20 Gy] a [0,2 Gy - 200 Gy]. Em relação à resposta OSL o intervalo de linearidade mantevese o mesmo.
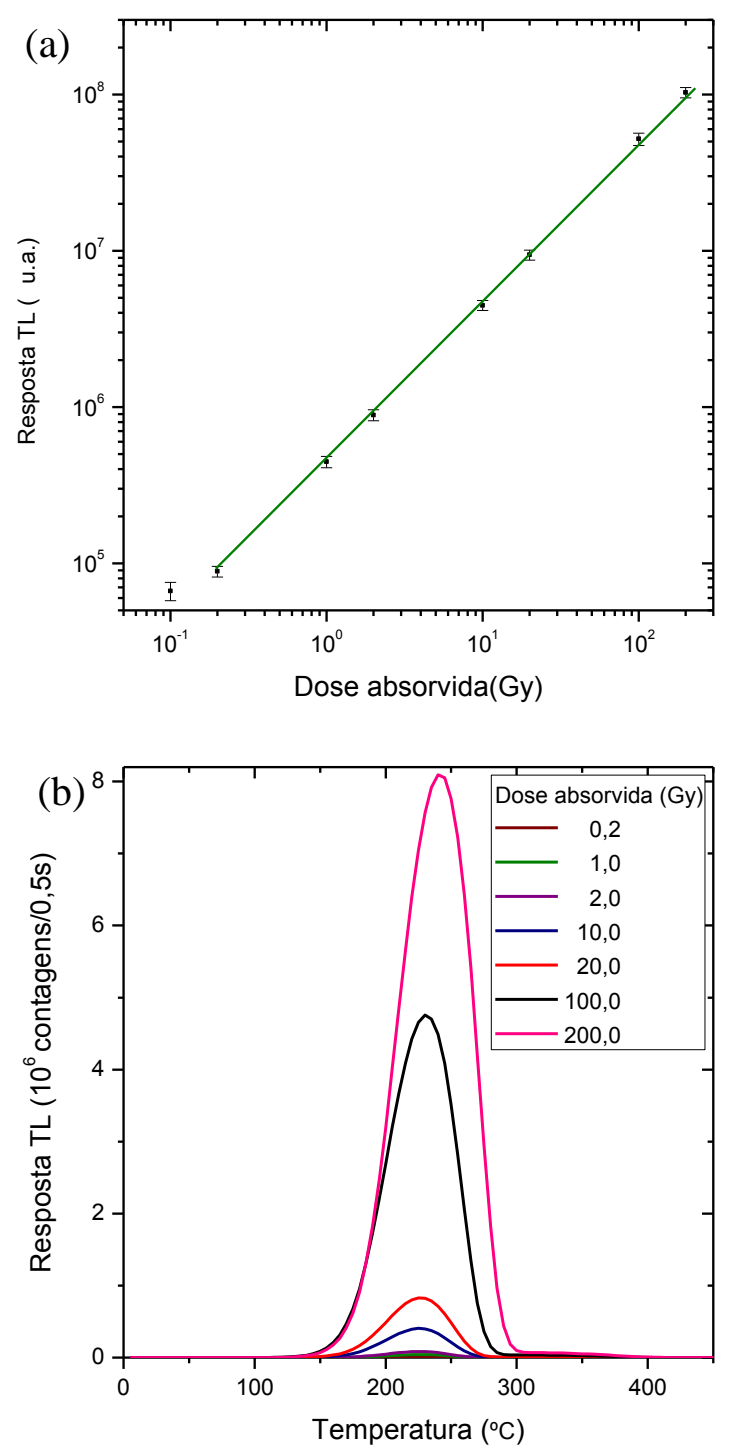

FIGURA 4.15 - (a) Curva de dose-resposta TL sem colimação para amostras de $\mathrm{BeO}$, expostas à radiação alfa com doses absorvidas de 0,1 Gy a 200,0 Gy.

(b) Curvas de emissão TL sem colimação de uma amostra de BeO exposta a doses de radiação alfa no seu intervalo de linearidade (0,2 Gy a 200 Gy). 

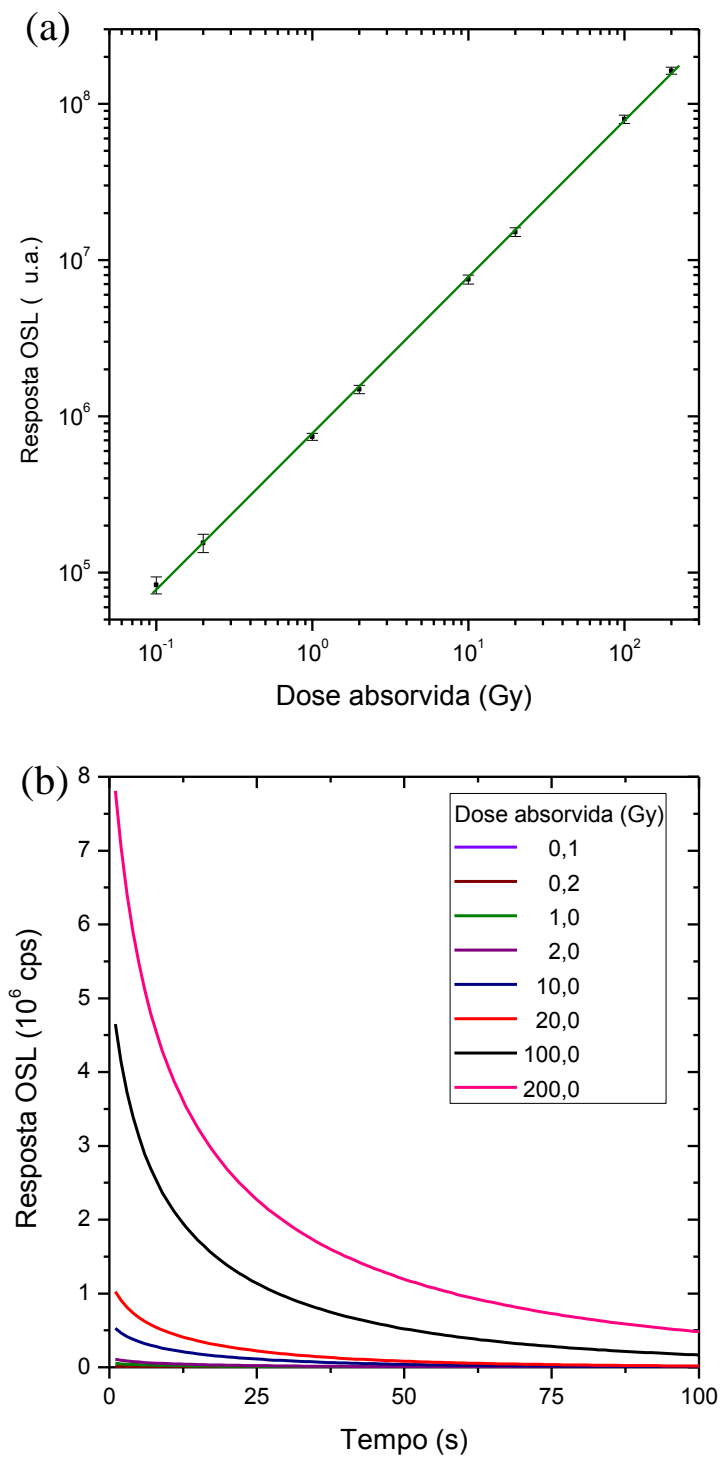

FIGURA 4.16 - (a) Curva de dose-resposta OSL sem colimação para amostras de $\mathrm{BeO}$, expostas à radiação alfa com doses absorvidas de 0,1 Gy a 200,0 Gy.

(b) Curvas de decaimento OSL sem colimação de uma amostra de BeO exposta a doses de radiação beta no seu intervalo de linearidade (0,1 Gy a 200,0 Gy). 


\subsection{Limite Inferior de Detecção (LID)}

Por meio da medição da resposta de dosímetros não irradiados foi possível determinar o valor do limite inferior de detecção das amostras de $\mathrm{BeO}$, pelas técnicas de TL e OSL, que é representado como três vezes o desvio padrão destas leituras, dado em unidade de dose absorvida. Para tanto, foi necessário determinar o fator de calibração $(\theta)$ do equipamento em dose absorvida, para cada tipo de radiação e técnica de medição. Este fator de calibração foi obtido pela Eq. 7 (PAGONIS et al, 2006).

Vinte amostras de $\mathrm{BeO}$ foram medidas 10 vezes para cada técnica luminescente, e a resposta obtida pelo sistema de medição e o seu desvio padrão foram corrigidos pelo fator de calibração para cada tipo de radiação, obtendo-se, assim, o resultado dos limites inferiores de detecção em dose absorvida (TAB. 4.6.). Para a determinação de todos os LIDs foi utilizado o colimador de $2 \mathrm{~mm}$ nas medições TL e OSL.

TABELA 4.6 - Limite inferior de detecção (LID) das amostras de BeO utilizando as técnicas TL e OSL, para diferentes tipos de radiação

\begin{tabular}{|c|c|c|c|}
\hline \multirow{2}{*}{$\begin{array}{c}\text { Técnica } \\
\text { luminescente }\end{array}$} & \multicolumn{3}{|c|}{ LID (mGy) } \\
\cline { 2 - 4 } & \multicolumn{3}{|c|}{ Tipo de radiação } \\
\cline { 2 - 4 } & Alfa & Beta & X \\
\hline TL & $160,3 \pm 3,4$ & $7,02 \pm 0,10$ & $1,99 \pm 0,03$ \\
\hline OSL & $199,2 \pm 3,5$ & $0,71 \pm 0,01$ & $2,02 \pm 0,03$ \\
\hline
\end{tabular}

É possível verificar que este valor não depende apenas das características intrínsecas do material, mas também do sistema de medição e do tipo de radiação à qual a amostra foi exposta. Nota-se também que apesar dos valores de LID terem sido obtidos, não foi possível averiguar estes limites para todos os casos, por limitações dos sistemas de radiações. No caso da radiação alfa, os valores do LID são os mesmos apresentados na curva de dose-resposta. Para radiação beta, as doses inferiores a 0,1 Gy não foram exequíveis, não sendo 
possível verificar seu LID; da mesma forma, a verificação do LID para radiação $X$ não foi possível, porém nota-se que para uma dose de 10 mGy as amostras já apresentam linearidade.

Os LIDs também foram determinados para as amostras irradiadas com radiação alfa, mensuradas sem o colimador. Neste caso, os valores obtidos foram de 0,2 mGy e 40 mGy para as técnicas TL e OSL, respectivamente. Os LIDs obtidos para as medições sem o uso do colimador foram muito inferiores aos obtidos com o uso do colimador, demonstrando que as amostras de $\mathrm{BeO}$ podem detectar doses mais baixas, isto quando o intuito não é a comparação das respostas dos diferentes tipos de radiações estudados. Isso prova que a sensibilidade do $\mathrm{BeO}$ à radiação alfa é realmente inferior quando comparadas às radiações beta e $\mathrm{X}$, porém sua detecção também é exequível.

\subsection{Sinal Residual}

Para a determinação do sinal residual da resposta das amostras, elas foram submetidas a uma segunda leitura TL, para verificar se o sinal havia sido destruído. Foram analisados os sinais residuais para todas as doses estudadas: não houve desvio padrão superior a 5\%, para as respostas obtidas na segunda avaliação TL. Os dados encontram-se na TAB. 4.7.

TABELA 4.7 - Sinal residual na resposta TL das amostras realizando-se uma medição TL subsequente.

\begin{tabular}{|c|c|c|}
\hline $\begin{array}{c}\text { Tipo } \\
\text { de }\end{array}$ & $\begin{array}{c}\text { Dose } \\
\text { "zero" }\end{array}$ & $\begin{array}{c}\text { Sinal } \\
\text { residual }\end{array}$ \\
\hline radiação & (contagens.0,5 s $\left.{ }^{-1}\right)$ & $\left(\right.$ contagens.0,5 s $\left.{ }^{-1}\right)$ \\
\hline alfa & & $532,26 \pm 22,11$ \\
\hline beta & $487,88 \pm 27,08$ & $530,98 \pm 20,71$ \\
\hline$X$ & & $516,70 \pm 22,44$ \\
\hline
\end{tabular}


Para todas as exposições com os três tipos de radiação, as amostras apresentaram o mesmo comportamento, independente da dose absorvida: resposta superior ao sinal de "dose zero", em aproximadamente $7 \%$.

Além das duas medições pela técnica TL, foi ainda realizado um estudo tomando-se medições TL após as leituras OSL. Primeiramente as amostras foram irradiadas e avaliadas com a técnica OSL, depois da medição OSL foi realizada outra medição da mesma amostra, porém com a técnica TL. A Figura 4.17 representa as curvas de emissão TL obtidas após a aquisição das curvas de decaimento OSL. Só foram ilustradas as curvas cujas doses se apresentaram dentro do intervalo de linearidade da resposta OSL, para cada tipo de radiação.

A resposta TL mostrou-se presente após as leituras pela técnica OSL, o que significa que a leitura OSL não esvazia as armadilhas, necessitando realmente do tratamento óptico das amostras antes da sua reutilização. Embora as amostras tenham demonstrado uma resposta TL considerável, não foi possível obter uma curva de dose-resposta para esta resposta TL, devido à grande variação das respostas para cada pastilha, de aproximadamente $18 \%$. 

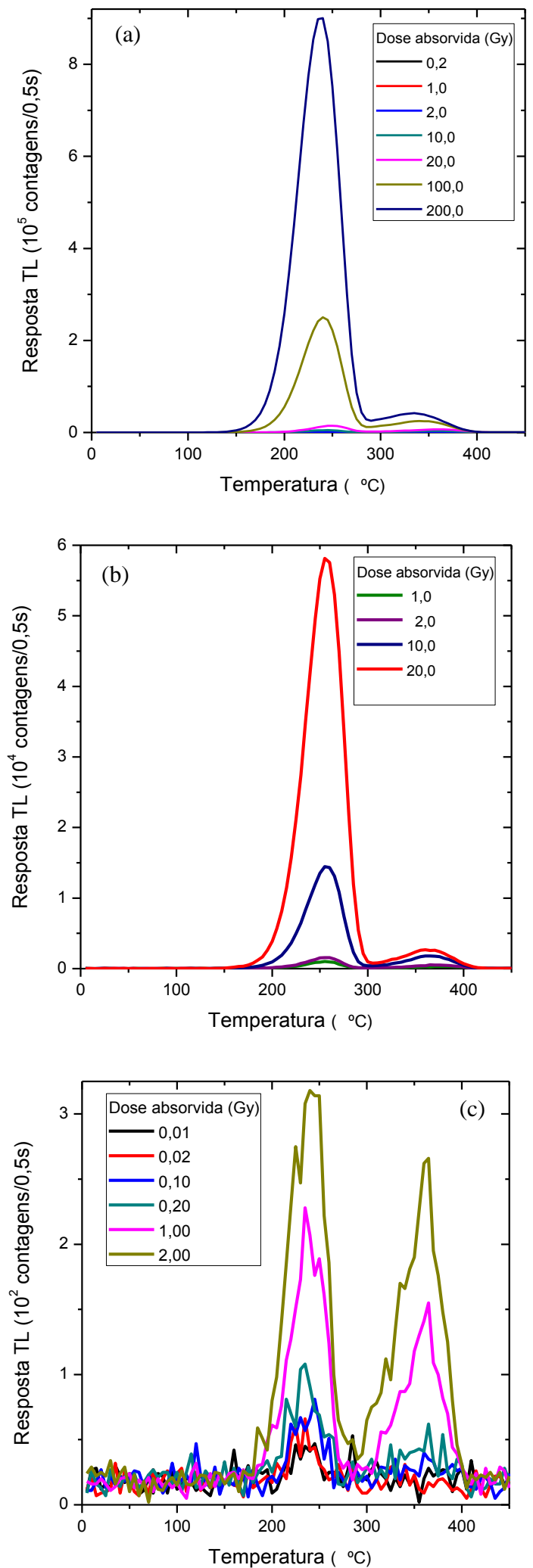

FIGURA 4.17 - Curva de emissão TL para uma amostra de BeO obtida após medição da curva de decaimento OSL, para vários intervalos de dose absorvida de radiações (a) alfa, (b) beta e (c) X. 


\subsection{Dependência Energética}

Quatro qualidades de radiação X padronizadas (RQR3, RQR5, RQR8 e RQR10), estabelecidas no sistema Pantak/Seifert, foram utilizadas neste estudo. As amostras de $\mathrm{BeO}$ foram irradiadas nos feixes de radiação $X$ das qualidades de radiodiagnóstico convencional e posteriormente suas respostas TL e OSL foram obtidas. Para todas as qualidades de radiação, os fatores de correção foram normalizados para os resultados obtidos nos feixes de radiação RQR5. As TAB. 4.8 e 4.9 apresentam os resultados da dependência energética para as técnicas de medições TL e OSL, respectivamente.

Foi realizado também um estudo da dependência energética para feixes atenuados, utilizando-se quatro qualidades de radiação $X$ padronizadas (RQA3, RQA5, RQA8 E RQA10). Como no caso dos feixes diretos, para todos os feixes atenuados foram obtidos os fatores de correção normalizando-se os resultados para a qualidade de radiação RQA5. As TAB. 4.10 e 4.11 apresentam os resultados da dependência energética para feixes atenuados para as técnicas de medições TL e OSL, respectivamente.

TABELA 4.8 - Coeficientes de calibração TL e fatores de correção TL para amostras de $\mathrm{BeO}$ irradiadas em feixes diretos (RQR) de radiação com qualidades de radiodiagnóstico convencional.

\begin{tabular}{|c|c|c|c|}
\hline $\begin{array}{c}\text { Qualidade } \\
\text { da }\end{array}$ & $\begin{array}{c}\text { Camada } \\
\text { Semirredutora }\end{array}$ & $\begin{array}{c}\text { Coeficiente de } \\
\text { Calibração } \\
(\mu \text { Gy/cps })\end{array}$ & $\begin{array}{c}\text { Fator } \\
\text { de }\end{array}$ \\
\hline Radiação & $(\mathrm{mmAl})$ & Correção \\
\hline RQR 3 & 1,78 & $10,80 \pm 0,29$ & 0,72 \\
\hline RQR 5 & 2,58 & $15,04 \pm 0,41$ & 1,00 \\
\hline RQR 8 & 3,97 & $14,37 \pm 0,59$ & 0,95 \\
\hline RQR10 & 6,57 & $13,25 \pm 0,23$ & 0,88 \\
\hline
\end{tabular}


TABELA 4.9 - Coeficientes de calibração OSL e fatores de correção OSL para amostras de $\mathrm{BeO}$ irradiadas em feixes diretos $(R Q R)$ de radiação com qualidades de radiodiagnóstico convencional.

\begin{tabular}{|c|c|c|c|}
\hline $\begin{array}{c}\text { Qualidade } \\
\text { da }\end{array}$ & $\begin{array}{c}\text { Camada } \\
\text { Semirredutora } \\
\text { Radiação }\end{array}$ & $\begin{array}{c}\text { Coeficiente de } \\
\text { Calibração } \\
(\text { mmAl })\end{array}$ & $\begin{array}{c}\text { Fator } \\
\text { de } \\
\text { Correção }\end{array}$ \\
\hline RQR3 & 1,78 & $2,68 \pm 0,09$ & 1,01 \\
\hline RQR5 & 2,58 & $2,66 \pm 0,06$ & 1,00 \\
\hline RQR8 & 3,97 & $2,65 \pm 0,07$ & 0,99 \\
\hline RQR10 & 6,57 & $2,51 \pm 0,07$ & 0,94 \\
\hline
\end{tabular}

A dependência energética máxima da resposta $T L$ do $\mathrm{BeO}$ exposto aos feixes diretos foi de $28 \%$; entretanto, ao se desconsiderar a qualidade RQR3, para outras três qualidades de radiação a dependência foi de $12 \%$. Por outro lado, a dependência energética (feixes diretos) no caso da técnica OSL foi de apenas 7\%. Estudos realizados por Jahn et al (2013) e Sommer et al (2007) para feixes de radiação $X$ (com energias efetivas similares às estudadas) mostraram uma dependência energética da resposta OSL do BeO de aproximadamente $12 \%$.

TABELA 4.10 - Coeficientes de calibração TL e fatores de correção TL para amostras de $\mathrm{BeO}$ irradiadas em feixes atenuados (RQA) de radiação com qualidades de radiodiagnóstico convencional.

\begin{tabular}{|c|c|c|c|}
\hline $\begin{array}{c}\text { Qualidade } \\
\text { da }\end{array}$ & $\begin{array}{c}\text { Camada } \\
\text { Semirredutora } \\
\text { Radiação }\end{array}$ & $\begin{array}{c}\text { Coeficiente de } \\
\text { Calibração } \\
(\text { mGAl) }\end{array}$ & $\begin{array}{c}\text { Fator } \\
\text { de } \\
\text { Correção }\end{array}$ \\
\hline RQA 3 & 3,8 & $7,10 \pm 0,17$ & 1,02 \\
\hline RQA 5 & 6,8 & $6,94 \pm 0,21$ & 1,00 \\
\hline RQA 8 & 10,1 & $6,74 \pm 0,20$ & 0,97 \\
\hline RQA10 & 13,3 & $6,33 \pm 0,23$ & 0,91 \\
\hline
\end{tabular}


TABELA 4.11 - Coeficientes de calibração OSL e fatores de correção OSL para amostras de $\mathrm{BeO}$ irradiadas em feixes atenuados (RQA) de radiação com qualidades de radiodiagnóstico convencional.

\begin{tabular}{|c|c|c|c|}
\hline $\begin{array}{c}\text { Qualidade } \\
\text { da }\end{array}$ & $\begin{array}{c}\text { Camada } \\
\text { Semirredutora } \\
\text { Radiação }\end{array}$ & $\begin{array}{c}\text { Coeficiente de } \\
\text { Calibração } \\
(\text { mGAl) }\end{array}$ & $\begin{array}{c}\text { Fator } \\
\text { de } \\
\text { Correção }\end{array}$ \\
\hline RQA 3 & 3,8 & $1,17 \pm 0,04$ & 0,99 \\
\hline RQA 5 & 6,8 & $1,18 \pm 0,05$ & 1,00 \\
\hline RQA 8 & 10,1 & $1,22 \pm 0,05$ & 1,03 \\
\hline RQA10 & 13,3 & $1,22 \pm 0,05$ & 1,03 \\
\hline
\end{tabular}

A dependência energética da resposta TL do material em feixes atenuados foi de $11 \%$; a qualidade de radiação que apresentou maior dependência energética foi a RQA10, mas desconsiderando esta qualidade de radiação, a dependência energética foi de apenas $5 \%$. A dependência energética da resposta OSL nos feixes atenuados foi de $4 \%$, este valor foi menor que 0 obtido para feixes diretos (7\%).

Para ambos os feixes, diretos e atenuados, a dependência energética obtida foi satisfatória. Pode-se observar que a técnica OSL apresentou a menor dependência com a energia do feixe de radiação $X$.

Embora o material ideal para dosimetria deva apresentar baixa dependência energética, o conhecimento das características do material, assim como os fatores de correções adequados a cada faixa de energia, pode permitir sua aplicação em dosimetria deste tipo de radiação (MCKEEVER et al, 1995). 


\subsection{Desvanecimento das Respostas TL e OSL}

A estabilidade da resposta TL e OSL das amostras de BeO expostas às radiações alfa, beta e $X$ foi investigada durante quatro meses. $O$ experimento foi dividido em duas etapas devido ao número restrito de amostras. Primeiro investigou-se o desvaneciemento da resposta ao longo de uma semana; as amostras foram irradiadas e as medições TL e OSL foram realizadas $10 \mathrm{~min}, 6 \mathrm{~h}$, 24 h, 48 h e 168 h após a irradiação. Posteriormente as amostras foram tratadas e submetidas às mesmas condições de irradiação. As medições TL e OSL foram realizadas 1, 2, 3 e 4 meses após a irradiação.

Cada grupo de medição era composto por 3 amostras de BeO que foram expostas com uma dose de 1 Gy das radiações estudadas; para as avaliações com radiação $X$, as amostras foram submetidos a feixes de qualidade de radiodiagnóstico convencional (RQR 5). Após serem irradiadas, as amostras de BeO foram armazenadas em abrigo contra a luz, até o momento das medições.

As respostas TL e OSL relativas são apresentadas nas FIG. 4.18 e 4.19.

O desvanecimento da resposta TL, no primeiro dia, foi de $9 \%$ para os três tipos de radiação; nota-se que após este período a resposta permanece praticamente a mesma, apresentando um desvanecimento de $10 \%$ ao longo dos 4 meses. Um outro estudo do desvanecimento da resposta TL para amostras de $\mathrm{BeO}$ mostrou um decréscimo de 10\% da resposta em 3 meses, quando as amostras foram armazenadas em local escuro (CRASE e GAMMAGE, 1975).

O desvanecimento da resposta OSL, após 24 horas, foi de aproximadamente $6 \%$ em comparação à primeira medição. A resposta OSL, após uma semana, manteve-se constante. Sommer e colaboradores mostraram resultados de um desvanecimento inicial também de $6 \%$ nas primeiras horas, porém nos seis meses seguintes a resposta OSL permaneceu praticamente a mesma, ou seja, com um desvanecimento de apenas 1\% (SOMMER et al, 2007).

Nota-se também que o decaimento das respostas TL e OSL para a radiação $X$ é mais brusco nas primeiras 6 horas, quando comparado às radiações alfa e beta. 

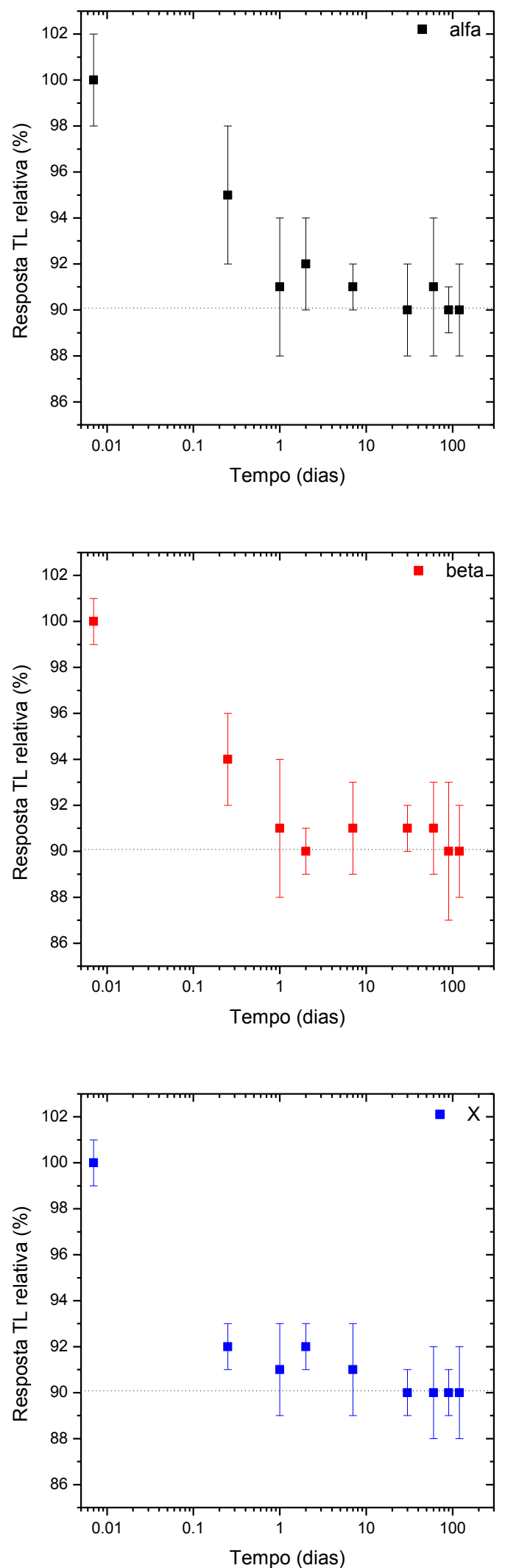

FIGURA 4.18 - Desvanecimento da resposta TL de amostras de BeO expostas às radiações alfa, beta e X. As linhas pontilhadas indicam um desvanecimento da resposta TL de aproximadamente $10 \%$ no período de estudo. 

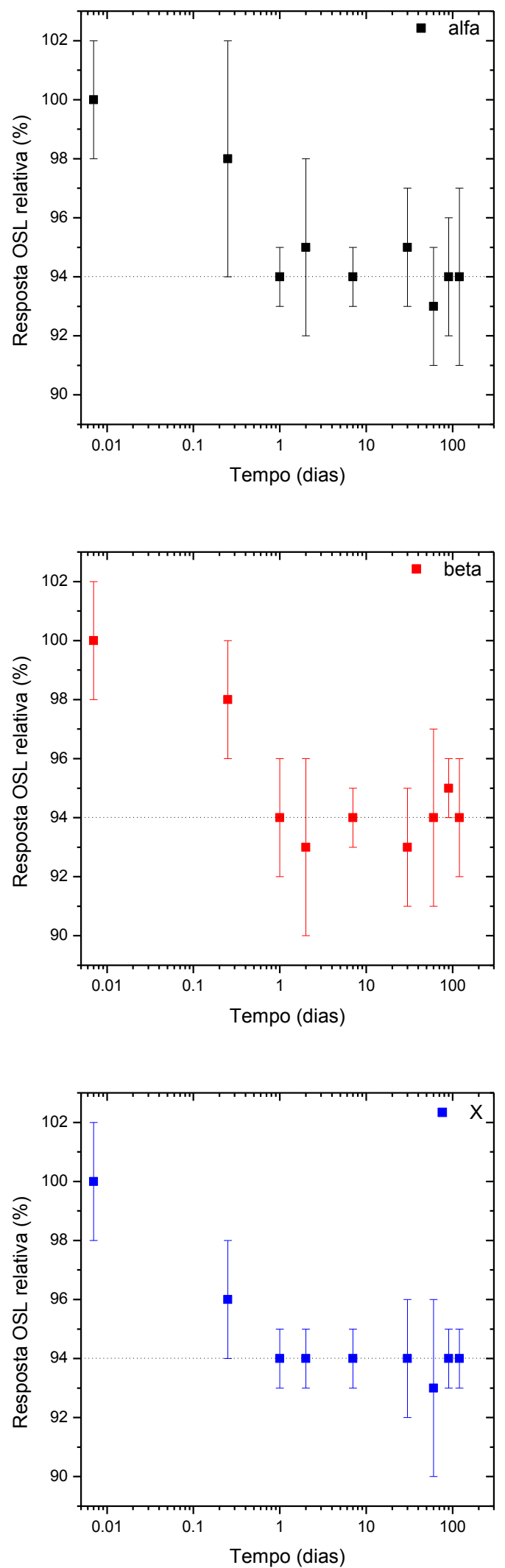

FIGURA 4.19 - Desvanecimento da resposta OSL de amostras de BeO expostas às radiações alfa, beta e $\mathrm{X}$. As linhas pontilhadas indicam um desvanecimento da resposta OSL de aproximadamente $6 \%$ no período de estudo. 


\subsection{Efeito da Temperatura nas Medições OSL}

Foram realizadas medições com a técnica OSL variando a temperatura de medição entre $20^{\circ} \mathrm{C}$ e $400^{\circ} \mathrm{C}$. As amostras foram expostas ao feixe da qualidade de radiação $X$ (RQR5), com uma dose de 1Gy. A FIG. 4.20 apresenta algumas das curvas de decaimento OSL, para efeito de visualização, e a resposta OSL relativa em função da temperatura durante a medição.
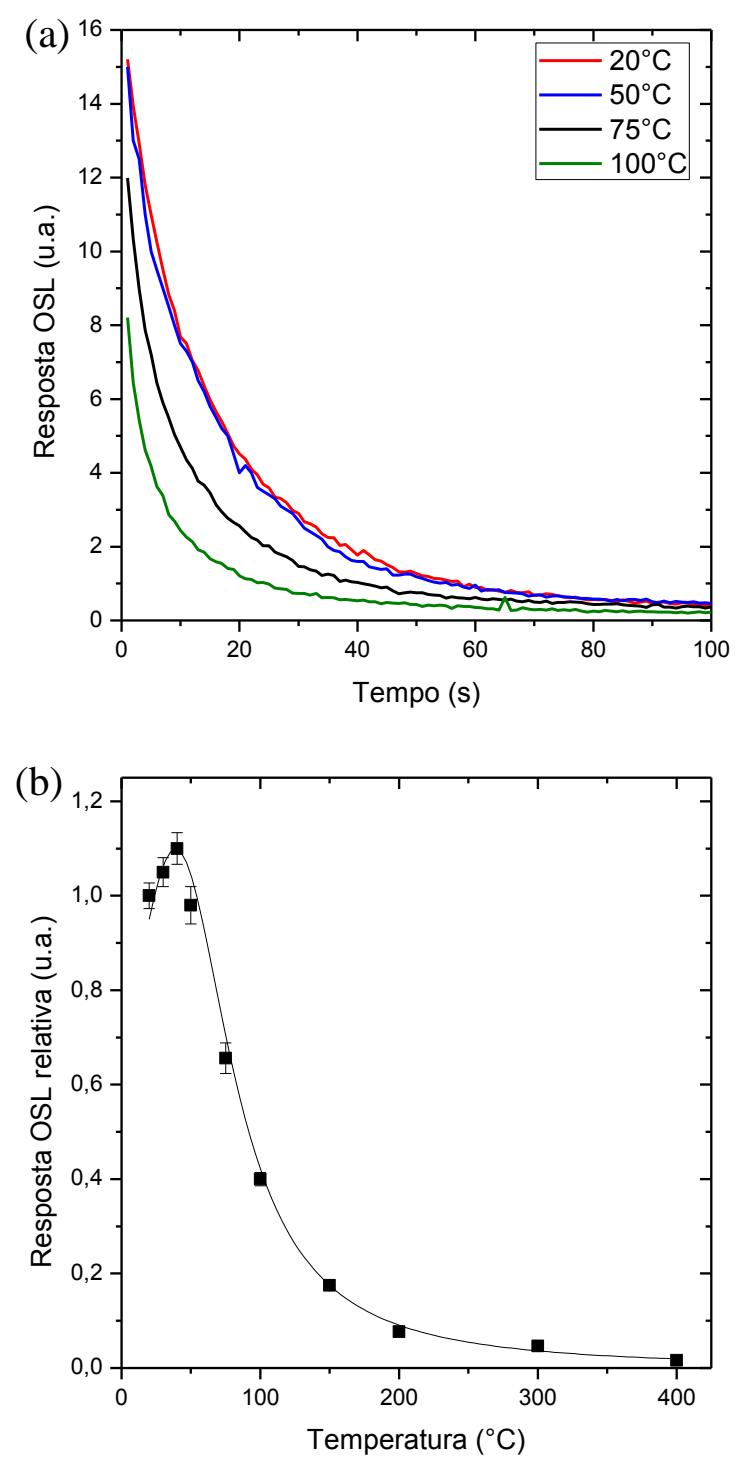

FIGURA 4.20 - (a) Curvas OSL da amostra de BeO para diferentes temperaturas de leitura. (b) Resposta OSL em função da temperatura de medição, normalizada para a temperatura de $20^{\circ} \mathrm{C}$ (temperatura ambiente). 
O aumento da temperatura reduz a eficiência da luminescência e o tempo de decaimento da curva OSL (FIG. 4.16(a)). Isto se deve a uma maior probabilidade de transições não-radiativas dos estados excitados para o estado fundamental dos centros de luminescência (AKSELROD et al, 1999). A resposta OSL também diminui à medida que a temperatura aumenta; esta redução é semelhante à obtida por Yukihara (YUKIHARA, 2011). O aumento inicial da resposta OSL às temperaturas baixas (FIG. 4.16(b)) pode ocorrer devido à influência de armadilhas rasas que liberam cargas durante o estímulo luminoso; este fato pode retardar o processo de decaimento OSL. No entanto, a temperaturas mais elevadas, o armadilhamento de cargas torna-se menos eficaz. Para temperaturas acima de $40 \cong \mathrm{C}$ ocorre o thermal quenching, isto é, a perda da eficiência de luminescência com o aumento da temperatura (BOTTER-JENSEN et al, 2003). 


\section{CONCLUSÕES}

Os resultados obtidos neste trabalho são de muita importância para a caracterização de materiais a serem empregados como dosímetros.

As amostras foram inicialmente estudadas pelas técnicas de análise de difração de raios $\mathrm{X}$ e fluorescência de raios $\mathrm{X}$, mostrando o $\mathrm{BeO}$ como principal componente das amostras estudadas, sendo responsável por 99\% da sua composição. Outros elementos também se fizeram presentes, porém os de maiores concentrações foram o silício, o potássio e o alumínio, respectivamente.

Para o estudo da sensibilidade das amostras pelas técnicas TL e OSL, - BeO apresentou maior sensibilidade para a radiação beta, seguido da radiação $\mathrm{X}$ e, por último, a radiação alfa.

O estudo da reprodutibilidade das respostas TL e OSL mostrou um coeficiente de variação máximo de 3,6\% para a técnica TL e de 4,2\% para a técnica OSL, representando uma ótima reprodutibilidade, ou seja, inferior a $5 \%$.

Com a obtenção das curvas de dose-resposta foi possível notar que para cada tipo de técnica (TL e OSL) e tipo de radiação, obteve-se um intervalo de linearidade distinto. Além destas variações, outros fatores que alteram a resposta luminescente são as limitações que o próprio aparelho de medição apresenta, como por exemplo o nível de saturação do tubo fotomultiplicador. Os maiores intervalos de linearidade foram obtidos com a técnica OSL.

Os estudos das respostas TL e OSL das amostras de $\mathrm{BeO}$ com a variação da energia dos feixes de raios $X$ demonstraram que a técnica OSL apresenta menor dependência energética, uma vez que a dependência energética da resposta $T L$ foi de $28 \%$ e a dependência da resposta OSL foi de apenas $7 \%$ para o mesmo intervalo de energia estudado (feixes diretos padronizados em radiodiagnóstico). Para o estudo da dependência energética com feixes atenuados, o valor obtido foi de 11\% para a resposta TL e de 4\% para a resposta OSL. A dependência energética da resposta OSL foi inferior à dependência 
energética da resposta TL para os dois tipos de feixes de radiação $X$, diretos $e$ atenuados.

As amostras de $\mathrm{BeO}$ apresentaram um desvanecimento da resposta TL de 10\% nos primeiros 4 meses após a irradiação e um desvanecimento da resposta OSL de 6\% no mesmo período para os três tipos de radiação estudados: alfa, beta e X.

De forma geral, as respostas luminescentes obtidas foram melhores para a técnica OSL: maior intervalo de linearidade e menor dependência energética da resposta luminescente.

As características dosimétricas obtidas neste trabalho mostram a possibilidade de aplicação das amostras de $\mathrm{BeO}$ em dosimetria das radiações ionizantes X, alfa e beta, considerando os intervalos de dose empregados, especialmente nos procedimentos de radiodiagnóstico e radioterapia. 


\section{REFERÊNCIAS}

AKSELROD, M. S.; BOTTER-JENSEN, L.; McKEEVER, S. W. S. Optically stimulated luminescence and its use in medical dosimetry. Radiat. Meas. 41, S78-S99, 2007.

AKSELROD, M. S.; LARSEN, N. A.; WHITLEY, V. H.; McKEEVER, S. W. S. Thermal quenching of $\mathrm{F}$-center luminescence in $\mathrm{Al}_{2} \mathrm{O}_{3}: \mathrm{C}$. Appl. Phys. 84, 3364-3373, 1999.

AKSELROD, M. S.; McKEEVER, S. W. S.; MOSCOVITCH, M.; EMFIETZOGLOU, D.; DURHAN, J. S.; SOARES, C. G. A. A thin-layer $\mathrm{Al}_{2} \mathrm{O}_{3}$ beta $\mathrm{TL}$ detector. Radiat. Prot. Dosim. 66, 105-110, 1996.

ATTIX, F. H. Introduction to Radiological Physics and Radiation Dosimetry. New York: John Wiley \& Sons, 1986.

BOS, A. J. J. Theory of thermoluminescence. Radiat. Meas. 41, S45-S56, 2006.

BOTTER-JENSEN, L. Development of optical stimulated luminescence techniques using natural minerals and ceramics, and their application to retrospective dosimetry. RIS $\varnothing$ National Laboratory Repost-1211 (EN). Roskilde, 2000.

BOtTER-JENSEN, L.; McKeEVER, S. W. S.; WINTLE, A. G. Optically Stimulated Luminescence Dosimetry. Amsterdam: Elsevier Science, 2003.

BOTTER-JENSEN, L.; SOLONGO, S.; MURRAY, A. S.; BANERJEE, D.; JUNGNER, $H$. Using the OSL single-aliquot regenerative-dose 
protocol with quartz extract from building materials in retrospective dosimetry. Radiat. Meas. 32, 841-845, 2000.

BULUR, E.; GÖKSU, H. Y. OSL from BeO ceramic: New observations from an old material. Radiat. Meas. 29, 639-650, 1998.

BULUR, E.; BOTTER-JENSEN, L.; MURRAY, A.S. LM-OSL signals from some insulators: An analysis of the dependency of the detrapping probability on stimulation light intensity. Radiat. Meas. 33, 715-719, 2001.

CAMERON, J. R.; SUNTHARALINGAM, N.; KENNEY, G. N. Thermoluminescent Dosimetry. Londres: The Colonial Press, 1968.

CHEN, R.; MCKEEVER, W. S. Theory of Thermoluminescence and Related Phenomena. Singapore: World Scientific, 1997.

CRASE, K. W.; GAMMAGE, R. B. Improvements in the use of ceramic $\mathrm{BeO}$ for TLD. Health Phys. 29, 739-746, 1975.

CURRY, T. S.; DOWDEY, J. E. MURRY, R.C. Christensen's Physics of Diagnostic Radiology. 4. Ed. London: Lea \& Febiger, 1990.

EISBERG, R.; RESNICK, R. Física Quântica - Átomos, Moléculas, Sólidos, Núcleos e Partículas. Rio de Janeiro:Campus, 1979.

GAMMAGE, R. B.; CHEKA, J. S. Further characteristics important in the operation of ceramic BeO TLD. Health Phys. 32, 189-192, 1977.

GARLIK, G. F. J.; GIBSON, A. F. The electron trap mechanism of luminescence in sulphide and silicate phosphors. Proc. Physical Society. London: 60, 574-590, 1948.

IAEA - INTERNATIONAL ATOMIC ENERGY AGENCY. Radiation Oncology Physics: A Handbook for Teachers and Students. Vienna; 2005. 
ICRU - INTERNATIONAL COMMISSION ON RADIATION UNITS AND MEASUREMENTS. "Recommendations of the International Commission on Radiological Units". Brit. J. Rad. 27, 243-247, 1954.

ICRU - INTERNATIONAL COMMISSION ON RADIATION UNITS AND MEASUREMENTS. Radiation Quantities and Units. ICRU Report 33. Bethesda, Maryland: 1980.

IEC - INTERNATIONAL ELECTROTECHNICAL COMMISSION. Medical Diagnostic X-ray Equipment - Radiation Conditions for Use in the Determination of Characteristics. $2^{\text {nd }}$ ed. IEC 61267. Genève: IEC, 2005.

ISO - INTERNATIONAL ORGANIZATION FOR STANDARDIZATION. Guia para Expressão da Incerteza de Medição. 3ª Edição brasileira. Rio de Janeiro: ABNT, 2003.

JAHN, A.; SOMMER, M.; ULLRICH, W.; WICKERT, M.; HENNIGER, J. The BeOmax system - Dosimetry using OSL for several applications. Radiat. Meas. http://dx.doi.org/10.1016/j.radmeas.2013.01.069, 2013.

JCPDS - JOINT COMMITTEE ON POWDER DIFFRACTION STANDARDS. Powder Diffraction file Alphabetical Index. JCPDS 78-1560. Swarthmore: JCPDS, 1991.

JOHNS, H. E; CUNNINGHAM, J. R. The Physics of Radiology. Illinois: Charles C. Thomas., 3를. 1974.

KHAN, F. M. The Physics of Radiation Therapy. 2. Ed. Baltimore: Williams \& Wilkins, 1994.

KNOLL, G. F. Radiation Detection and Measurements. New York: John Willey \& Sons, 4⿳亠丷厂 Ed., 2010. 
KORTOV, V. S.; MILMAN, I. I.; MONAKHOV, A. V.; SLESAREV, A.I.; KIJKO, V. S. New BeO ceramics for TL ESR dosimetry. Radiat. Prot. Dosim. 47, 263-270, 1993.

KRON, T. Applications of thermoluminescence dosimetry in medicine. Radiat. Prot. Dosim. 8 (1-4), 333-340, 1999.

LACKOWICZ, J. R. Principles of Fluorescence Spectrometry. New York: Plenum Press, 1983.

MAY, C. E.; PARTRIDGE, J. A. Thermoluminescent kinectics af alpha-irradiated alkali halides. J. Phys.: Cond. Matt. 5, 633-636, 1964.

McKEEVER, S. W. S.; MOSCOVITCH, M. On the advantages and disadvantages of optically stimulated luminescence dosimetry and thermoluminescence dosimetry. Radiat. Prot. Dosim. 104 (3), 263$270,2003$.

McKEEVER, S. W. S. Thermoluminescence of Solids. Cambridge: Cambridge University Press; 1985.

McKEEVER, S. W. S.; MOSCOVITCH, M.; TOWNSEND, P. D. Thermoluminescence Dosimetry Materials: Properties and Uses. Ashford: Nuclear Technology Publishing; 1995.

OKUNO, E.; YOSHIMURA, E. Física das Radiações. São Paulo: Oficina de Textos, 2010.

OBERHOFER, M.; SCHARMANN, A. Applied Thermoluminescence Dosimetry. Ispra: Adam Hilger Ltd (Commission of European Communities), 1981.

PAGONIS, V.; KITIS, G.; FURETTA, C. Numerical and Practical Exercises in Thermoluminescence. New York: Springer, 2006.

RANDALL, J. T.; WILKINS, M. H. F. Phosphorescence and electron traps: I. The study of trap distributions. Proc. Royal Soc. London A. 184, 366.389, 1945. 
RASHEEDY, M. S. On the general-order of the thermoluminescence glow peak. $\boldsymbol{J}$. Phys.: Cond. Matt. 5, 633-636, 1993.

RISÖ NATIONAL LABORATORY. Manual do sistema leitor RIS $\varnothing$ TL/OSL-DA-20. Disponível em: www.risoe.dk. Acesso em 22/06/2013.

RHYNER, C. R.; MILLER, W. G. Radiation dosimetry by optically-stimulated luminescence of BeO. Health Phys. 18, 681-684, 1970.

ROCCA, R. R.; TATUMI, S. H.; WATANABE, S.; ROSSETTI, D. F. OSL dating of coastal post-barreiras sediments from northern Brazil. J. Earth Sci. Eng. 2, 515-521, 2012.

SAW, C. B. Foundation of Radiological Physics. Omaha: CBSaw Inc, 2002.

SCARPA, G.; BENINCASA, G.; CERAVOLO, L. Further studies on the dosimetric use of $\mathrm{BeO}$ as a thermoluminescent material. Proc. 3rd. Int. Conf. on Luminescence Dosimetry. RIS $\varnothing$, Denmark, 427-434, 1971.

SCHEMBRI, V. E.; HEIJMEN, J. M. Optically stimulated luminescence (OSL) of carbon-doped aluminiun oxide $\left(\mathrm{Al}_{2} \mathrm{O}_{3}: \mathrm{C}\right)$ for film dosimetry in radiotherapy. Med. Phys. 34 (6), 2113-2118, 2007.

SOMMER, M.; FREUDENBERG, R.; HENNIGER, J. New aspects of BeO-based optically stimulated luminescence dosimeters. Radiat. Meas. 42, 617-620, 2007.

SPRAWLS, P. Physical Principles of Medical Imaging. Gaithersburg: Aspen Publishers, 2 ed, 1993.

TAhUATA, L.; SAlATI, I. P. A., PRINZIO, R. D., PRINZIO, M. A. R. R. D. Radioproteção e Dosimetria: Fundamentos. Rio de Janeiro: IRD/CNEN, 5ํㅡ. Ed., 2003.

TUDELA, D. R. G.; TATUMI, S. H.; YEE, M.; BRITO, S. L. M.; MORAIS, J. L.; MORAIS, D.; PIEDADE, S. C.; MUNITA, C. S. P.; HAZENFRATZ, R. TL, OSL and C-14 dating results of the sediments and brincks from 
mummified nunn's grave. An. Acad. Bras. Cienc. 84(2), 237-244, 2012.

WATANABE, S.; RAO, T. K. G.; PAGE, P. S.; BHATT, B. C. TL, OSL E ESR studies on beryllium oxide. J. Lumines.. 130, 2146-2152, 2010.

WINN, J. Physical Chemistry. New York: Harper Collins, 1995.

YAMAMOTO, S.; KAWAGUCHI, Y. Mechanically and optically stimulated luminescence spectra of silica glass: The roles of defects on photoradiation. Radiat. Prot. Dosim. 65, 409-412, 1996.

YAMASHITA, Y.; YASUNO, Y.; IKEDO, M. Beryllium oxide doped with lithium or sodium for thermoluminescence dosimetry. Health Phys. 27, 201206, 1974.

YASUDA, H.; FUJITAKA, K. Non-linearity of the high temperature peak area ratio of LiF:Mg,Ti (TLD-600). Radiat. Meas. 32, 355-360, 2000.

YOSHIMURA, E. M.; YUKIHARA, E. G. Optically stimulated luminescence (OSL) dosimetry in medicine. Phys. Med. Biol., 53, R351-R379, 2008.

YUKIHARA, E. G. Luminescence properties of $\mathrm{BeO}$ optically luminescence (OSL) detectors. Radiat. Meas. 46, 580-587, 2011.

YUKIHARA, E. G.; McKEEVER, S. W. S. Optically stimulated luminescence (OSL) dosimetry in medicine. Phys. Med. Biol. 53, R351 - R37, 2008.

YUKIHARA, E. G.; McKEEVER, S. W. S. Optically Stimulated Luminescence: Fundamentals and Applications. Oklahoma: John Wiley \& Sons; 2011.

YUKIHARA, E. G.; SAWAKUCHI, G. O.; GUDURU, S.; McKEEVER, S. W. S.; GAZA, R.; BENTON, E. R.; YASUDA, N.; UCHIHORI, Y.; KITAMURA, $\mathrm{H}$. Application of the optically stimulated luminescence (OSL) technique in space dosimetry. Radiat. Meas. 41, 1126-1135, 2006. 